\title{
WestVirginiaUniversity
}

THE RESEARCH REPOSITORY @ WVU

Graduate Theses, Dissertations, and Problem Reports

2013

\section{Energy Management Control for Multimode Microgrid Renewable Integration}

Roopa Ramachandran

West Virginia University

Follow this and additional works at: https://researchrepository.wvu.edu/etd

\section{Recommended Citation}

Ramachandran, Roopa, "Energy Management Control for Multimode Microgrid Renewable Integration" (2013). Graduate Theses, Dissertations, and Problem Reports. 674.

https://researchrepository.wvu.edu/etd/674

This Thesis is protected by copyright and/or related rights. It has been brought to you by the The Research Repository @ WVU with permission from the rights-holder(s). You are free to use this Thesis in any way that is permitted by the copyright and related rights legislation that applies to your use. For other uses you must obtain permission from the rights-holder(s) directly, unless additional rights are indicated by a Creative Commons license in the record and/ or on the work itself. This Thesis has been accepted for inclusion in WVU Graduate Theses, Dissertations, and Problem Reports collection by an authorized administrator of The Research Repository @ WVU. For more information, please contact researchrepository@mail.wvu.edu. 


\title{
Energy Management Control for Multimode Microgrid Renewable Integration
}

By

\section{Roopa Ramachandran}

\author{
Thesis submitted to the \\ Benjamin M. Statler College of Engineering and Mineral Resources \\ at West Virginia University \\ in partial fulfillment of the requirements \\ for the degree of \\ Master of Science \\ in \\ Electrical Engineering \\ Parviz Famouri, Ph.D., Chair \\ Yaser P. Fallah, Ph.D., \\ Muhammad A. Chouhdry, Ph.D., \\ Lane Department of Computer Science and Electrical Engineering \\ Morgantown, WV
}

2013

Keywords: Battery Energy Management Control, Renewable Integration, Optimization in PSCAD

Copyright 2013 Roopa Ramachandran 


\section{ABSTRACT \\ Energy Management Control for Multimode Microgrid Renewable Integration}

\section{Roopa Ramachandran}

The need for storing energy has grown in correlation with the need for renewable and distributed energy resources. Designing a storage unit system which complements the distributed generation is required for increased efficiency and reducing the burden on the utility grid. The energy storage model used in this thesis is the Li-ion battery which is efficient, has high energy density and has applications in field of electronics, transportation and electric power industry. The wind turbine generator, photovoltaic (PV) and the energy storage unit modeled in this work share a symbiotic relationship even though they are completely separate entities which can be connected at separate locations. This study contributes better control as well as ease of connection to the system. To show the effect of storage unit on microgrid distribution system two test systems were considered, standalone system and standard IEEE 13 node feeder system with wind turbine generator and photovoltaic panel. The integration and control of energy storage system is achieved using a battery energy management control (BEMC) at the upper level and a real/reactive power controlled voltage source converter at the lower level. To enhance the control, optimization is performed where the proportional gain and the integral time constant of the PI controller are optimized using genetic algorithm which reduces the losses and increases the efficiency of the system. The results show that the battery energy management control system is effective in controlling the modes of operation of energy storage module based on the wind and solar conditions and is able to completely balance the power produced by the wind generator and PV modules. In this thesis all the test systems and the control were implemented in PSCAD as it is emerging as the new industry standard for transient power applications research. 


\section{ACKNOWLEDGEMENTS}

I would like to sincerely thank my advisor Dr. Parviz Famouri for his guidance and encouragement during the course of my study. This thesis would not be possible without his support and advice. I would like to thank my committee members, Dr. Yaser Fallah and Dr. Muhammad Choudhry for their invaluable insights and suggestions.

I would like to thank the PSCAD support team of Manitoba International for providing me with the generic battery model and answering my doubts. I would also like to specially thank my labmates Neda Nasirani and Kaveh Rahimi.

I would like to extend my gratitude to my husband for his patience and care shown during my studies and to my Father, Mother, Brother, Father-in-Law, and Mother-in-Law for their prayers and support. 


\section{TABLE OF CONTENTS}

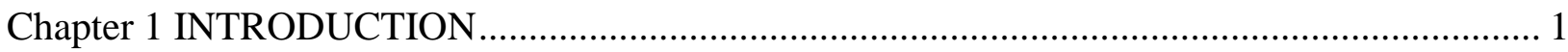

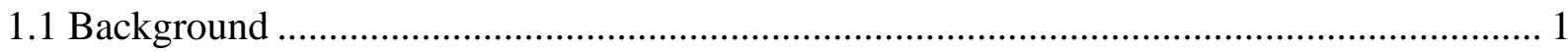

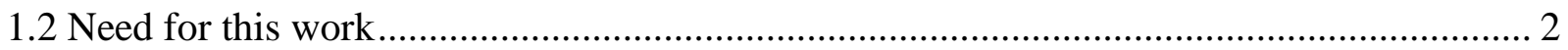

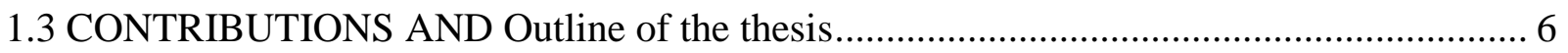

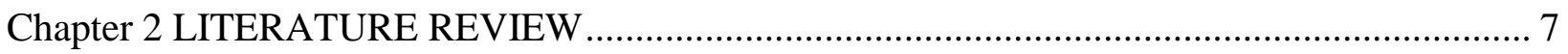

2.1 Battery Models and Controls ………............................................................................ 8

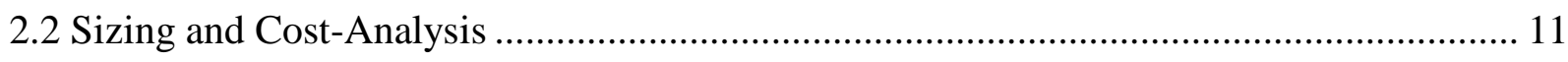

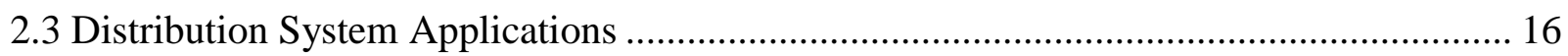

2.4 Wind Power Smoothing Applications ............................................................................. 18

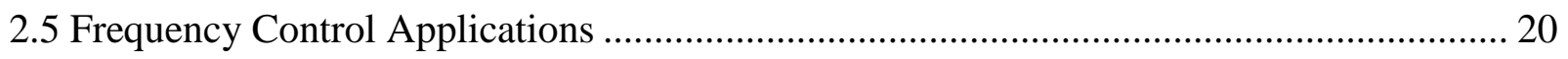

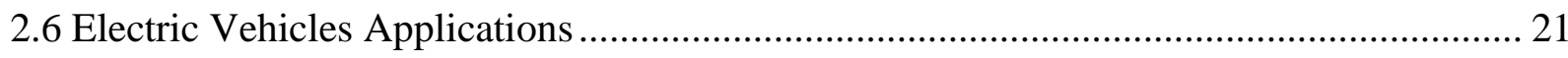

2.7 Summary and contribution of current research work........................................................ 23

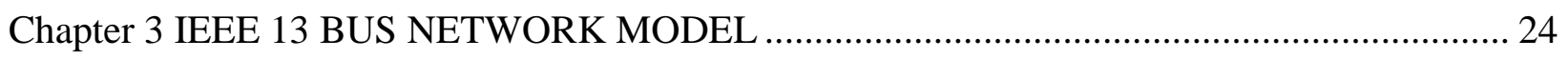

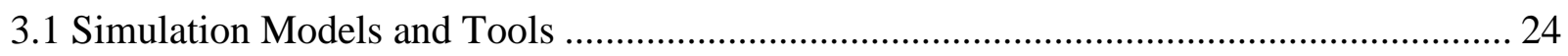

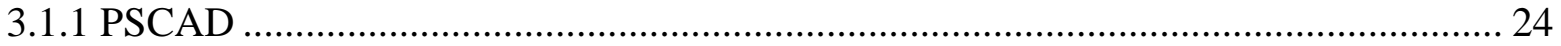

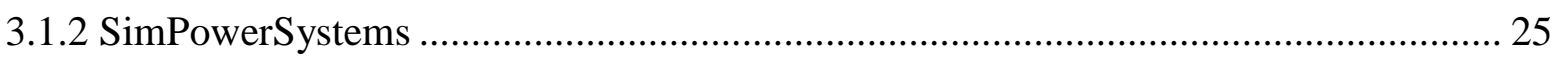

3.1.3 Power World Simulator ........................................................................................ 25

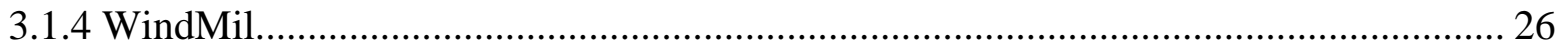

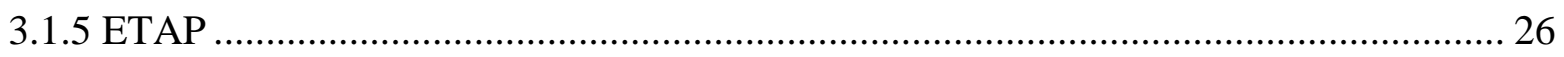

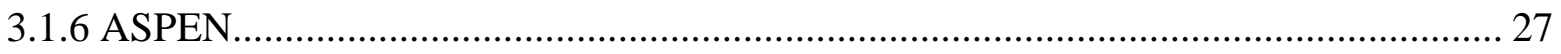

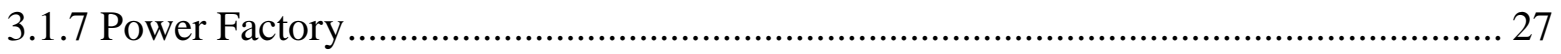

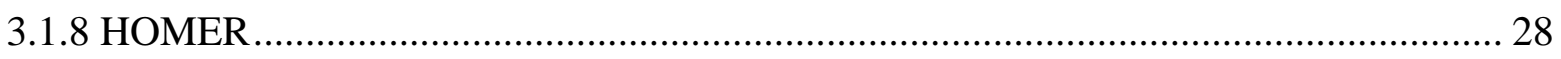

3.2 Modeling IEEE 13 Node Test Feeder in PSCAD ………………………………........... 29

3.2.1 3-PH and 2-PH and 1-PH Transmission Line Model ................................................ 30

3.2.2 Step Voltage Regulator Model ............................................................................. 32

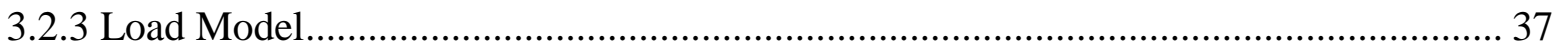

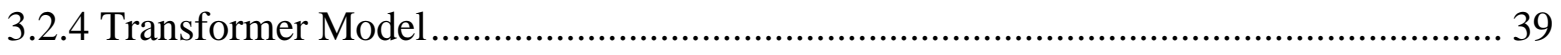

3.2.5 Wind Turbine Generator Model .............................................................................. 40

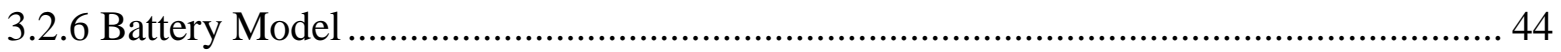

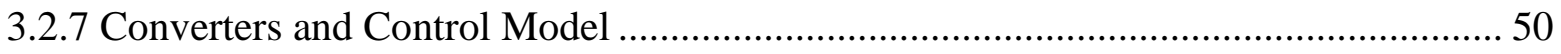




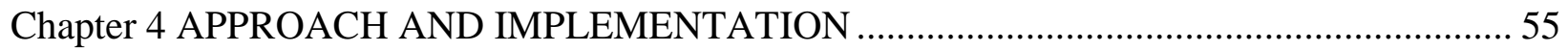

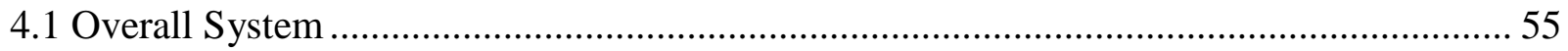

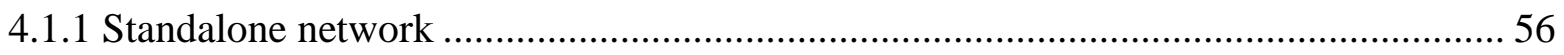

4.1.2 IEEE 13 Node Test Feeder Network ………………............................................ 57

4.1.3 Building the model in PSCAD ........................................................................ 58

4.2 Battery Energy Management CONTROL (BEMC) ……………………………............ 60

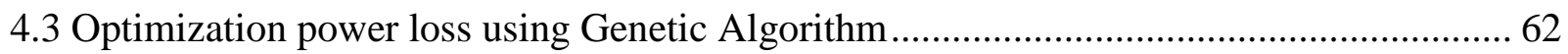

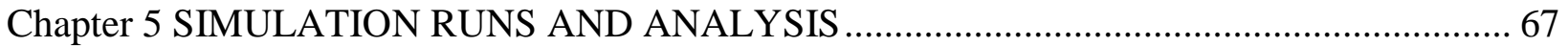

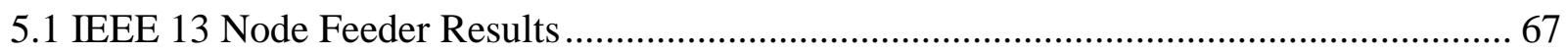

5.2 Li-ion Battery Model Results ....................................................................................... 73

5.2.1 Battery Discharging Mode Simulation Output Parameters ......................................... 75

5.2.2 Battery Charging Mode Simulation Output Parameters ................................................. 78

5.3 Multi-mode Battery Energy Management Control (BEMC) operation ............................... 82

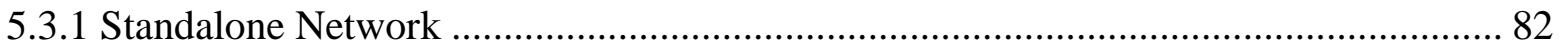

5.3.2 IEEE 13 Node Feeder Distribution System Analysis with Wind Turbine Generator .. 89

5.3.3 IEEE 13 Node Feeder Distribution System Analysis with Photovoltaic Panel............ 90

5.3.4 Microgrid Hybrid System Analysis ............................................................................. 92

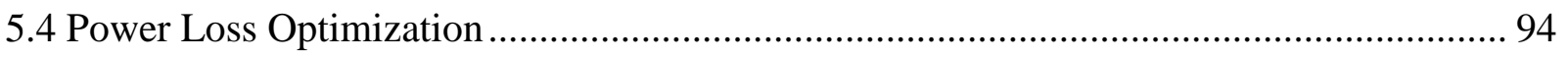

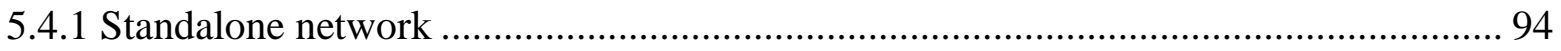

5.4.2 IEEE 13 Node Distribution Feeder Network ............................................................. 97

Chapter 6 CONCLUSION AND FUTURE RESEARCH .................................................... 103

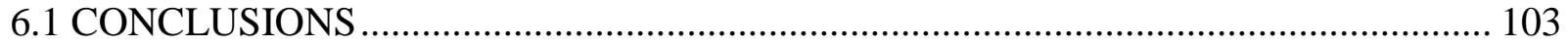

6.2 DIRECTIONS FOR FUTURE RESEARCH.............................................................. 104

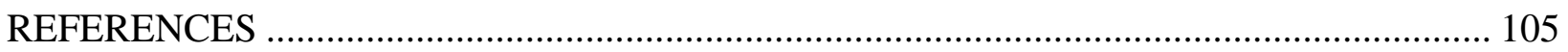




\section{LIST OF FIGURES}

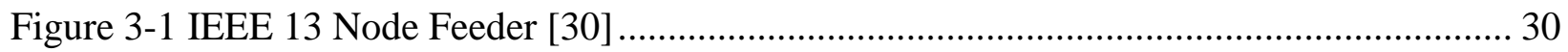

Figure 3-2 Single-phase view of Transmission Line ...................................................... 30

Figure 3-3 Three-phase view of Transmission Line ........................................................... 31

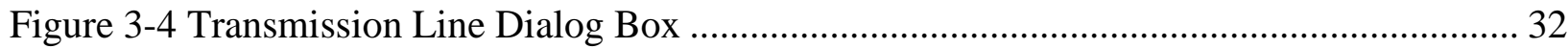

Figure 3-5 Step Voltage Regulator Module.......................................................................... 33

Figure 3-6 Type B Step Voltage Regulator [61] ............................................................. 33

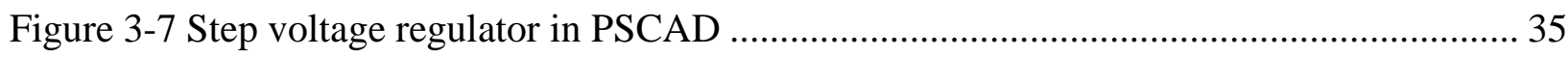

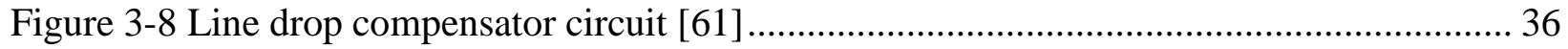

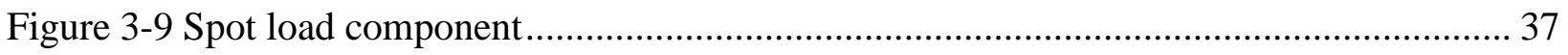

Figure 3-10 Phase to phase load module ............................................................................. 39

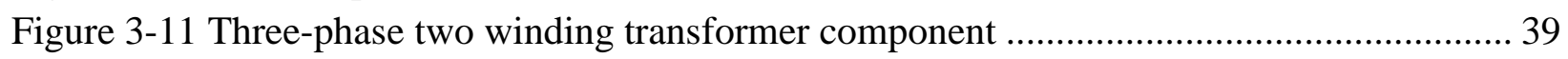

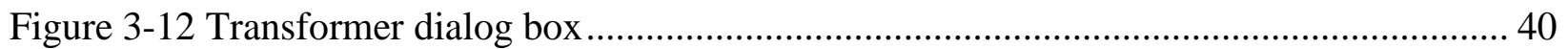

Figure 3-13 Wind turbine generator module ................................................................. 41

Figure 3-14 Wind source component............................................................................... 41

Figure 3-15 Wind turbine and governor components ............................................................ 42

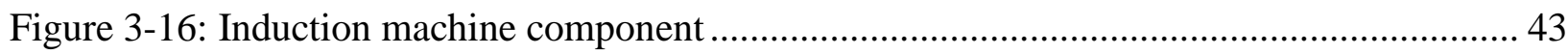

Figure 3-17 Battery Circuit Model ..................................................................................... 44

Figure 3-18 Discharge Characteristics [44] ...................................................................... 44

Figure 3-19 Li-ion battery module in PSCAD ................................................................. 46

Figure 3-20 Battery module dialog box ..................................................................... 46

Figure 3-21 Battery discharge control component........................................................... 49

Figure 3-22 Battery charge control component ................................................................ 49

Figure 3-23 Voltage Source Converter Model........................................................................ 51

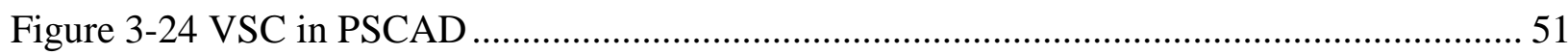

Figure 3-25 Real/Reactive Power Controller....................................................................... 52

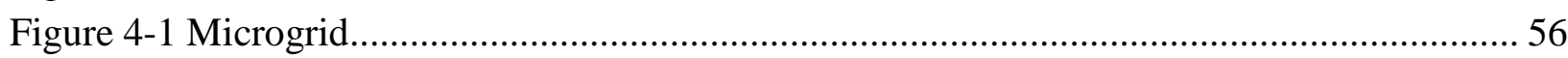

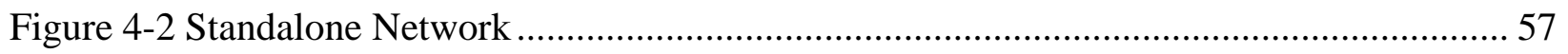

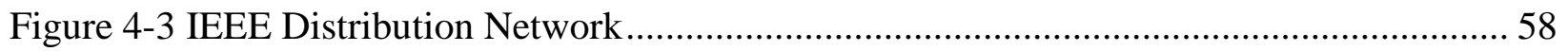

Figure 4-4 Flowchart for Battery Control ........................................................................ 61

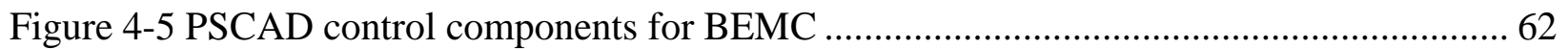

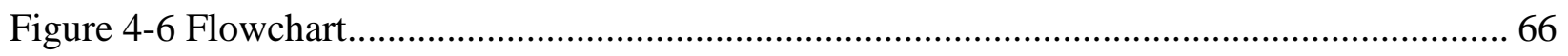

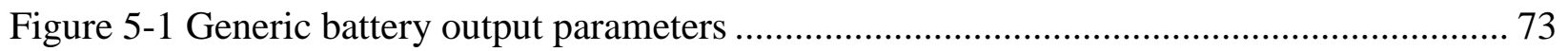

Figure 5-2 Li-ion battery output parameters ................................................................... 74

Figure 5-3 Real and reactive power variation of storage/wind turbine module ....................... 75

Figure 5-4 Frequency and voltage variation of storage/wind turbine module in p.u.................. 76

Figure 5-5 Converter output voltage three phase waveform and rms value .............................. 76

Figure 5-6 Voltage and current across the de link capacitor ................................................ 77

Figure 5-7 Magnitude and angle variation of the reference signal ...................................... 77 
Figure 5-8 Modulation signals and battery discharging current .......................................... 77

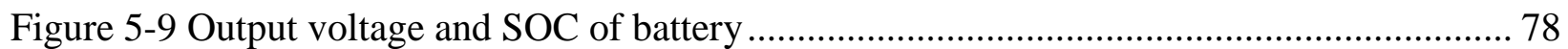

Figure 5-10 Output speed and current of the induction generator ........................................... 78

Figure 5-11 Real and reactive power variation of storage/wind turbine module ..................... 79

Figure 5-12 Frequency and voltage variation of storage/wind turbine module in p.u................ 79

Figure 5-13 Converter output voltage three phase waveform and rms value ............................. 79

Figure 5-14 Voltage and current across the dc link capacitor .............................................. 80

Figure 5-15 Magnitude and angle variation of the reference signal ....................................... 80

Figure 5-16 Modulation signals and battery charging current.............................................. 80

Figure 5-17 Output voltage and SOC of battery .......................................................... 81

Figure 5-18 Output speed and current of the induction generator ....................................... 81

Figure 5-19 SOC Variation and Wind/Battery Power for Initial SOC 0.9 ............................. 83

Figure 5-20 SOC Variation and Wind/Battery Power for Initial SOC 0.1 ............................. 83

Figure 5-21 SOC Variation and Wind/Battery Power for Initial SOC 0.9 .............................. 84

Figure 5-22 SOC Variation and Wind/Battery Power for Initial SOC 0.1 .............................. 84

Figure 5-23 SOC Variation and Wind/Battery Power for Initial SOC 0.9 .............................. 85

Figure 5-24 SOC Variation and Wind/Battery Power for Initial SOC 0.1 .............................. 86

Figure 5-25 Variable wind speed .................................................................................... 86

Figure 5-26 SOC Variation and Wind/Battery Power for Initial SOC 0.9 ............................. 87

Figure 5-27 SOC Variation and Wind/Battery Power for Initial SOC 0.1 ............................. 87

Figure 5-28 SOC upper charging limit variation and Wind/Battery power variation ................. 88

Figure 5-29 SOC lower discharging limit variation and Wind/Battery power variation............. 88

Figure 5-30 SOC Variation and Wind/Battery Power for Initial SOC 0.9 .............................. 89

Figure 5-31 SOC Variation and Wind/Battery Power for Initial SOC 0.1 .............................. 90

Figure 5-32 SOC Variation and PV/Battery Power for Initial SOC 0.9 ................................. 91

Figure 5-33 SOC Variation and PV/Battery Power for Initial SOC 0.1 ................................. 91

Figure 5-34 Hybrid system with wind turbine generator and solar panel................................ 92

Figure 5-35 Real power output of battery without PV module ............................................ 93

Figure 5-36 Real power output of battery with PV module.................................................. 93

Figure 5-37 SOC of battery without PV module ................................................................ 93

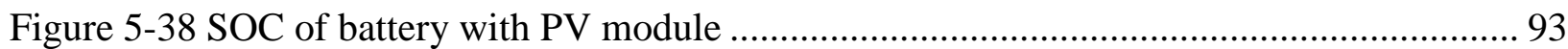

Figure 5-39 Power waveforms and total Pdiff for 10s run time ............................................ 95

Figure 5-40 Optimized power waveforms and total Pdiff for 10s run time............................... 95

Figure 5-41 Power waveforms and total Pdiff for 60s run time ............................................ 96

Figure 5-42 Optimized power waveforms and total Pdiff for 60s run time.............................. 96

Figure 5-43 Power output to grid without battery ............................................................... 97

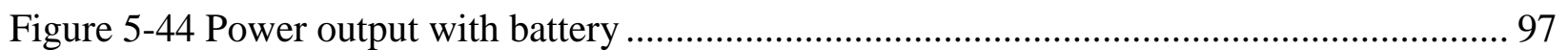

Figure 5-45 Power waveforms and total Pdiff for 10s run time ............................................ 98

Figure 5-46 Optimized power waveforms and total Pdiff for 10s run time............................. 98

Figure 5-47 Power waveforms and total Pdiff for 60s run time ........................................... 99 
Figure 5-48 Optimized power waveforms and total Pdiff for 60s run time............................. 99

Figure 5-49 Power output to grid without battery ............................................................. 100

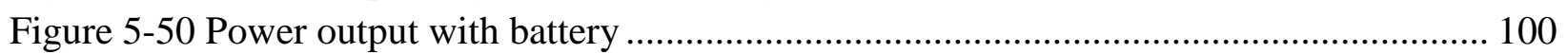

Figure 5-51 Total transmission loss before optimization ................................................ 101

Figure 5-52 Total transmission loss after optimization ...................................................... 101

\section{LIST OF TABLES}

Table 5-1 Power flow results comparison in each phase ....................................................... 68

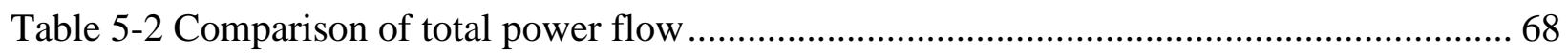

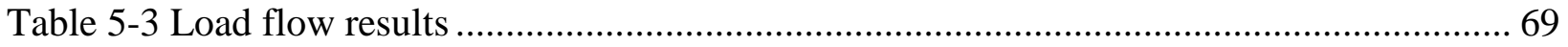

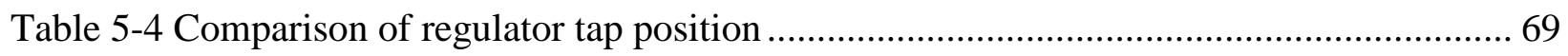

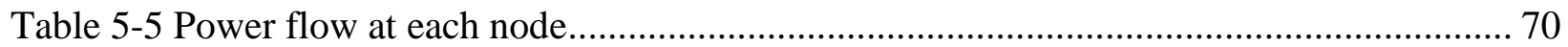

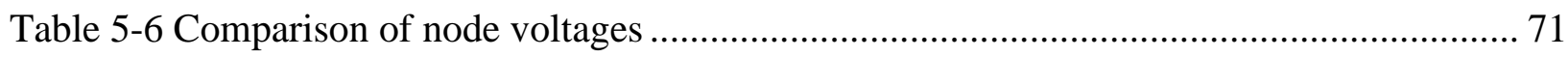

Table 5-7 Comparison of regulator tap position with wind generator ..................................... 71

Table 5-8 Comparison of node voltages with optimized parameters .................................... 102 


\section{Chapter 1 INTRODUCTION}

\subsection{BACKGROUND}

Conserving for the future has always been a positive notion for mankind. Power and energy savings is the need of the hour because of the limited supply of functional resources. Saving electrical energy can be realized in many different forms like gravitational energy in reservoirs, kinetic energy in flywheels, electrochemical energy in batteries etc. Due to the advancement in technology, energy storage devices have become one of the essentials of saving energy. Its application has increased the efficiency of operation of renewable resources like wind and solar. Hence studying, modeling, application, and analysis of Battery Energy Storage Systems (BESS) have become a hot topic in power and energy fields of research. Studies comprising storage technologies have been carried out for more than 100 years. Recently they have gained popularity in the electronics, transportation and power industry. Toyota Prius, Nissan Leaf, plug-in GM Volt and hybrid busses are only some of the examples that have taken advantage of batteries in the transportation field. These energy storage devices are also gaining momentum in utility sector for supplying reliable energy since it is reported that approximately 80 billion dollars is lost in short power interruptions in U.S. power market. Many countries have already installed batteries for consistent management of power supply. In U.S, a 40-MW Ni-Cd battery is employed in Fairbanks, AK as a backup in case of power failure. A 1-MW sodiumsulphur battery is used in Long Island, NY as a provider of peak power. An $8 \mathrm{MW}$ Li-ion battery is deployed in Binghamton, NY for smoothing grid power [39] [10]. In West Virginia, Belington, a 32 MW Laurel Mountain energy storage project is assimilated with the Laurel Mountain wind 
farm to provide frequency regulation and to limit the rapid rate of change of wind power oscillations [33].

\subsection{NEED FOR THIS WORK}

Due to the growing demands for energy and other socio-political and environmental pressures, there is an increasing need to use renewable energy sources to complement the traditional power sources. Wind turbine generators and Photovoltaic panels are the most commonly employed sources of renewable energy. However integrating the renewable energy sources into the power grid will entail overcoming significant technological challenges and issues. Wind power generation is an unstable power source and the energy generated is intermittent. Since 1990s, the annual growth of wind power in the world is more than $26 \%$. Solar energy shares the same property of variability and uncertainty like wind energy. Some of the main challenges in integration of wind power and solar power are:

- Management of uncertain and intermittent wind and solar power generation for transmission: High level integration of renewable energy will result in increased variability and intermittency leading to inaccurate load forecasting. Also transmission constraints significantly reduce the actual contribution of solar power [26] [67] [17] [57].

- Managing off-peak and peak periods: When the wind energy is high during the off-peak period, there will be potential for over generation which can only be resolved either by reducing wind power or the power output from baseline generation. When the generation using renewable energy drops, additional conventional resources are required as standby reserves to meet the variable generation and load conditions which results in inefficient load points. There is more burden on the conventional resources during the morning and 
evening in the case of solar power generation as solar power is low at that time. Also there is increased burden due to keeping more generators on standby thus not meeting the primary goal of integration of alternative energy which focusses on complementing the existing system. High level penetration of PV resources causes reduction in power quality due to voltage fluctuations and frequency variation. [26] [21] [17] [20] [57].

- Voltage profile variation: Receding voltage profile due to reactive power absorption by induction generators. Variation in voltage profile is also caused due to the injection of harmonics by power electronic as well as other non-linear devices. Harmonic distortion due to power electronic converters affects the voltage quality. [26] [17] [34].

- Managing contingency conditions: Contingency conditions leads to potential overloading of transmission lines, hence there is a need to analyze both normal and contingency conditions in steady-state power flow studies. Continuous evaluation and infrastructure improvement is required to check short circuit currents [17].

- Stability: Dynamic simulations are required for stability assessments [17] [35].

- High infrastructure costs: Wind energy harnessing sites are usually located in remote areas, so to deliver power to the load centers large wind power transmission technology and substantial infrastructure improvement is required and this increases the cost of the system. For smooth operation, addition of complicated components is required since electrical characteristics of wind generated energy and power quality are different from the traditional plant generated energy [67] [17] [20].

- System modification challenges: To integrate wind energy into the existing system, modification to the system configuration and changes in current operating conditions are required. The conditions for synchronizing like frequency, voltage phase and phase 
sequence matching should be met by the power generated by alternative energy resources [17] [36] [19] [20].

- Regulation challenges: On the transmission side, grid system needs to be more flexible to accommodate combined fluctuations of both load variation and renewable generation. This issue can be resolved only through accurate regulation, close load following and fast-ramping services [20] [57].

- Predicting future wind speeds and solar radiation: Wind climate assessment and forecasting methodologies are also required for reliable operation of the grid. Like wind energy systems, weather forecasting is required for efficient operation. Seasonal and geographic variation impact the solar power production. Even the moving clouds can impact the voltage in power networks by producing fast and short irradiance fluctuations [26] [21] [67] [57].

Addressing these concerns has become the main focus for numerous research efforts in the domain of using renewable energy for meeting power load requirements. Some of the above mentioned issues can be accounted for by integrating BESS along with renewable energy resources [10].

- Smoothing of wind power and solar power fluctuations: BESS technologies can be used for stabilizing the output wind power as well as solar power. Storage devices act as buffer systems and manage the intermittent nature of wind and solar energy. These devices should have high ramp rate and must be able to charge and discharge quickly. They should also be provided with power flow converters that can be used for either injecting power into the system or absorbing power from the system. In the case of solar power, 
energy storage devices can reduce the burden on the grid specifically at night time. [65] [14] [55].

- Frequency regulation: BESS can be employed for damping the oscillations shaped due to the variable nature of wind speed and variation of solar radiation during a day. Frequency domain analysis is done for studying the stability of the system. Storage devices with high ramp rate and reasonable response time are favored for this application [9] [52].

- Voltage and reactive power assistance: Power conditioning converters integrated in batteries are used to improve the voltage profile and control the reactive power in a weak grid. They can also protect the dc-link from over voltage. Batteries with high ramp rate and fast power modulation are the main features required [8] [53].

- Monetary benefit: Large storage devices can be used as spinning or stand-by reserves. They are also useful in peak shaving and load following. Huge amount of money can be saved by distributed generation (DG) owners by engaging the storage devices to absorb power during off-peak hours when the spilled energy is more than $10 \%$ and by supplying power at peak demand periods. Different market models are studied for cost-analysis. Proper dimensioning or sizing to obtain optimized capacity plays a big role in managing the expense and making profit [37] [16] [23].

- Transmission loss and infrastructure reduction: In remote areas where wind generators and solar panels are employed for power generation, connecting them to utility grid requires long transmission lines. For continuous supply of power in these areas storage devices can be used along with wind generators and solar panels. This reduces transmission loss as well as saves money [28] [6]. 


\subsection{CONTRIBUTIONS AND OUTLINE OF THE THESIS}

The focus of this research is to develop an energy storage battery model and an associated control that reacts to the variation in the wind power and solar power generated. When the wind power is high, the battery stores the power generated and it supplies power when the wind speed is low. The same theory applies for solar power generation as well. When the solar power generation is high during the day time, battery stores energy and during the night time battery provides energy as the solar radiation and temperature is less. The charging and discharging mode of battery is based on the state of charge (SOC) of the battery. In this thesis, a Li-ion battery model has been implemented in PSCAD. A novel Battery Energy Management Control (BEMC) system has been developed that controls the mode of operation of the battery based on the wind, solar conditions and the SOC of the battery. A bi-directional voltage source converter has been implemented for integrating the battery with the grid which is controlled using a real/ reactive power controller. The parameter for the PI controller has been optimized using Genetic Algorithm in PSCAD. The effects of storage device on real power, reactive power, frequency and voltage profile is also examined at the point of common coupling (PCC) of a wind generator and PV panel to a distribution network (DN) in charging and discharging conditions.

A synthesis of relevant literature in the area of energy storage research and its

applications in power sector is provided in Chapter 2. Chapter 3 summarizes the features of important softwares and describes the modeling of each component in PSCAD. The details of BEMC and the genetic algorithm based optimization are provided in Chapter 4. The computational runs conducted on two test networks and the important insights are provided in Chapter 5. Chapter 6 presents the conclusions and directions for future research. 


\section{Chapter 2 LITERATURE REVIEW}

This chapter describes past research relevant to the work conducted in this thesis in the domain of different energy storage battery models, power electronic converters and controls that are used for interfacing the storage devices to the utility grid, its effect on distribution network, dimensioning the storage devices and applying them in different areas/locations of power and energy sector. The general trends in energy storage devices and applications are given in papers [63] [39] [10] [64]. In [63] the authors have reviewed current relevant works in the domain of optimum sizing of standalone hybrid generation systems. Optimum sizing is important for better economic returns and also is related to the reliability of the system. The authors have segregated the spheres of optimization into four main categories - the graphical construction method, probabilistic approach, iterative method, and artificial intelligence method. The authors also look into works for statistical and time series generation of meteorological data as well as the papers which are connected to the modeling of photovoltaic arrays, wind turbine system and energy storage system. The authors have identified power reliability analysis and system cost analysis as the main criteria for the hybrid system optimization.

In [39] the author studies the past, present and future developments of energy storage system focusing more on Lithium based batteries and their cell chemistry. The author briefly discusses about the needs of energy storage in electronic industry, transportation industry and utility grid. The author discusses the general advantages of renewable energy which are reduced cost, power output stability, and peak shaving capability. He proposes his vision for the next twenty five years for energy storage devices pointing out a cost effective scenario with low cost flow batteries built in each home and cars with electrical drives and thermal storage system. Low 
cost metal oxygen or metal sulphur will be more popular and due to limited supply of lithium in the world, non-lithium based battery technology will gain momentum. However currently and in the near term future lithium based batteries will be used widely.

\subsection{BATTERY MODELS AND CONTROLS}

There are different models of battery and power conditioning units that are used in the research [44] [7] [8] [53]. The authors have listed three types of battery models electrochemical, experimental and electric circuit based and used the electric circuit based model as it can represent the state of charge (SOC) of the battery as a state variable in [44]. Their model has a control voltage source in series with a constant internal resistance. The authors point out that a disadvantage in the Shepherds model [18] is the algebraic loop problem in the closed loop simulation of the battery model. They derive equations for extracting approximate values of internal resistance based on efficiencies of batteries. The battery model parameters are estimated for common types such as lead acid, nickel cadmium, lithium ion, and nickel metal hydride from the discharge curves of the batteries. These parameters are based on voltage at full charge, exponential zone end and nominal zone end. The models were validated using MATLAB SIMULINK Simpower systems and were compared with the manufacturer's data sheet. The model was also implemented in Toyota Prius THS II vehicle. The authors concluded that accuracy in battery model is important for better control and management of energy. Battery lifetime, efficiency and the control applied in the Power Conditioning System (PCS) are also important factors for better performance. Application of super capacitors increases the battery lifetime in a small wind farm hybrid system (less than $10 \mathrm{KW}$ ) [7]. The authors develop a control algorithm to move the high frequency component of current in charging and discharging towards the super capacitor in real time. They employ a hysteresis current controlled DC/DC converter 
for controlling the inductor current and a voltage control loop is implemented for keeping the super capacitor voltage greater than the battery voltage. They have tested their theory in a prototype in a 12 V 75 AH lead acid battery series with 24 V DC nominal voltage. They used 22 super capacitors each with 2.7 V DC $1800 \mathrm{~F}$ capacity. The system was simulated in MATLAB SIMULINK. The authors concluded that by using battery super capacitor hybrid system the reversal of polarities are less and hence the SOC of battery undergoes lesser number of charge and discharge cycles. Rain flow counting algorithm was used to determine the battery cycle for a period of 7 days. They have also mentioned that the battery lifetime increases approximately $19 \%$ by using a super capacitor. In addition they have noticed the reduction in peak current which reduced the battery stress. The losses are more in the hybrid system; approximately $4.1 \%$ compared to the system without super capacitor.

Different controls for the power conditioning system (PCS) are discussed in [8] [53] [51] and [1]. The authors look into two different scenarios - one when a unidirectional power flow controller acts as an interface between the DC side and the AC side in [8]. This controller is responsible for voltage regulation on the DC side. The second scenario is the fully controlled bidirectional AC-DC and DC-AC converter system which controls the bidirectional flow of power. In the paper they illustrate both the scenarios using mathematical modeling and circuits. They support their argument by comparing simulation and experimental in transient as well as steady state conditions. The authors conclude that the vector decoupling technique is effective in power sharing between DC and AC microgrids.

The authors investigate the single phase bi-directional DC/AC converter in [53] which is connected to an $\mathrm{AC}$ microgrid. In the inverter mode for the power flow controller three different types of switching schemes are considered - hysteresis current control, predictive control, and 
the ramp comparison control. For the charging mode, the authors used the trickle charging method keeping the duty cycle constant and found that this method was not the best way. The system was implemented in MATLAB/SIMULINK and output wave form for hysteresis and ramp comparison switching control scheme in inverter mode were studied.

In [51], the authors study the supervisory control strategy on a hybrid system with wind turbine generator, photovoltaic cells, and energy storage unit - connected to a common DC bus interfaced with power electronics converters. The authors look into three different modes of control for the grid inverter at the supervisory control level. The first is the normal operation where the wind and the PV arrays act as complementary sources to provide maximum power output and no storage is connected to the system. The common bus voltage is maintained by the grid inverter. The second is the dispatch operation mode. Here the wind photovoltaic array and the battery output power are controlled to reach a desired set power. This is useful in peak load shaving, active load control etc. The third mode is the averaging operation mode. Here the output power as well as the voltage and current harmonic variations are stabilized with power averaging control. Its successful implementation requires prediction of average output power of wind, photovoltaic and battery system. In addition to the supervisory control each source has its own local control. The wind turbine has the variable speed control to regulate the active reactive power. Maximum Power Point Tracking (MPPT) control provides maximum power output for photovoltaic arrays. Modified hysteresis control is implemented for battery charging and discharging to maintain a common DC bus voltage. They performed the simulation studies in PSCAD/ EMTDC as well as deployed the control on a $30 \mathrm{KW}$ prototype of the hybrid system. They concluded that the control strategy is effective and efficient in all modes of operation. They were also able to stabilize the output power current harmonic and excursions. 
A back to back converter interfaces a Permanent Magnet Synchronous Generator (PMSG) to grid in a wind storage hybrid system [1]. The storage is connected across the common DC link through a DC/DC buck boost converter and a dump resistance. The wind turbine generator speed follows the wind speed for maximum power output. The error along with the real power output is used as a reference to generate gate pulses using space vector pulse width modulation (SVPWM) technique for the generator side converter. The grid side converter is fired using gate pulses generated by the difference in reference DC voltage and the actual DC voltage. It is also used in regulating the reactive power output. The authors study two modes of operation - one with constant wind and variable load and the other with constant load and variable wind. They were able to show how the storage bridges the gap between the generator current and the load current. These modes are implemented in PSIM software. The control is found to be effective in regulating the output power and voltage in spite of the variations in wind power.

\subsection{SIZING AND COST-ANALYSIS}

There are numerous papers which focus on dimensioning the storage devices and the benefit of procuring an income from optimum sizing. In [37], the system mainly consists of photovoltaic panels, Valve Regulated Lead Acid (VRLA) battery and ultracapacitor banks as the sources in isolated Hybrid Energy Storage Systems (HESS). Different scenarios like constant, peak, pulse and domestic load conditions were used to study the undersized, oversized and optimized system. Initially the authors calculated the number of solar panels required to meet the average load considering the solar radiation and temperature. Then they computed the number of battery cells in series and parallel to supply the total load for a certain period of time and the number of ultracapacitors required to meet the peak load demand. The system performance was 
evaluated and the number of solar panels, batteries and ultracapacitors are adjusted based on the lifetime system cost and the Loss of Power Supply Probability (LPSP) in a MATLAB Simulink model. The authors rationalize the optimization by stating that undersized and oversized batteries results in overcharging and sulphation and stratification respectively when compared to the size of solar panel. Increased number of ultracapacitor will also increase the capital cost.

Energy Management Systems (EMS) minimizes the storage size and hence the cost of hybrid winds energy systems. When the wind penetration increases, some of the main issues emerging are power imbalance, voltage excursions and low voltage ride through (LVRT) capability [16]. The authors suggest that energy storage systems (ESS) together with power electronic interface can smooth out the power fluctuations created due to wind generation and will also have the capability for low voltage ride through (LVRT) by serving as a power sink during low system voltage events. They have also listed some of the short term (Supercapacitors, Superconducting Magnetic Energy storage Systems (SMES) etc.) and long term (Batteries, Hydro pump storage etc.) energy storage devices and their properties. The authors indicated different configurations of back-to-back voltage source converters (VSC) connected to the DFIG. The energy storage system was connected to the DC grid interfaced with bidirectional two quadrant DC/DC converters. The authors provided a fuzzy rule based EMS which was based on wind speed data, ESS device status and AC voltage measurements. The EMS adopts a reference grid power based on these rules which helps in stabilizing the output power. The authors also suggest that the EMS can be implemented on a higher level using SCADA systems. Then the authors discuss the system in two different operating scenarios, one with the normal operating conditions in islanded mode and the other is the case with a faulted transmission network. In 
normal operating condition ESS stabilizes the output power and in faulted system scenario ESS is better than the active crow bar case in voltage magnitude response characteristic.

The authors have tried to achieve the optimized solution for the sizing of solar wind hybrid system in order to minimize the loss of power supply probability (LPSP) to improve power reliability and minimum annualized cost of the system (ACS) in [23]. Genetic algorithm was used to obtain the solution for the optimization problem for a remote telecommunication relay station. The authors developed models for PV array, wind turbine generator, and battery units. They have particularly focused on SOC, floating charge voltage, and lifetime of the battery system and considered these variables as the constraints for the optimization. This minimizes the total system cost by meeting the LPSP criteria. A lead- acid battery with 1000 ampere hour rating and $24 \mathrm{~V}$ nominal voltage was used. The authors concluded that with only one of the source the same LPSP is achieved at higher cost. Energy storage life of 3 to 5 days has been found suitable for power reliability and system configuration of hybrid system and system configuration in $1 \%$ and $2 \%$ LPSP case.

Several studies have exclusively advocated energy storage as a solution to reduce the operating cost of large scale wind integrated systems [58] [56] [11] [5] [54] [66]. According to [58], energy storage will reduce the burden on hydro and fossil fuel energy generators. Here power flow control approach is used to determine the dimensions of the zinc-bromide flow battery system. The simulations are implemented in MATLAB. Initially the actual wind farm data is used to forecast the combined power output of wind farm and the energy storage system allowing only $\pm 4 \%$ error, $90 \%$ of the time. This forecast model is based on one-hour ahead persistence model. The authors come up with a technique to determine the desired energy storage power output command for the power flow controllers which determines its charging (negative 
command) and discharging (positive command) course. This technique is based on a set of rules centered on the SOC of the battery, forecasted wind power output and actual wind power output. These rules are implemented using simple, fuzzy, artificial neural networks (ANN) and advanced ANN logic algorithms to obtain an optimized cost-effective energy storage system. The authors conclude that simple and fuzzy control logics have much less error occurrence than the ANN based control logics. But the advanced ANN produced the best results in terms of cost.

In [56], the authors discuss the ability of sodium sulphur (NAS) battery to shift the wind generation from light load to heavy load condition and limit the ramp rate of the wind farm output. They also consider the battery as a separate entity and present the cost and market analysis for employing the battery as a source. The battery they considered is a $1 \mathrm{MW} 7.2 \mathrm{MWH}$ $85 \%$ efficient NAS battery. The depth of discharge (DOD) of the battery is $90 \%$. They show how an optimally employed battery is able to shift the wind generating and its successful six hour discharge at peak load and ramp up period. They discuss the implications for the total revenue obtained by using battery for each application over a period of time. They conclude that the benefit is maximized when the battery is used as an operative reserve with longer battery lifetime greater than 20 years.

A new optimization technique based on forecasting of export power, minimizing the variability of wind power, maximizing the total output energy and hence maximizing the total revenue is proposed in [11]. The authors also develop a computationally efficient linear program based on buffer based smoothing problem where the battery capacity is used as the buffer to stabilize the export power. Losses occurring due to excess energy and battery charging and discharging are modeled. The authors conclude by showing how the method was used to 
maximize revenue by maximizing the energy export and draw comparisons between wind power output smoothing and video smoothing.

The authors have focused on economic factors like capital cost, replacement cost, operational maintenance cost in minimizing the overall system cost using genetic algorithms in [5]. The objective function aims to reduce the system cost and total diesel fuel consumption cost subjected to power and voltage constraints. Simulation results show the optimized number of batteries, PV cells, wind generators and diesel power requires reducing the system cost for two different cases of annual wind speed and solar radiation.

Reducing the power fluctuations and charge discharge cycle of a wind BESS hybrid system reduces the total system cost [54]. This system also includes a capacitor in parallel with the battery which reduces the charge discharge cycle for the battery by reducing the current drawn from the battery. A 1.5 MW wind turbine generator connected to a DFIG and $25 \mathrm{KW}$ battery capacity is used. In this work to smooth out the power fluctuations, the authors have separated the frequency into two regions by a high pass filter and a low pass filter. One region which is used to increase the BESS capacity to stabilize the output power variation lies between $0.01 \mathrm{~Hz}$ and $1 \mathrm{~Hz}$ and the other frequency window above $1 \mathrm{~Hz}$ is discarded. The authors have implemented the system in MATLAB and demonstrated how their controller is able to smooth power output excursions in addition to decreasing the BESS capacity.

A DG owner can maximize his profit by storing all the spilled wind energy into an Energy Storage System (ESS) [66]. A cost-benefit analysis was also performed by the authors to verify their notion. The size of ESS was calculated based on the power and energy rating of the spilled wind energy. The total annual cost of the system includes the capital cost, maintenance 
cost and replacement cost. The multi-objective optimization problem formulation (OPF) is to minimize the total annual cost with optimum size and location of ESS. The ESS acts as a load during the off-peak periods and as a source during the peak demand time. The authors used a $27.6 \mathrm{kV}$ rural distribution network with peak load of 18.2 MVA and maximum feeder capacity of 300A for the case study. Also connected to the system are three distribution generators. ARMA model was used to generate the wind speed data in MATLAB and demand profile was obtained from IEEE-RTS. The authors found that maximum amount of energy were spilled during the winter nights which were used as the main factor for determining the size of ESS. In conclusion, $\mathrm{Zn} / \mathrm{Br} \mathrm{ESS}$ was found as the most economical for the distribution system as it was the least expensive ESS technology.

\subsection{DISTRIBUTION SYSTEM APPLICATIONS}

Connecting the storage devices to a distribution network and analyzing its implications on the network is important to study the reliability of the system. To date relatively few papers have focused on this area [4] [3] [28] [6]. In [4] and [3], the authors develop a flexible battery management system (FBMS) for active reactive optimal power flow (A-R-OPF) in distribution systems. The solution for A-R-OPF problem is to minimize the transmission energy loss and expand the voltage profile. They have used a mixed integer nonlinear program to optimize the charge and discharge time periods of battery for each day [4]. This program is implemented in two stages. The integer variables like the charge discharge periods are optimized in the upper stage and the continuous variables are optimized by the nonlinear program (NLP) in the lower stage. The battery charging and discharging have been restricted to one cycle per day. The authors have studied three different energy price models and recommended a two-tariff price 
model in which the spilled energy from the wind generator during the off-peak hours can be stored at lower tariff and this energy can be released during peak hours at higher tariff for economic benefit [3]. The model of Energy storage System (BSS) along with the Power Conversion System (PCS) generates both active and reactive power. The demand profile for the simulation is obtained from IEEE-RTS winter days. The A-R-OPF optimization problem is to maximize the profit and minimize the loss with wind power and demand curve as the inputs. The decision variables are active power, reactive power and wind power curtailment factor. One-day and multi-day time slices were considered for optimization. The authors tested their theories on a $27.6 \mathrm{kV}, 41$ bus radial distribution network with maximum feeder capacity 14.3 MVA. Three embedded wind generators and five BSS were also connected to the network. The authors found that $12 \%$ energy loss reduction and $90 \%$ reactive energy supply can be achieved through their optimization strategy. It is also economically beneficial in addition to the curbing of output power fluctuations.

A linear lossless DC OPF in IEEE 30 bus and IEEE 118 bus system with and without location constraints on storage devices is used in [28] for maximum economic benefit as well as reduced transmission and generation losses. Linear function of rated power and energy is applied in network reduction method for proper deployment of storage devices in order to increase the system efficiency. The authors concluded that for an optimally dispatched renewable generation, fewer number of storage devices are needed and hence prove more economical.

The technical and economic aspect of connecting a distributed generator (DG) to a distribution network is described in [6]. The technical aspect is studied by focusing on the transient stability of the system with DG, storage devices, and ultra-capacitors subjected to different types of fault and penetration levels. Rotor speed and angle, oscillations and terminal 
voltage are taken as the transient stability indicators. The economic aspect is studied by taking into account the cost of the system with distributed generators, storage devices, and ultracapacitors. This analysis is carried out using a simulation tool called "hybrid optimization model for electric renewables (HOMER)" developed by National Renewable Energy Laboratory. The transient stability was studied in an eight bus system with three DG's and storage devices which were modeled in MATLAB SIMULINK. The authors concluded that the net present cost of diesel generator decreases when storage device is added. Diesel battery system cost was less compared to the diesel ultra-capacitor system cost due to higher cost for ultra-capacitors. In addition, the storage devices also enhance the transient stability of the system.

\subsection{WIND POWER SMOOTHING APPLICATIONS}

Numerous works have been conducted for wind power smoothing for both stand-alone and grid connected applications of storage devices [65] [14] [55] [47]. In [65], the authors propose the BESS as a buffer power source that complements the stochastic wind power source in order to deliver a steady power to the grid. The hybrid system mainly consists of a PMSGturbine with Lead-acid BESS and a capacitor connected across back-to-back converter which is tied to the main grid. The difference between the varying wind power and the fixed power supplied to the grid gives the battery power and energy. The battery capacity is designed based on the maximum deviance value. These values are then used to determine the optimal value of constant power delivered to the grid which proves the most cost-effective. The authors also estimate and numerically derive the value of shunt capacitance needed to maintain the dc-link voltage within limits. The capacitor acts as harmonic filters and in addition intersects the transient voltage violations. The authors simulate the system using PSCAD/EMTDC and MATLAB simulation software and exemplify the proposed scheme using an example. 
In [14], the authors study the effect of BESS integrated with a STATCOM for wind power applications. For BESS modeling the authors propose two different types of equivalent circuits and control strategy. The first is based on open circuit voltage of battery and the second is the current based method which varies with battery SOC. A third order lead acid battery model which is validated through experimental and simulation based studies is used by the authors. The battery parameters are obtained by optimization. The size and performance of battery with converter and control is evaluated to obtain the complete system. The authors conclude that this system along with the STATCOM can stabilize the wind power output. The authors also suggest that with higher nominal current of battery, higher charging and discharging cycles will occur and hence the size of the batter is a significant factor in designing the system.

The authors focus on optimizing the use of BESS for large wind farms [55]. BESS is designed to balance the error between wind power output and the reference wind power forecasted from the average power output for the next one hour. The authors also mention the importance of state of charge (SOC) and depth of discharge (DOD) in the context of battery lifetime. For BESS optimal control, the controllability of a state space model is checked. The performance index (PI) of the control is specified using a quadratic cost function along with the constraints and limits. The solution to the optimal control problem is obtained using two methods. Initially they implement the open loop control optimal control (OLOC) for signal control periods of 100 seconds, 5, 15 and 30 minutes. OLOC was not able to meet the limits when the control period was more than 15 minutes. This issue was solved using the model predictive control algorithm (MPC). The simulations were performed in PSCAD/EMTDC and the optimal control problem was solved using DIDO version 7.3. From the PI measured, the authors concluded that the best performance was obtained when the prediction window was 
longer since it reduces the occurrence of big variations. The authors also concluded that $15-25 \%$ of the size of the wind farm is required for BESS capacity to smooth out the wind power output effectively.

In [47], the authors have focused on reducing the wind power fluctuations at two different time scales. In one the maximum power fluctuation restrictions (MPFRs) of wind and BESS output is limited for one minute time window and in the other the MPFRs is limited for 30 minute time window. To attain dynamic stability and operation economy both the operations are performed simultaneously. The authors develop a discrete first order low pass filter (FLF) configuration to smooth the output power of wind with variable time constant $\left(\mathrm{T}_{\mathrm{f}}\right)$. Particle swarm optimization (PSO) is used to determine the optimization variable associated with $\mathrm{T}_{\mathrm{f}}$. The authors propose a procedure for coordinating the two timescale controls in restricting the power fluctuations. A MATLAB SIMULINK simulation of a $750 \mathrm{~V}$ Lithium Ion battery connected to a $6 \mathrm{MW}$ wind farm was performed. The authors have also derived the capacity and power rating of the storage and concluded that the FLF algorithm is efficient in reducing the wind power fluctuations.

\subsection{FREQUENCY CONTROL APPLICATIONS}

The frequency impacts of BESS have been researched by several authors [9] [52]. BESS is used for primary frequency control in [9]. The authors compare four different types of battery energy storage system (BESS) technologies and conclude that Lead-Acid BESS is the most costeffective for a 10MW unit. The authors also discuss pricing and market for the primary frequency control reserves in central European countries. They propose solutions for power balance by limiting the non-critical frequency window to $\pm 20 \mathrm{mHz}$ using optimized capacity for 
BESS units. They suggest that maximum profit will be obtained by using dynamically varying SOC limits, recharge power, sell power as main constraints and using emergency resistors as budget constraints in case of extreme frequency digression where the SOC is at maximum for the BESS unit.

The effects of frequency fluctuation damping due to a disturbance in the power output of a microgrid is analyzed in [52]. A multi-agent concept was used for this study along with user datagram protocol/internet protocol (UDPIP) for communication. The authors have employed the battery only when transients occur in the output power hence reducing the battery ampere hour rating. They have obtained the gains for the controllers using bacterial foraging optimization (BFO) technique which is successful in damping the oscillations of frequency. Their models of microgrid have wind power, solar power, diesel generator, fuel cell, aqua electrolizer, and a battery. Microgrid central controller is employed to control the generation by appropriately connecting or disconnecting the sources through circuit breakers for proper generation. All commands are communicated via UDP/IP. They have studied different cases of microgrid in MATLAB/SIMULINK and concluded that BFO is successful in tuning the controller parameter for damping the output oscillations following a disturbance.

\subsection{ELECTRIC VEHICLES APPLICATIONS}

Energy storage devices have also found a huge application in the transportation industry [62] [38]. Steady state optimal operation of plug in electric vehicles (PEVs) in reducing the energy cost for both spot and regulation markets is described in [62]. The authors also show the advantage of PEVs in minimizing the wind power deviations. Initially the authors derive a model for PEVs and formulate an optimization problem for minimizing the energy cost subject to the constraints. The sequential quadratic programming is used for solving the optimization problem. 
A winter weekday and summer weekday were used to study the energy cost for spot price market and regulation price market. For the spot price market $91.6 \%$ of energy saving was found for the winter weekday. The same was the case for the summer weekday even though the percentage of energy saving was less compared to the winter weekday. For the regulation price market study, the simulations were performed using DIgSILENT power factor software and the authors found that better regulation is obtained for power exchange between West Denmark and Union for the Coordination of Electricity Transmission (UCTE) control area by using PEVs for both summer and winter weekdays. The authors considered operating the PEVs on both spot and regulation market simultaneously and concluded that it not only minimizes optimal costs in spot markets but also provides regulation power for all cases.

In [38], the relation between storage capacity of electric vehicles (EV) and variability nature of wind power is analyzed. Genetic algorithm along with real time communication system, smart meter and home area networks (HAN) were used for employing an energy management system (EMS) to minimize the cost and maximize the utilization of renewable energy. Initially the authors consider a Lithium Ion Chevy Volt 2011 model for PHEV and propose an optimization problem for maximum utilization of wind generation by coordinating the charge and discharge periods of electrical vehicles. The authors study the different scenarios with fixed charge instants; fixed percentage of EV's and optimizes the decision variable. These variables are the mean charging period, percentage of EV connected in each period, and the conventional power generated. The authors found that the third scenario with the optimized decision variable is the most economically viable scenario and provides more flexibility in generation. 
The significant majority of this chapter has reviewed literature which focuses on the different aspects of using storage devices to enhance the grid. In [22], the authors caution about absolute need of employing energy storage devices in the utility grid. They point out that all applications of storage can also be achieved otherwise and discuss the expenses and limitations of storage devices in power energy applications. They differentiate the storage applications into power application where more MW is needed compared to MWh and energy application where MWh should be higher than MW capacity of battery. They particularly look into the economic aspects of generation capacity, equipment capacity, line congestion, wind and solar power smoothing and frequency regulation. They suggest that for wind and solar power smoothing, power rating of the storage device should be more than the energy capacity to reduce the ramp rates of wind and solar power. They conclude the paper by weighing the options between storage and alternate solutions for different power energy applications.

\subsection{SUMMARY AND CONTRIBUTION OF CURRENT RESEARCH WORK}

In this chapter, existing work on different battery models, their sizing and control along with some of their applications in wind power stabilization, frequency regulation and electric vehicle application have been reviewed. In this research, a bi-directional converter with novel control and mode selection technique for a Li-ion battery model as a separate element of power system network is developed. Its operation to smooth wind power fluctuations in a distribution system is studied using power system simulation software PSCAD. The effects of storage device

on real power, reactive power, frequency and voltage profile was also examined at the point of common coupling (PCC) of a wind generator to a distribution network (DN). 


\section{Chapter 3 IEEE 13 BUS NETWORK MODEL}

This chapter first reviews the various simulation softwares used in the industry and academic for designing, simulating and analyzing power system components which increases the reliability, efficiency and revenue of the system. The various components are modeled in PSCAD to study the interfacing effects of distributed generation along with storage and converters on a distribution network. The IEEE 13-Node feeder is simulated in PSCAD as the

test case. Wind turbine generator and energy storage modules are also modeled in PSCAD and added to the test case to study its influence on distribution.

\subsection{SIMULATION MODELS AND TOOLS}

There are many standard types of software that are available in the market for designing, modeling, simulating and analyzing the different aspects of power system. These softwares play an important role in effective use of resources and for asset management which results in favorable investments. The available softwares are mainly differentiated based on the type of application, mathematics behind modeling, simulation and analysis methods and userfriendliness. These softwares are designed in accordance with IEEE, NEC (NFPA), NESC and IEC industry standards [32].

\subsubsection{PSCAD}

Power Systems Computer Aided Design (PSCAD) [40] developed by Manitoba HVDC Research Centre is a powerful transient simulation tool for power systems where EMTDC solution engine is interfaced through graphical user interface. Some of the main features of PSCAD are: 
i. A well-defined state of the art library and standard real world examples for building, simulating, modifying and analyzing any electrical network.

ii. Ability to control variables during simulation with online plotting functions for studying the effects of change in the network.

iii. Creating user-defined components and modules which help to customize and program different cases according to the researcher's requirement.

iv. Capability to integrate with other softwares like MATLAB, C and to export import data for detailed analysis of the system.

\subsubsection{SimPowerSystems}

SimPowerSystem [60] was created by Hydro-Québec of Montreal and marketed by MathWorks. It has a detailed library with all components of power system including machines, drives, FACTS devices, renewable energy systems etc. SimPowerSystem also has a library for control system components for state-space analysis to determine the system performance. One can also build custom models using MATLAB/SIMULINK multi-domain environment. Similar to PSCAD, SimPowerSystem co-ordinates with other simulation softwares and hardwares. It has discretization and phasor simulation modes for faster model execution and supports C-code generation.

\subsubsection{Power World Simulator}

Power World simulator [46] is powerful simulation software which is highly efficient in solving a 100000 bus power flow network. The software is equipped with full-color animated one-line diagram with zooming and panning capability. It has graphical interactive features with 
a library collection consisting of devices like buses, loads, generators, transformers etc. Transmission and generation components can be easily added or removed. In addition to solving power flow, it can execute integrated economic dispatch, area transaction economic analysis, power transfer distribution factor (PTDF) computation, short circuit analysis and contingency analysis. Its optimal power flow (OPF) algorithm uses sequential linear programming based on simplex codes. The main products include the Simulator for high voltage power system operation, Retriever for system visualization tools using real-time data, Trainer as a multi-user platform, TransLineCalc to determine transmission line parameters and Viewer for viewing the animated power flow solution graphically.

\subsubsection{WindMil}

WindMil [42] is a software tool designed for electric distribution system planning, protection and operational analysis. It was developed by Milsoft Utility Solutions. It can be used to represent radial and loop electric power networks connected to individual customers, inline and endpoint devices and also to distributed generators. Modeling and analyzing power flow, voltage drop, reliability, contingencies, short-circuit and fault current, protective device coordination and arc flash hazard are some of the applications of WindMil software. It also has full geographic representation feature. This software can also be integrated with CIS, SCADA, AMR/AMI data sources.

\subsubsection{ETAP}

ETAP [45] developed by Operational Technologies Inc., is a power system analysis software focusing on planning, design, analysis, operation, control, optimization, training, 
simulation and automation of generation, transmission and distribution networks. ETAP delivers software solutions for arc flash, load flow, short-circuit, transient stability, relay co-ordination and optimal power flow. It is applied in intelligent power monitoring, energy management, system optimization, advanced automation and real-time prediction. This software can be customized due to its modular nature and has the potential to manage, control, visualize, optimize and automate power networks in real time.

\subsubsection{ASPEN}

ASPEN [13] is a user friendly and efficient software tool for power industry. It has embedded programs like One Liner and Relay Database for short-circuit and relay co-ordination study, DistriView for load flow harmonic and reliability analysis in addition to short-circuit and relay co-ordination for the distribution network, Breaker Rating Module for circuit breaker studies, Power Flow Program for studying power flow in transmission network and Line Constants Programs and Line Database for electric parameter calculation of lines and cables. It applies sparse-vector computational methods and graphical user machine interfaces for power system applications.

\subsubsection{Power Factory}

DigSILENT [24] is a stand-alone software that models and analyses generation, transmission, distribution and industrial grids. It is an efficient tool in analyzing renewable energy resources and large power systems. It also has the capability to co-ordinate with GIS, DMS and EMS supporting open system standards. Some of the basic features of the software are data management, network and graphic diagrams and external data format support. Distribution 
network optimization, optimal power flow, harmonic and reliability analysis, state estimation and protection are some of the advanced functions of Power Factory in addition to the basic functions like load flow analysis, fault analysis, distribution network analysis etc. This software is also furnished with examples and videos of real-world power applications.

\subsubsection{HOMER}

Hybrid Optimization Model for Electric Renewables (HOMER) [29] software marketed by HOMER Energy LLC is an analysis and optimization tool specifically designed for distribution system and systems with high penetration of renewable energy resources . HOMER was developed by the National Renewable Energy Lab, a division of the U. S. Department of Energy. This software is used for sensitivity analysis and optimization of distributed generation (DG) both on and off-grid. They estimate operational and technical cost and feasibility for renewable energy applications. They specialize in chronological modeling and simulation for modeling solar, wind and combined heat and power energy sources. In addition, they can also model conventional energy sources.

There are also other power system analysis softwares like GE PSLF from GE's power system analysis program [27], Easy Power from ESA [25], NEPLAN by BCP Inc. in collaboration with $\mathrm{ABB}$ utilities $\mathrm{GmbH}$ and Swiss Federal Institute of Technology [15] , SynerGEE Electric of Advantica Stoner [59], IPSA software from IPSA Power Limited [31], HYBRID2 by Renewable Energy Research Laboratory of University of Massachusetts [50], HOGA by Electric Engineering Department of University of Zaragoza (Spain) [48] etc. Among these softwares PSCAD is gaining popularity due to the high speed EMTDC electromagnetic transient simulation engine which is employed by engineers, scientists, academic institutions, 
manufacturers as well as consultants likewise. In [43] it was proved by authors that PSCAD is the most favorable power system analysis tool in terms of accuracy and speed for complicated power flow networks. The user-friendly nature of PSCAD in addition to the convenience in adjusting generation and load both on-line and off-line was preferred by many researchers. The authors modeled the IEEE 30 bus system in MATLAB and PSCAD and compared the results. They found that even though the results from MATLAB iteration method and PSCAD simulation method match, the computation time required for PSCAD is smaller with better accuracy. Hence they concluded that PSCAD is the ideal software solution for power flow studies in industry as well as academia.

\subsection{MODELING IEEE 13 NODE TEST FEEDER IN PSCAD}

The IEEE 13 node test feeder [30] is considered as a prototype of real world radial distribution network as it is unbalanced and has most components of a distribution system like 3phase, 2-phase and single phase distribution lines, underground cables, distributed loads, regulator and breaker system. In this thesis, the IEEE 13 node test feeder is modeled in PSCAD $\mathrm{X} 4$ (Version 4.4.1.0) is shown in Figure 3-1. Models of overhead transmission and distribution lines, underground lines, transformers, capacitors, regulator and loads including spot load and distributed load were designed using PSCAD master library components and components available in the examples. The regulator was modeled using a single-phase two winding autotransformer with online tap changer and its appropriate control circuits modeled using the ANSI standards. Spot loads like PQ, Z and I load were modeled using the standard library components and the appropriate values for each parameter were entered. After modeling each component, the whole system was integrated and the simulation was done to obtain the required 
results. The model was simulated and the power flow results were compared with the standard IEEE test system results.

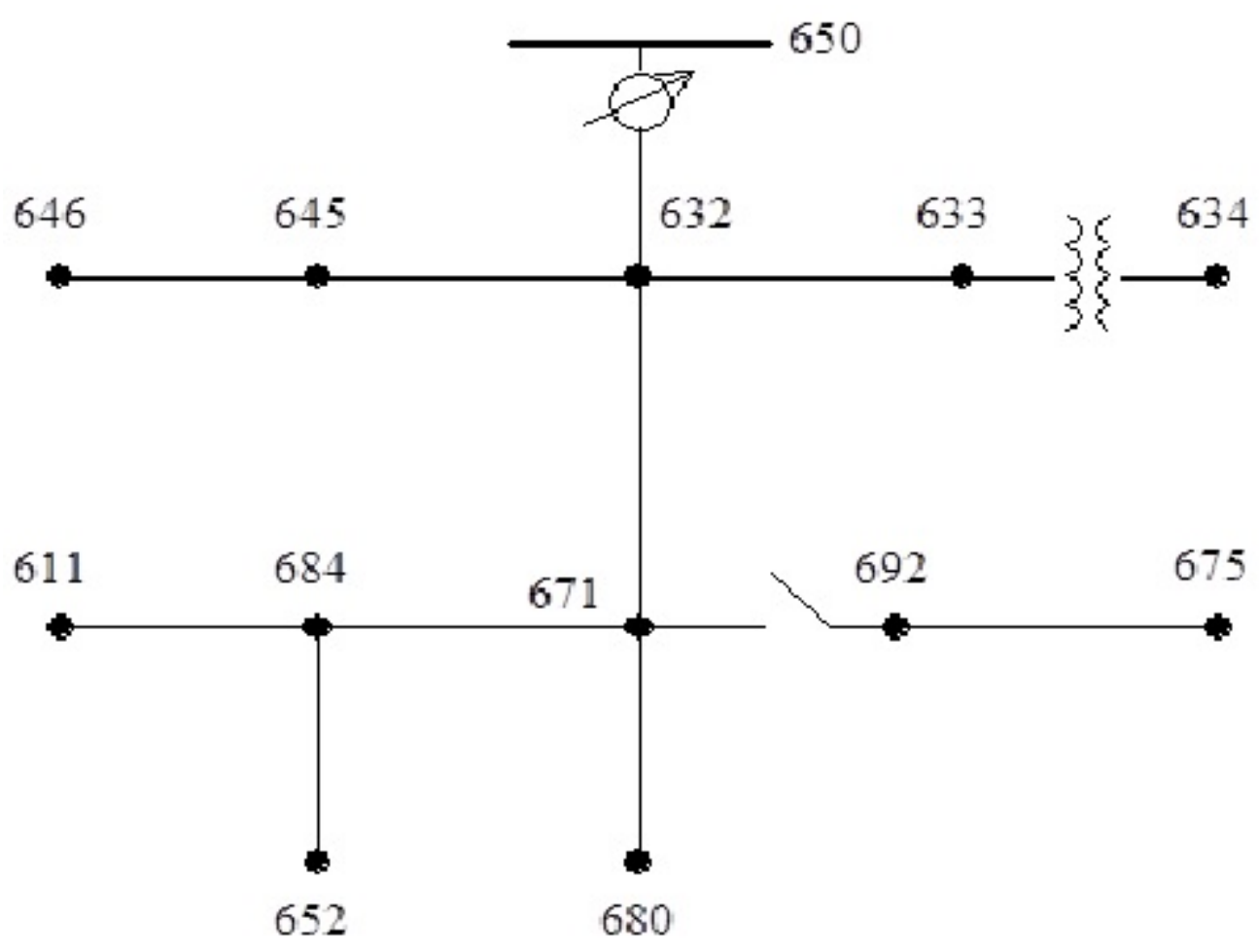

Figure 3-1 IEEE 13 Node Feeder [30]

\subsubsection{3-PH and 2-PH and 1-PH Transmission Line Model}

The single phase and 3-phase view of transmission line are shown in Figure 3-2 and Figure 3-3 below:

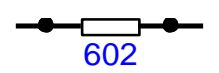

Figure 3-2 Single-phase view of Transmission Line 


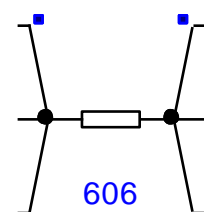

Figure 3-3 Three-phase view of Transmission Line

The transmission or distribution system can be modeled using the Tline components and modules from the master library. But since the transmission lines are really short (less than 80 $\mathrm{km}$ ), equivalent coupled pi section lines were employed. For more accuracy instead of using transmission line and cable data, the impedance ( $\mathrm{Z}$ ) matrix and susceptance (B) matrix parameters of the transmission line which is available in the IEEE 13 Node Test Feeder data sheet are entered into the required areas in the dialog boxes of the unbalanced short line component. Overhead line configurations 601, 602 and underground line configurations 606 are 3-phase distribution lines. Configurations 603 and 604 are 2-phase distribution lines, and 605 and underground line 607 are single-phase distribution lines. By changing the script of the Tline component, two-phase transmission line can be easily derived from the three-phase transmission line component and for single phase, the values of resistance and reactance are modeled directly using resistors, inductors and capacitors. The impedance $(\mathrm{Z})$ matrix and susceptance (B) matrix are given in the form:

$$
\begin{aligned}
Z_{a b c} & =\left[\begin{array}{lll}
Z_{a a} & Z_{a b} & Z_{a c} \\
Z_{b a} & Z_{b b} & Z_{b c} \\
Z_{c a} & Z_{c b} & Z_{c c}
\end{array}\right] \\
B_{a b c} & =\left[\begin{array}{lll}
B_{a a} & B_{a b} & B_{a c} \\
B_{b a} & B_{b b} & B_{b c} \\
B_{c a} & B_{c b} & B_{c c}
\end{array}\right]
\end{aligned}
$$

where off-diagonal elements $Z_{a b}, Z_{a c}$ and $Z_{b c}$ are mutual impedances and $Z_{a a}, Z_{b b}$ and $Z_{c c}$ are self-impedances. The impedance $\mathrm{Z}$ of the transmission line is also given by the equation: 


$$
Z=R \pm j X
$$

where $R$ is the resistance and $X$ is the reactance. Using the above equations and the parameters of transmission line given in the data sheet, we can enter all the values in dialog box as shown below:
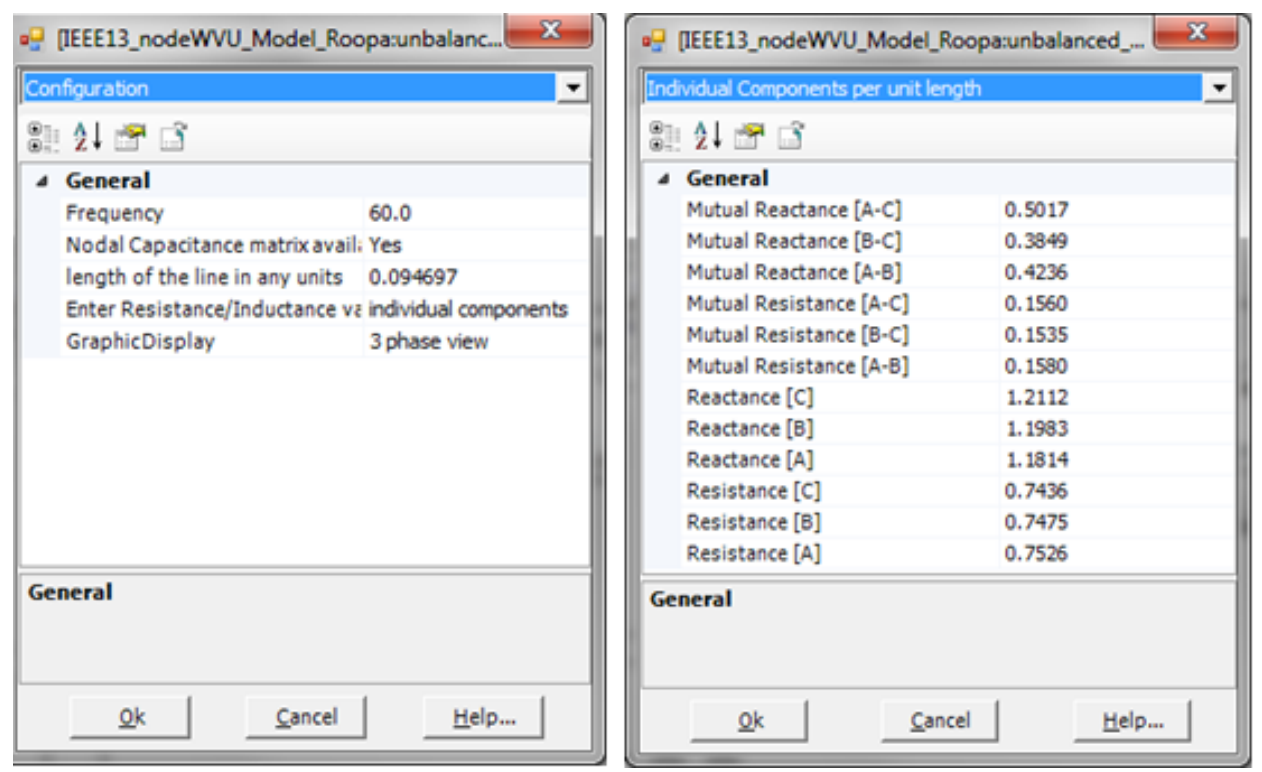

Figure 3-4 Transmission Line Dialog Box

\subsubsection{Step Voltage Regulator Model}

A step voltage regulator shown in Figure 3-5 is modeled in PSCAD. It is a tap-changing auto transformer employed to maintain the voltage at every end points at all situations of load within a certain range defined by the ANSI standards. The two most common methods of maintaining a desired voltage range are the switched shunt capacitor method and step voltage regulator method. Step voltage regulator is applied in this thesis for voltage regulation in distribution network. The model is obtained from the paper [61]. Also a compensator circuit is used to determine the instance of tap change to maintain the voltage within a specified bandwidth at the "regulation point" at the given $\mathrm{R}$ and $\mathrm{X}$ setting. The goal is to design a voltage 
regulator where the maximum voltage imbalance should be within 3\% according to ANSI standard.

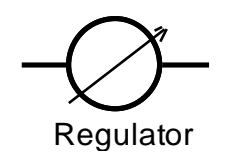

\section{Figure 3-5 Step Voltage Regulator Module}

The voltage imbalance is given as:

$$
\text { Voltage }_{\text {Imbalance }}=\frac{\text { Max deviation from average voltage }}{\text { average voltage }} \times 100 \%
$$

The model for a step voltage regulator mainly has an auto transformer with a load tapchanging control circuit. Type A and type B are the two classes of step voltage regulators found in literature. In this thesis type B step voltage regulator is employed. The model of type B step voltage regulator is shown in Figure 3-6 below:

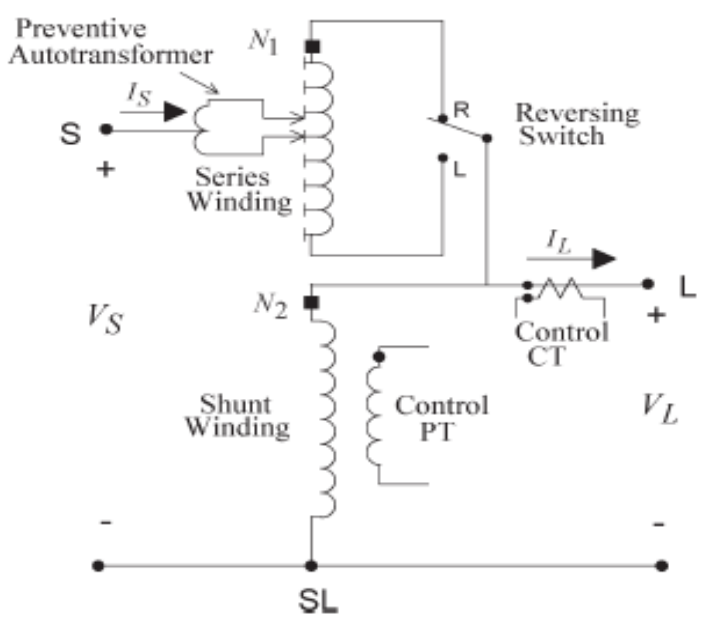

Figure 3-6 Type B Step Voltage Regulator [61] 
To change the voltage, the number of turns on the series winding $\left(N_{1}\right)$ of the preventive autotransformer is changed with each tap equal to $5 / 8 \%$ or 0.00626 p.u of the base voltage. Standard step voltage regulator has $\pm 10 \%$ regulation range. Position of the tap is determined by the compensator circuit. The input output voltage and current equations are given as:

$$
\begin{gathered}
V_{L}=\frac{1}{a_{R}} V_{S} \\
I_{L}=a_{R} I_{S}
\end{gathered}
$$

where the effective regulator ratio $a_{R}$ is,

$$
a_{R}=1 \mp \frac{N_{2}}{N_{1}}
$$

'-'when the regulator is in the raise position and '+' when the regulator is in the lower position.

$V_{S}$ and $I_{S}$ are the input voltage and current respectively. $V_{L}$ and $I_{L}$ are the output voltage and current respectively. The effective regulator ratio can also be given as:

$$
a_{R}=1 \mp 0.00625 . \text { Tap }
$$



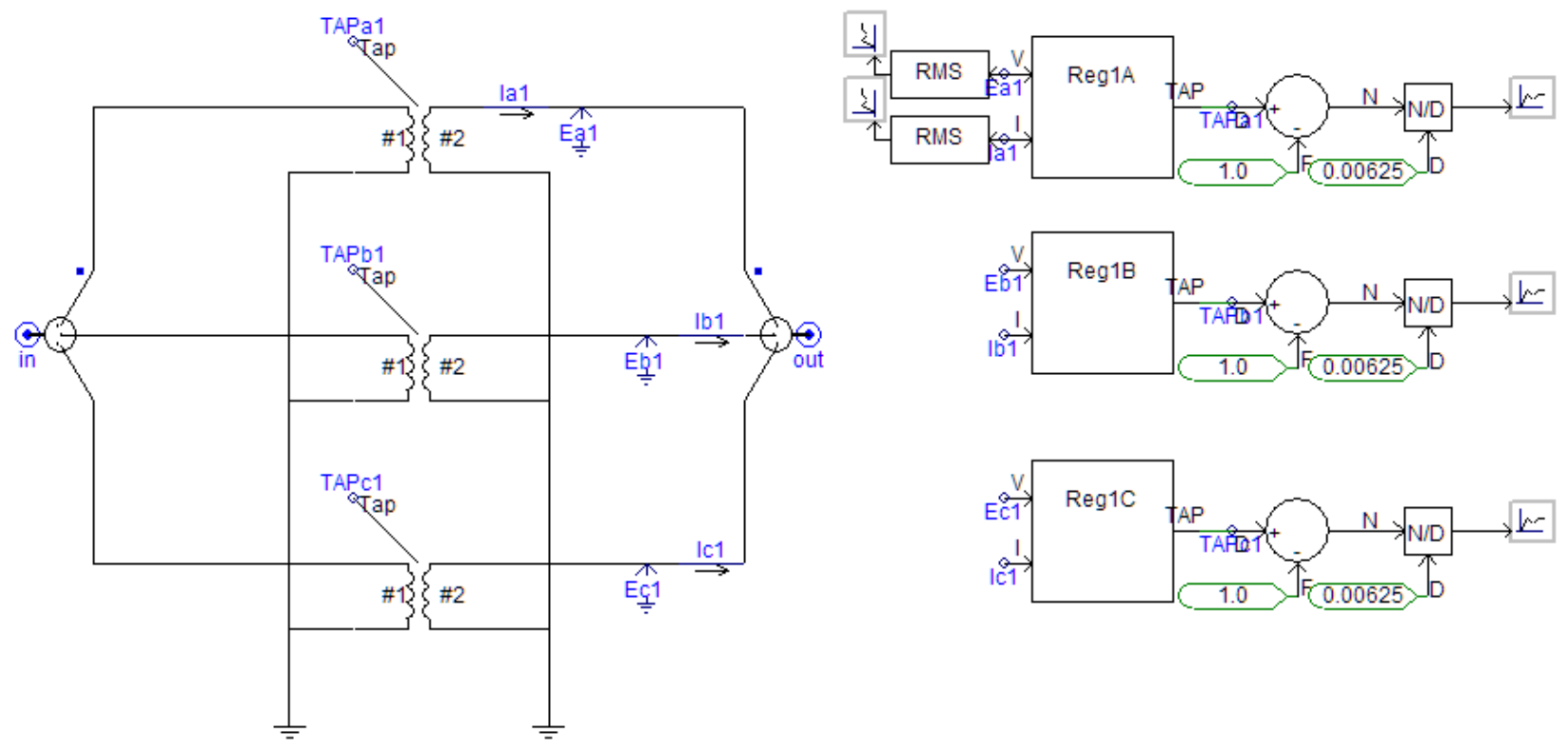

\section{Figure 3-7 Step voltage regulator in PSCAD}

In the above regulator model, three single-phase two-winding transformers are connected in wye. The single phase transformer has low leakage reactance and zero losses. The equations of voltages and currents for the three phase grounded wye are:

$$
\begin{array}{cc} 
& {\left[\begin{array}{l}
V_{A G} \\
V_{B G} \\
V_{C G}
\end{array}\right]=\left[\begin{array}{ccc}
a_{R a} & 0 & 0 \\
0 & a_{R b} & 0 \\
0 & 0 & a_{R c}
\end{array}\right]\left[\begin{array}{l}
V_{a g} \\
V_{b g} \\
V_{c g}
\end{array}\right]} \\
\text { or }\left[V_{L G}\right]_{A B C}=[a] .\left[V_{L G}\right]_{a b c} \\
{\left[\begin{array}{l}
I_{A} \\
I_{B} \\
I_{C}
\end{array}\right]=\left[\begin{array}{ccc}
\frac{1}{a_{R a}} & 0 & 0 \\
0 & \frac{1}{a_{R b}} & 0 \\
0 & 0 & \frac{1}{a_{R c}}
\end{array}\right]\left[\begin{array}{l}
I_{a} \\
I_{b} \\
I_{c}
\end{array}\right]} \\
\text { or } \\
{\left[I_{A B C}\right]=[d] .\left[I_{a b c}\right]}
\end{array}
$$

where $\left[V_{L G}\right]_{a b c}$ are the phase to ground voltage and $\left[I_{a b c}\right]$ are the line currents. 


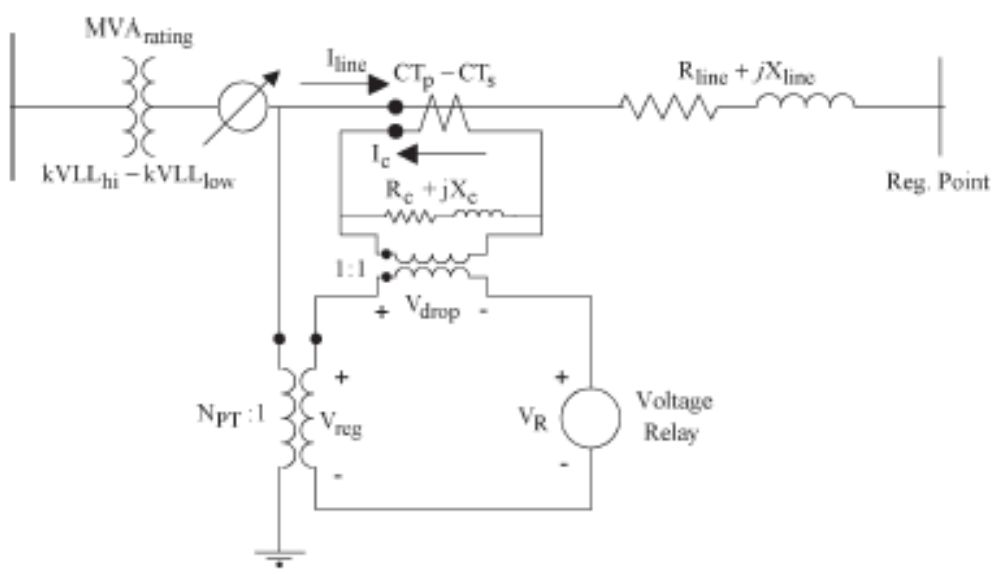

Figure 3-8 Line drop compensator circuit [61]

The line drop compensator model consists of a current transformer and a potential transformer as shown in Figure 3-8. A compensator control circuit requires set voltage, initial tap setting, R-X settings, voltage level to maintain regulation, bandwidth adjusted around the desired voltage level, out of band detections, control time delay required to change the tap if the voltage is not within limits, tap position calculator, time reset control and line compensator. The compensator circuit impedance $Z_{\text {comp }}$ is given by:

$$
Z_{\text {comp }}=\frac{Z_{\text {line }} C T}{N_{p t}}
$$

where $Z_{\text {line }}$ is the equivalent line impedance in ohms, $C T$ is the primary rating of current transformer and $N_{p t}$ is the potential transformer ratio.

The potential transformer ratio is

$$
N_{p t}=\frac{V_{L N} \text { rated }}{120}
$$

where $V_{L N}$ rated is the line to neutral rated voltage. 


\subsubsection{Load Model}

Spot loads like phase loads and phase to phase loads are connected to the distribution network. Distributed loads are also connected at interface points in this network. These loads are mainly classified as constant PQ, constant I and constant $\mathrm{Z}$ phase loads. The distributed load is modeled as two fractional loads, where two-third of the load is placed at the one-fourth distance from source and the rest one-third is placed at the end.

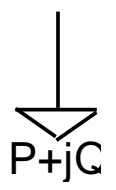

\section{Figure 3-9 Spot load component}

The model for the phase load to ground load is derived from the equations:

$$
\begin{aligned}
& P=P_{0}\left(\frac{V}{V_{0}}\right)^{N_{P}}\left(1+K_{P F} d F\right) \\
& Q=Q_{0}\left(\frac{V}{V_{0}}\right)^{N_{Q}}\left(1+K_{Q F} d F\right)
\end{aligned}
$$

The frequency variability is not considered. Hence $d F=0$.

$$
\begin{aligned}
& P=P_{0}\left(\frac{V}{V_{0}}\right)^{N_{P}} \\
& Q=Q_{0}\left(\frac{V}{V_{0}}\right)^{N_{Q}}
\end{aligned}
$$


For constant power PQ load $N_{P}, N_{Q}=0$. Therefore:

$$
\begin{aligned}
& P=P_{0} \\
& Q=Q_{0}
\end{aligned}
$$

For constant impedance $\mathrm{Z}$ load $N_{P}, N_{Q}=2$. Therefore:

$$
\begin{aligned}
& P=P_{0}\left(\frac{V}{V_{0}}\right)^{2} \\
& Q=Q_{0}\left(\frac{V}{V_{0}}\right)^{2}
\end{aligned}
$$

For constant current I load $N_{P}, N_{Q}=1$. Therefore:

$$
\begin{aligned}
& P=P_{0}\left(\frac{V}{V_{0}}\right) \\
& Q=Q_{0}\left(\frac{V}{V_{0}}\right)
\end{aligned}
$$

where $P_{0} Q_{0}$ and $V_{0}$ are steady state values of real power, reactive power and voltage respectively. $N_{P}$ and $N_{Q}$ are load parameters and $K_{P F}$ and $K_{Q F}$ are frequency sensitivity constants.

The phase to phase loads are modeled as variable resistors whose value depend on the real power demand and variable inductors whose value depend on the reactive power demand as shown in Figure 3-10. The quantities are updated after every time step according to the variation in voltage. 


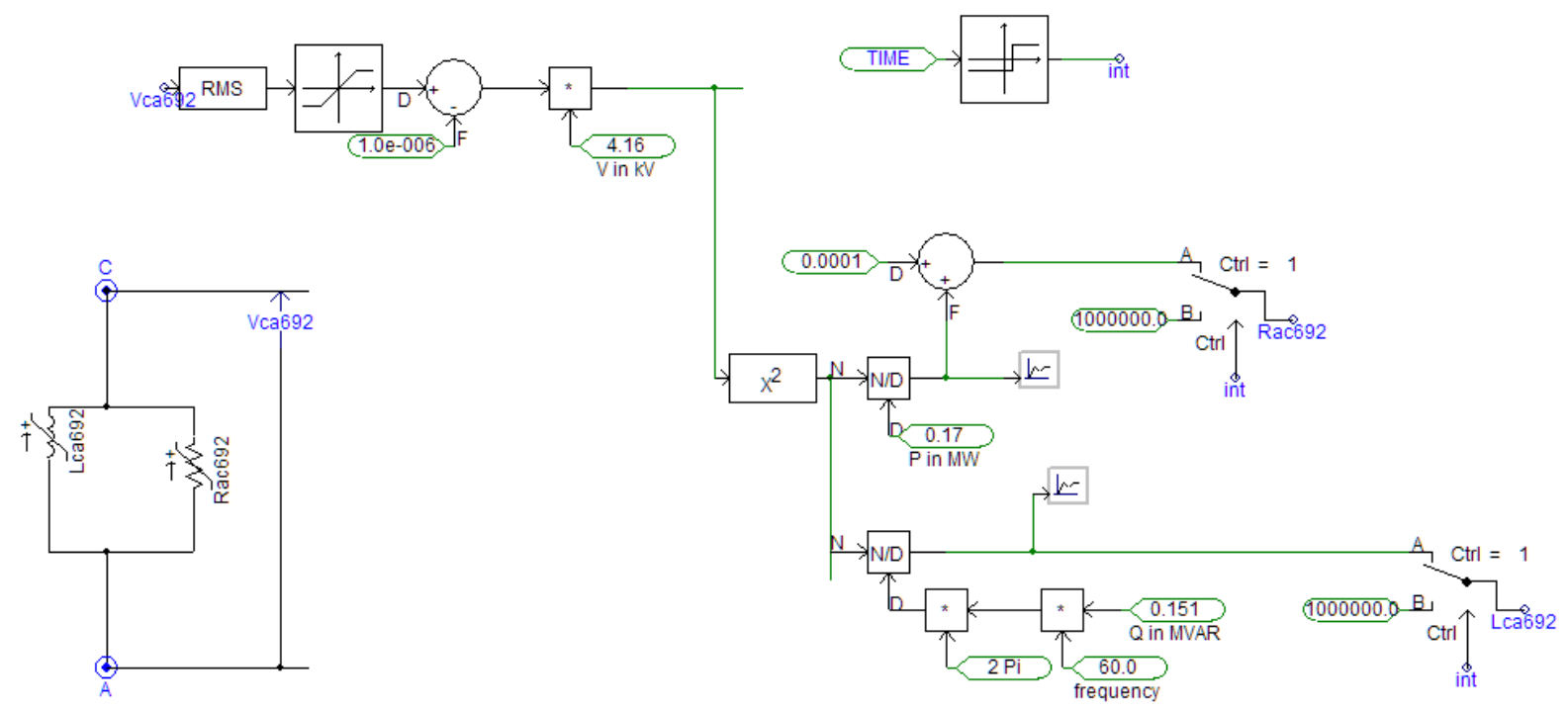

Figure 3-10 Phase to phase load module

\subsubsection{Transformer Model}

A three phase two winding step-down transformer is used between nodes 633 and 634 . The primary is connected in delta and the secondary in wye. It is a $500 \mathrm{KVA}, 4.16 / 0.48 \mathrm{KV}$ transformer with a $1.1 \% \mathrm{R}$ and $2 \% \mathrm{X}$ setting.

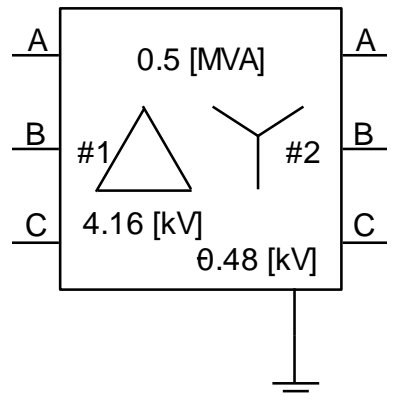

Figure 3-11 Three-phase two winding transformer component 


\begin{tabular}{||ll||}
\hline Configuration & \\
\hline General & \\
Transformer Name & \\
3 Phase Transformer MVA & T1 \\
Base operation frequency & 0.5 [MVA] \\
Winding \#1 Type & 60.0 [Hz] \\
Winding \#2 Type & Delta \\
Delta Lags or Leads Y & $Y$ \\
Positive sequence leakage reactance & Leads \\
Ideal Transformer Model & 0.02 [pu] \\
Noloadlosses & Yes \\
Copper losses & 0.0 [pu] \\
Tap changer on winding & 0.011 [pu] \\
Graphics Display & None \\
Display Details? & 3 phase view \\
\hline Ok & No \\
\hline General & \\
\hline
\end{tabular}

Figure 3-12 Transformer dialog box

\subsubsection{Wind Turbine Generator Model}

A $660 \mathrm{KW}$ wind-turbine generator is connected at node 675. This module as shown in Figure 3-13 mainly consists of a wind turbine module and a wound rotor induction machine. The wind turbine module has a wind source generator component and MOD 2 type governor and wind turbine component. 


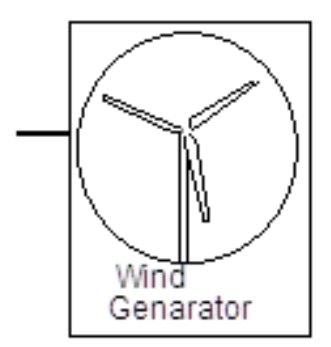

\section{Figure 3-13 Wind turbine generator module}

The wind source component models the base wind speed, gust wind, ramp wind and noise wind data as input parameters. One can also give a constant input wind speed or import actual wind pattern recording from real field data to wind turbine component.

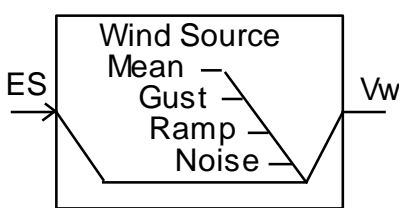

Figure 3-14 Wind source component

A MOD 2 type wind turbine governor component shown in Figure 3-15 models the pitch angle regulator where the mechanical speed of the machine $\omega_{m}$ and the power output of machine $P_{g}$ are given as inputs. The governor component provides the pitch angle $\beta$ in degrees to the MOD 2 type ( 3 blades) wind turbine component. The pitch angle along with blade configuration parameters like sweep area and radius, tip speed ratio, coefficient of power, wind speed and mechanical speed of machine, determines the output torque and power in p.u based on the machine rating. 


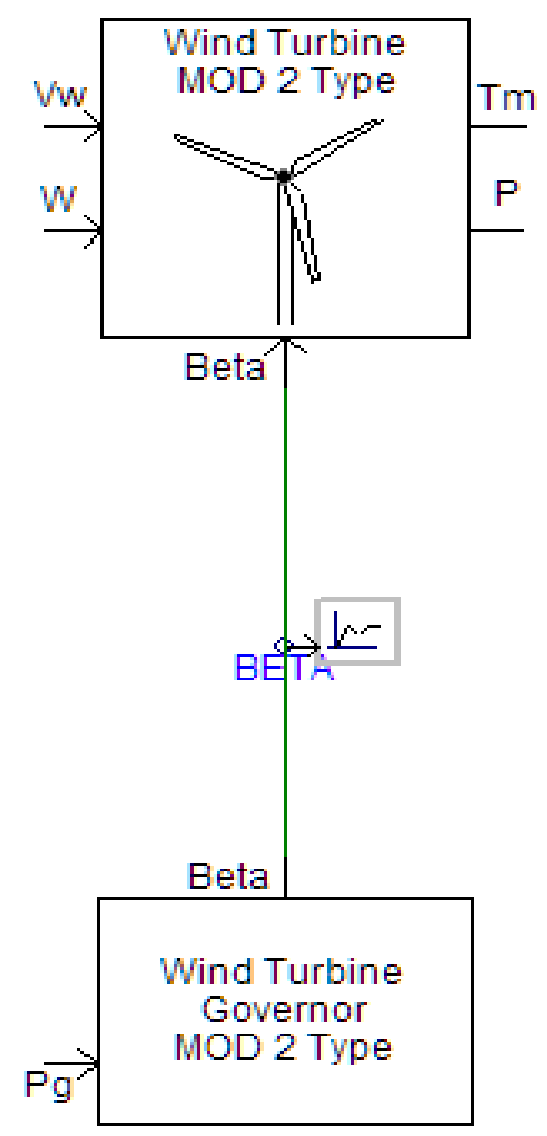

Figure 3-15 Wind turbine and governor components

The important wind turbine equations are:

Angular hub speed $\omega_{H}$ in $\mathrm{rad} / \mathrm{s}$ is,

$$
\omega_{H}=\frac{\omega}{G R}
$$

Turbine power $P_{\text {out }}$ in MW is,

$$
P_{\text {out }}=\frac{1}{2 \times 10^{6}} \cdot \rho_{\text {air }} \cdot A \cdot C_{P} \cdot v_{w}^{3} \cdot \eta_{G B}
$$


Tip Speed Ratio TSR is,

$$
T S R=\frac{2.237 v_{w}}{\omega_{H}}
$$

Coefficient of power $C_{P}$ is,

$$
C_{P}=\frac{1}{2}\left(T S R-5.6-\frac{\beta^{3}}{45}\right) e^{\frac{-T S R}{6}}
$$

where $\omega$ is the rotational speed of the machine, $G R$ is the gearbox ratio, $v_{w}$ is the wind speed in $\mathrm{m} / \mathrm{s}, \rho_{\text {air }}$ is the air density in $\mathrm{kg} / \mathrm{m}^{3}, A$ is the rotor area in $\mathrm{m}^{2}, \eta_{G B}$ is the gearbox efficiency in $\mathrm{p} . \mathrm{u}$ and $\beta$ is the pitch angle in degrees.

A $660 \mathrm{KW}$ wound rotor induction generator component in Figure 3-16 was connected to the wind turbine module. It is modeled using induction machine state space equations.

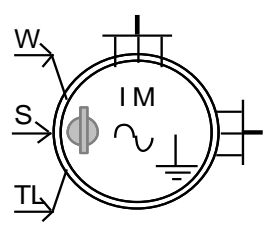

Figure 3-16: Induction machine component 


\subsubsection{Battery Model}

The most commonly used battery model for simulation studies is the modified Shepherd's model. The equations for these generic battery models are basically derived from Shepherd's equation for circuit based model [18]. The generic battery model circuit diagram is shown in Figure 3-17 and the discharge characteristic is shown in Figure 3-18 .

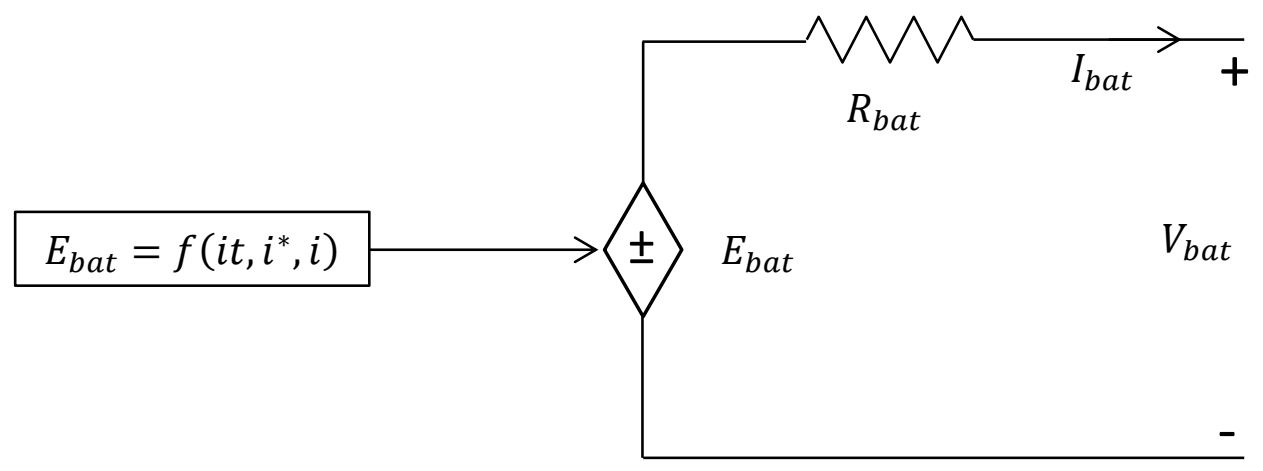

Figure 3-17 Battery Circuit Model

Typical discharge characteristic of a generic battery is shown below:

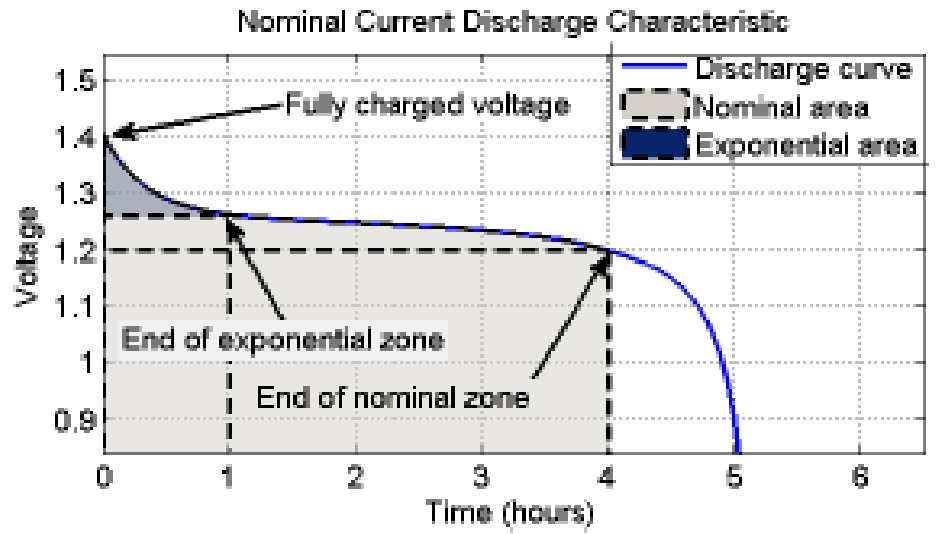

Figure 3-18 Discharge Characteristics [44] 
As mentioned earlier Li-ion batteries have numerous applications in electronics industry, transport industry as well as utility grid. Its battery module in PSCAD is shown in Figure 3-19. The equations for discharge and charge for a Li-ion battery model are [41]:

Discharge Equation $\left(i^{*}>0\right)$

$$
f_{1}\left(i t, i^{*}, i\right)=E_{0}-\frac{\mathrm{K} Q}{Q-i t} i^{*}-\frac{\mathrm{K} Q}{Q-i t} i t+A \exp (-B i t)
$$

Charge Equation $\left(i^{*}<0\right)$

$$
f_{2}\left(i t, i^{*}, i\right)=E_{0}-\frac{\mathrm{K} Q}{i t+0.1 Q} i^{*}-\frac{\mathrm{K} Q}{Q-i t} i t+A \exp (-B i t)
$$

where

$E_{0}$ is the constant voltage $\mathrm{V}$

$\mathrm{K}$ is the polarization constant $\mathrm{Ah}^{-1}$

$i^{*}$ is the low frequency current $\mathrm{A}$

$i$ is the battery current A

it is the extracted capacity Ah

$Q$ is the maximum battery capacity $\mathrm{Ah}$

$A$ is the exponential voltage $\mathrm{V}$

$B$ is the exponential capacity $\mathrm{Ah}^{-1}$ 


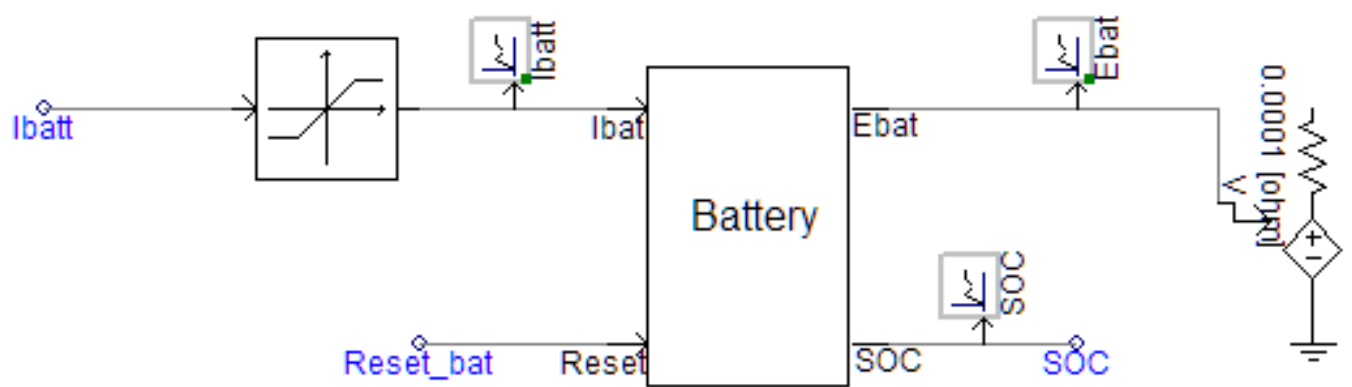

Figure 3-19 Li-ion battery module in PSCAD

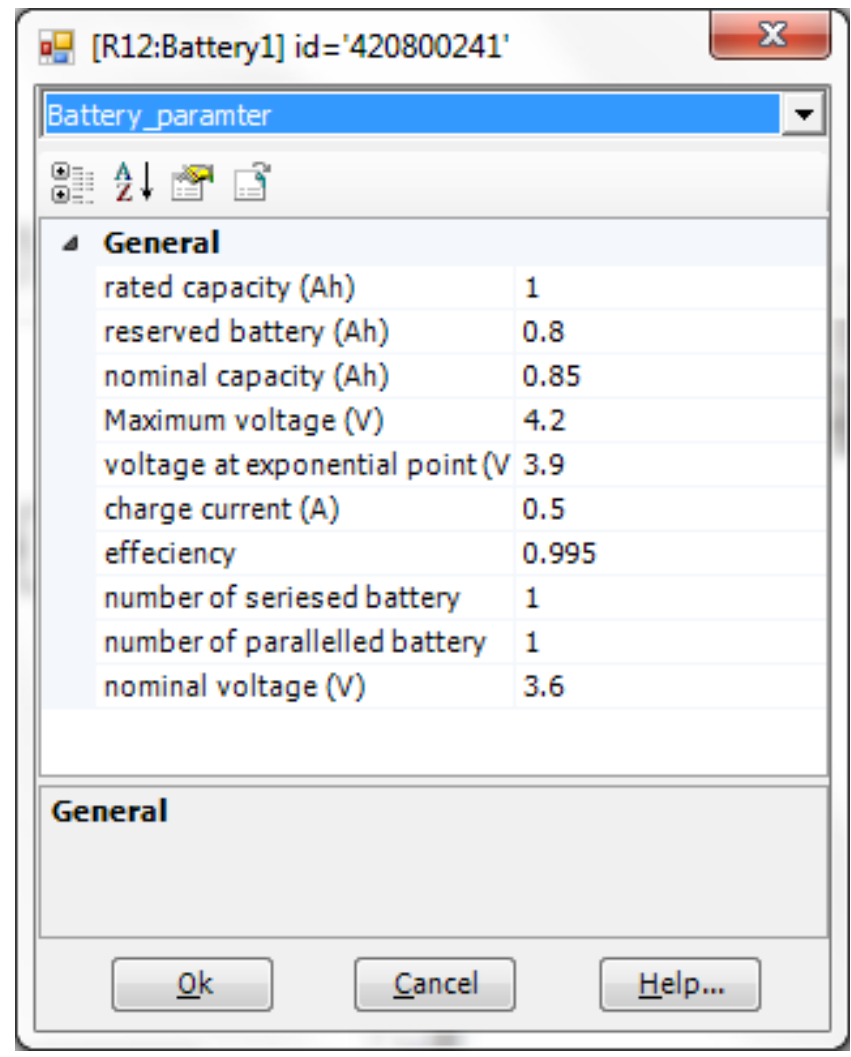

Figure 3-20 Battery module dialog box 
Each input parameter to the battery is defined below:

- Rated Capacity (Ah): It is the minimum effective battery capacity denoted as $Q_{\text {rated }}$.

- Reserved Battery (Ah): It is the reserved battery capacity denoted as $B A T_{\text {res }}$.

- Nominal Capacity (Ah): It is the battery capacity when the voltage drops under nominal voltage and denoted as $Q_{\text {nom }}$.

- Maximum Voltage (V): It is the voltage of the battery at fully charged condition for a given discharge current. It is denoted as $V_{\max }$.

- Voltage at exponential point (V): It is the voltage of the battery representing the end of the exponential zone. This voltage value lies between nominal voltage and maximum voltage denoted as $V_{\text {exp }}$.

- Charge current (A): It is the constant charge current required to charge the battery denoted as $I_{c h g}$.

- Nominal Voltage (V): It is the voltage of the battery corresponding to the end of the linear zone of the discharge characteristics denoted as $V_{\text {nom }}$.

- State of Charge (SOC): State of charge of battery is defined as the available capacity expressed as the percentage of its rated capacity.

SOC of the battery is given as,

$$
S O C=100\left(1-\frac{1}{Q_{\text {rated }}} \int_{0}^{t} i(t) d t\right)
$$

Where $\int_{0}^{t} i(t) d t$ denoted as ' $i t$ ' the actual extracted battery capacity. 
Therefore,

$$
i t=Q_{\text {rated }}(1-S O C)
$$

The battery internal resistance is given by the equation,

$$
R=\frac{V_{\text {nom }}(1-\eta)}{\left(0.2 * Q_{\text {nom }}\right)}
$$

Exponential zone amplitude in volts is,

$$
A=V_{\text {max }}-V_{\text {nom }}
$$

Exponential zone time constant inverse in $(\mathrm{Ah})^{-1}$ is,

$$
B=\frac{3}{Q_{\text {rated }}-Q_{\text {nom }}}
$$

The polarization voltage is,

$$
K=\left(V_{\text {max }}-V_{\text {nom }}+A e^{\left(-B Q_{\text {nom }}-1\right)}\right) \times\left(\frac{Q_{\text {rated }}-Q_{\text {nom }}}{Q_{\text {nom }}}\right)
$$

The battery constant voltage is,

$$
E_{0}=V_{\max }+K+R I_{c h g}-A
$$

The battery voltage in terms of SOC is given as,

$$
E_{\text {bat }}=E_{0}-K Q_{\text {rated }}\left(\frac{1-S O C}{S O C}\right)+A e^{\left(-B Q_{\text {rated }}(1-S O C)\right)}
$$

Battery output voltage is

$$
V_{b a t}=E_{b a t}-R_{b a t} I_{b a t}
$$


Battery control is the component shown in Figure 3-21 and Figure 3-22 are used to control the battery charging and discharging mode based on the SOC of the battery. If SOC is greater than $80 \%$, the battery will discharge and if SOC is less than $30 \%$, battery will charge. Normally the inverse of SOC is given by the parameter Depth of Discharge (DOD) of battery. DOD is always chosen more than $0 \%$ to increase the life expectance of battery. The SOC of the battery is not allowed to go beyond $100 \%$ to prevent over charging of the battery.

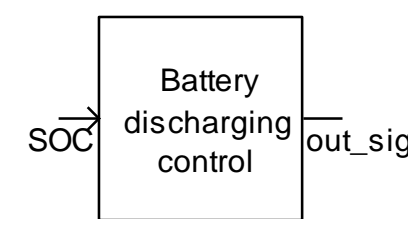

\section{Figure 3-21 Battery discharge control component}

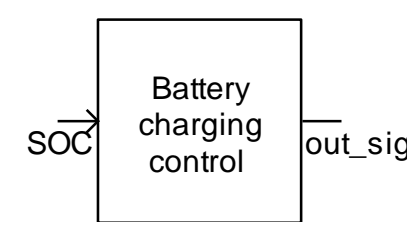

\section{Figure 3-22 Battery charge control component}

Number of cells in series and parallel

To determine the number of cells in series and parallel for the energy storage device we should know its capacity and voltage of the system. For reliable operation of the hybrid system it is important to have battery capacity to be at least $10 \%$ of wind capacity. The wind generator used in this system is $660 \mathrm{~kW}$; hence the battery should be at least $66 \mathrm{~kW}$. The number of cells in series and parallel are determined using the following equations. 


$$
P_{B}=0.1 P_{w}=66 \mathrm{~kW}
$$

The required battery capacity

$$
C_{\text {bat_req }} \geq I_{\text {sys }} T_{\text {bat }}=\frac{0.1 P_{W}}{V_{\text {sys }}} T_{\text {bat }}
$$

Where $V_{s y s}$ and $I_{s y s}$ are system voltage and current respectively. $T_{b a t}$ is the discharge time of battery which is equal to 2 hours for the modeled Li-ion battery. Therefore

$$
C_{\text {bat_req }}=\frac{66}{4160} \times 2=31.73 \mathrm{Ahr}
$$

Number of cells in parallel is

$$
N_{p}=\frac{C_{\text {bat_req }}}{Q_{\text {nom }}}=\frac{31.73}{0.85}=37.33 \cong 38 \text { cells }
$$

Number of cells in series is

$$
N_{s}=\frac{V_{\text {sys }}}{V_{\text {nom }}}=\frac{4160}{3.6}=1155.55 \cong 1156 \mathrm{cells}
$$

\subsubsection{Converters and Control Model}

Power electronic converters have become an integral part of power system. The power flow conversion system used in the thesis shown in Figure 3-24 consists of six IGBT switches with 6 diodes in parallel. Two sets of parallel IGBT and diode are connected in series across three legs of the six pulse converter. An LC filter circuit is also connected to the grid side of the converter which filters the harmonics. The power conditioning unit designed in this thesis is a bidirectional current controlled voltage source converter (VSC). It acts both as a rectifier for 
charging the battery by absorbing power from the grid and as an inverter by supplying power to the grid from the battery. The DC side of the VSC is connected to the battery. The firing of the gates is realized using sinusoidal pulse width modulation (SPWM) technique where the switching frequency is selected higher than the system frequency. For each switching period the carrier reference signal can be assumed as a step function.

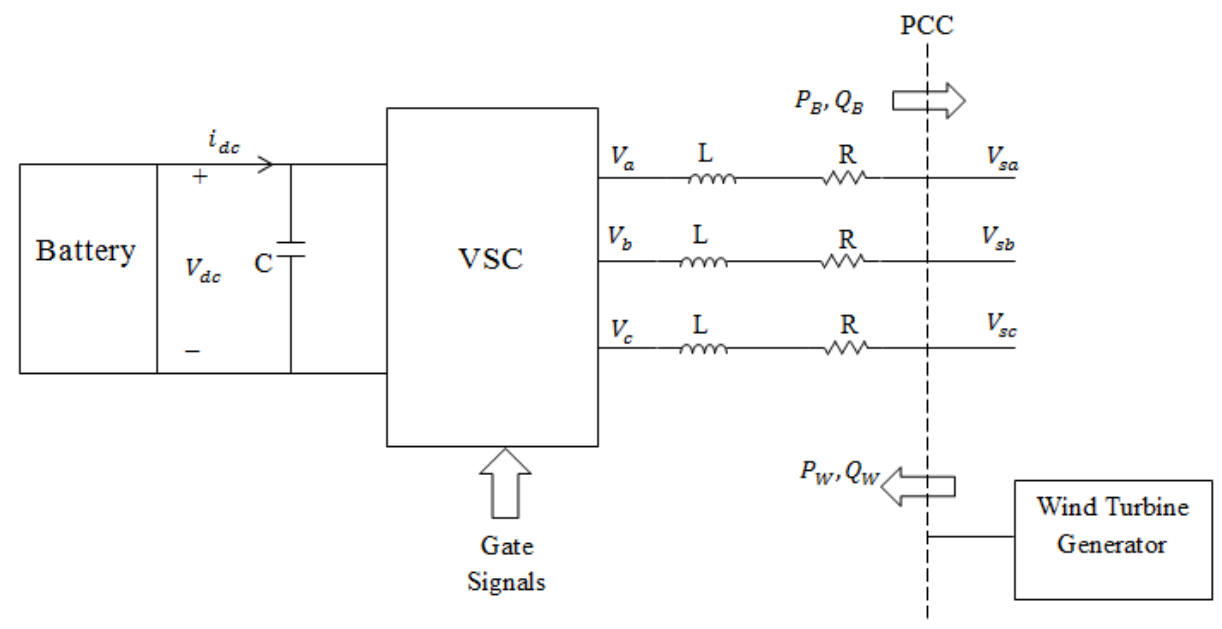

Figure 3-23 Voltage Source Converter Model

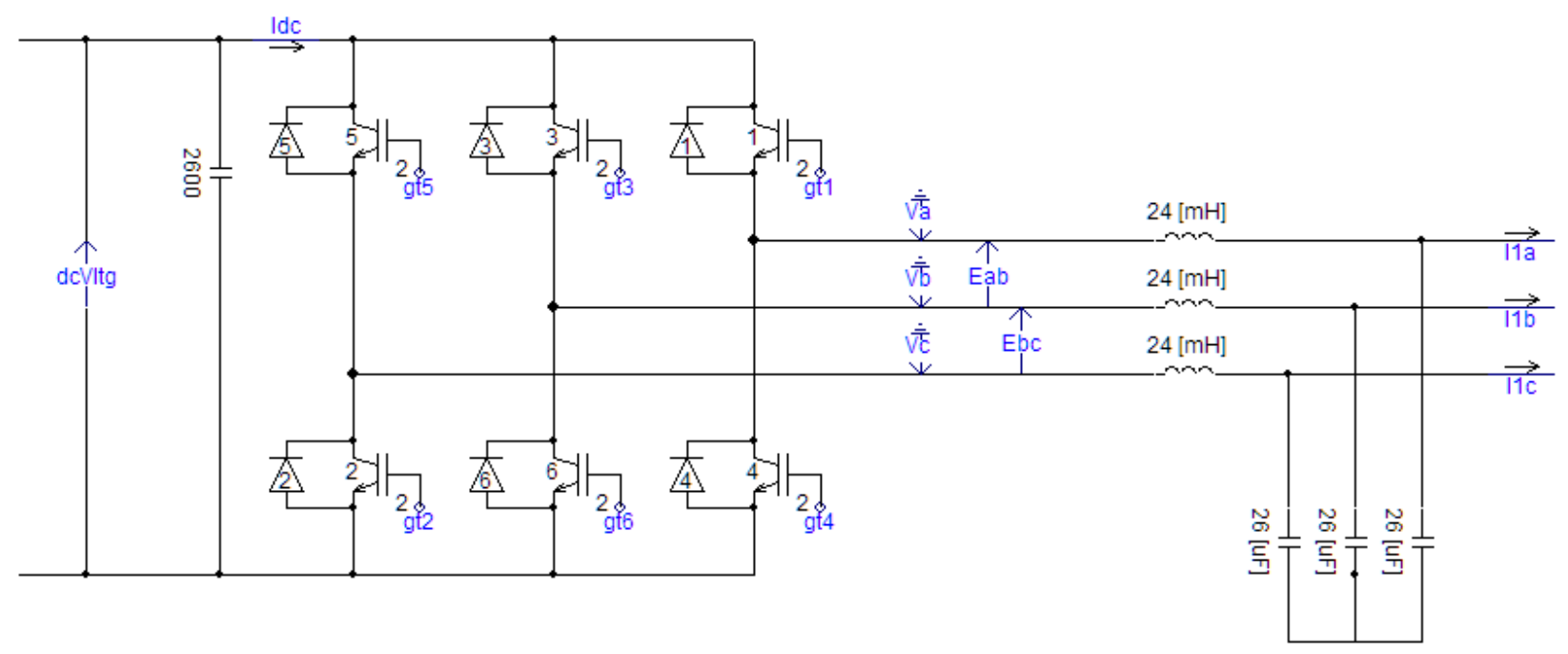

Figure 3-24 VSC in PSCAD 
The objective is to minimize the sum of the power difference between wind and battery power by controlling the exchange of real power and reactive power by the battery and wind module at the point of common coupling (PCC). This can be achieved using real/reactive power controllers for the VSC. The output voltage of VSC and the voltage at the PCC are almost matched with each other such that their magnitude and phase angle are almost equal. Hence the real and reactive power can be effectively decoupled and they can be independently controlled as the real power depends of the phase angle of voltage and reactive power on the magnitude of voltage.

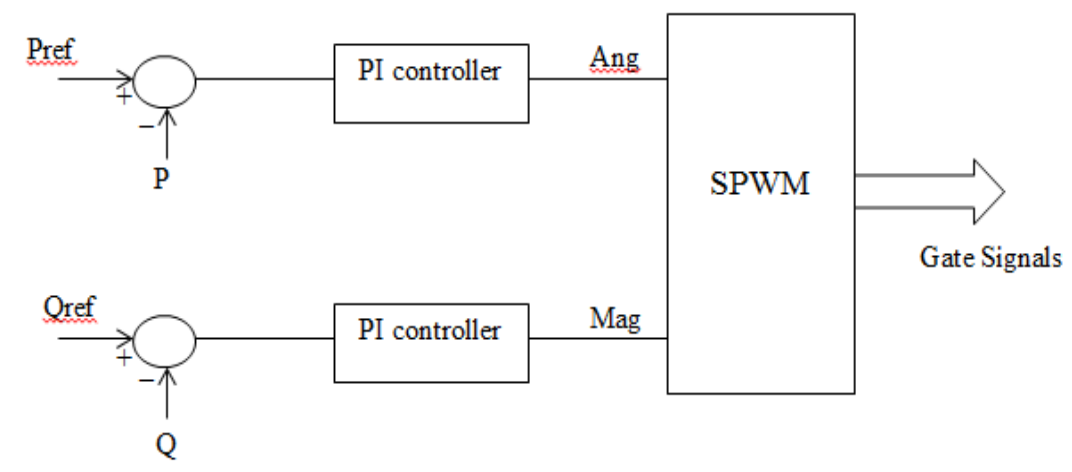

Figure 3-25 Real/Reactive Power Controller

For obtaining the required behavior for the energy storage module as a complementary source to the wind turbine generator, the reference signals for the real reactive power controller shown in figure is taken as the inverted real and reactive power output of the wind turbine generator module. The error generated is passed through a PI controller and then through a low pass filter. The error magnitude and angle which are proportional to the real and reactive power respectively are then used to generate gate signals using PWM depending on the mode of battery operation. The magnitude of the error remains constant for both charging and discharging 
operation whereas the angle varies between 0 and -90 degrees for charging and 0 to +90 degrees for discharging. This also changes the direction of flow of battery charging current.

\section{Mathematical model of Voltage Source Converter}

Assuming a stiff three phase AC system, the equations of voltage and current are given as: [2], [49], [12]

$$
\begin{gathered}
V_{s a}=V_{m} \sin \omega t \\
I_{s a}=I_{m} \sin (\omega t+\varphi) \\
V_{s b}=V_{m} \sin \left(\omega t-\frac{2 \pi}{3}\right) \\
I_{s b}=I_{m} \sin \left(\omega t-\frac{2 \pi}{3}+\varphi\right) \\
V_{s c}=V_{m} \sin \left(\omega t+\frac{2 \pi}{3}\right) \\
I_{s c}=I_{m} \sin \left(\omega t+\frac{2 \pi}{3}+\varphi\right)
\end{gathered}
$$

where $V_{m}$ and $I_{m}$ are the peak value of voltage and current respectively and $\varphi$ is the angle between them. The equations for a VSC are given as:

$$
V_{i}=r_{s} i_{i}+V_{d c} f_{i}-\frac{V_{d c}}{3}\left(f_{a}+f_{b}+f_{c}\right)
$$

Where $i=a, b, c$ and $f_{i}$ is the switching function. Its complimentary function is $f_{i}^{\prime}$ such that $f_{i}+f_{i}^{\prime}=1$ which prevents short circuiting in each leg of VSC. $r_{s}$ gives the switching losses in 
each thyristor. If $R_{S}$ and $L$ gives the resistance and reactance of the power transformer in series the voltage equation at each phase is given as:

$$
V_{s i}-V_{i}=L \frac{d i}{d t}+R_{s} i_{i}
$$

Substituting for $V_{i}$ from previous equation gives:

$$
\begin{aligned}
& V_{s i}-r_{s} i_{i}-V_{d c} f_{i}+\frac{V_{d c}}{3}\left(f_{a}+f_{b}+f_{c}\right)=L \frac{d i}{d t}+R_{s} i_{i} \\
& L \frac{d i}{d t}=V_{s i}-i_{i}\left(r_{s}+R_{s}\right)-V_{d c}\left(f_{i}-\frac{1}{3}\left(f_{a}+f_{b}+f_{c}\right)\right)
\end{aligned}
$$

Let $\left(r_{S}+R_{S}\right)=R$, therefore

$$
L \frac{d i}{d t}=V_{s i}-i_{i} R-V_{d c}\left(f_{i}-\frac{1}{3}\left(f_{a}+f_{b}+f_{c}\right)\right)
$$

Using KCL, the total DC current is given as:

$$
i_{d c}=i_{a} f_{a}+i_{b} f_{b}+i_{c} f_{c}-\left(\frac{V_{d c}-V_{b a t}}{R_{b a t}}\right)=C \frac{d V_{d c}}{d t}
$$

In state space form the above system can be given as:

$$
\left[\begin{array}{c}
\dot{i_{a}} \\
\dot{i_{b}} \\
i_{c} \\
V_{d c}
\end{array}\right]=\left[\begin{array}{cccc}
-R / L & 0 & 0 & -f_{a}+\frac{1}{3} \sum f_{i} \\
0 & -R / L & 0 & -f_{b}+\frac{1}{3} \sum f_{i} \\
0 & 0 & -R / L & -f_{c}+\frac{1}{3} \sum f_{i} \\
f_{a} / C & f_{b} / C & f_{c} / C & -1 / C R_{b a t}
\end{array}\right]\left[\begin{array}{c}
i_{a} \\
i_{b} \\
i_{c} \\
V_{d c}
\end{array}\right]+\left[\begin{array}{cccc}
1 / L & 0 & 0 & 0 \\
0 & 1 / L & 0 & 0 \\
0 & 0 & 1 / L & 0 \\
0 & 0 & 0 & -1 / C R_{b a t}
\end{array}\right]\left[\begin{array}{c}
V_{s a} \\
V_{s b} \\
V_{s c} \\
V_{b a t}
\end{array}\right]^{T}
$$




\section{Chapter 4 APPROACH AND IMPLEMENTATION}

\subsection{OVERALL SYSTEM}

In this thesis two different test systems are considered and modeled in PSCAD. The first system is a standalone hybrid system where only the wind turbine generator module and energy storage module are connected to the mains. The second network is the IEEE distribution system where the wind turbine generator module and energy storage modules are connected to the feeder 675 of the distribution network. The second case focusses on studying the effects of wind generation and battery operations on a distribution system. A battery energy management control system is also programmed to control the different modes of operation of battery based on wind conditions. A genetic algorithm based optimization is applied to determine the optimal value of proportional gain and the integral time constants of the PI controller which is used in controlling the firing angle of the power flow converter to minimize the power difference between battery and wind power. For IEEE 13 node test feeder an additional objective was analyzed which was to minimize the transmission loss. Transmission loss reduction is significant in the case of distribution systems as it reduces heating of the system. The optimized parameters are applied to both the network cases and it was found that a better performance of the controllers is achieved with optimized parameters. The schematic diagram of a Microgrid is shown in Figure 4-1. The main grid is connected to the IEEE 13 node test feeder in distribution system case and to an ideal source in standalone system case. The communication between various modules is assumed ideal. 


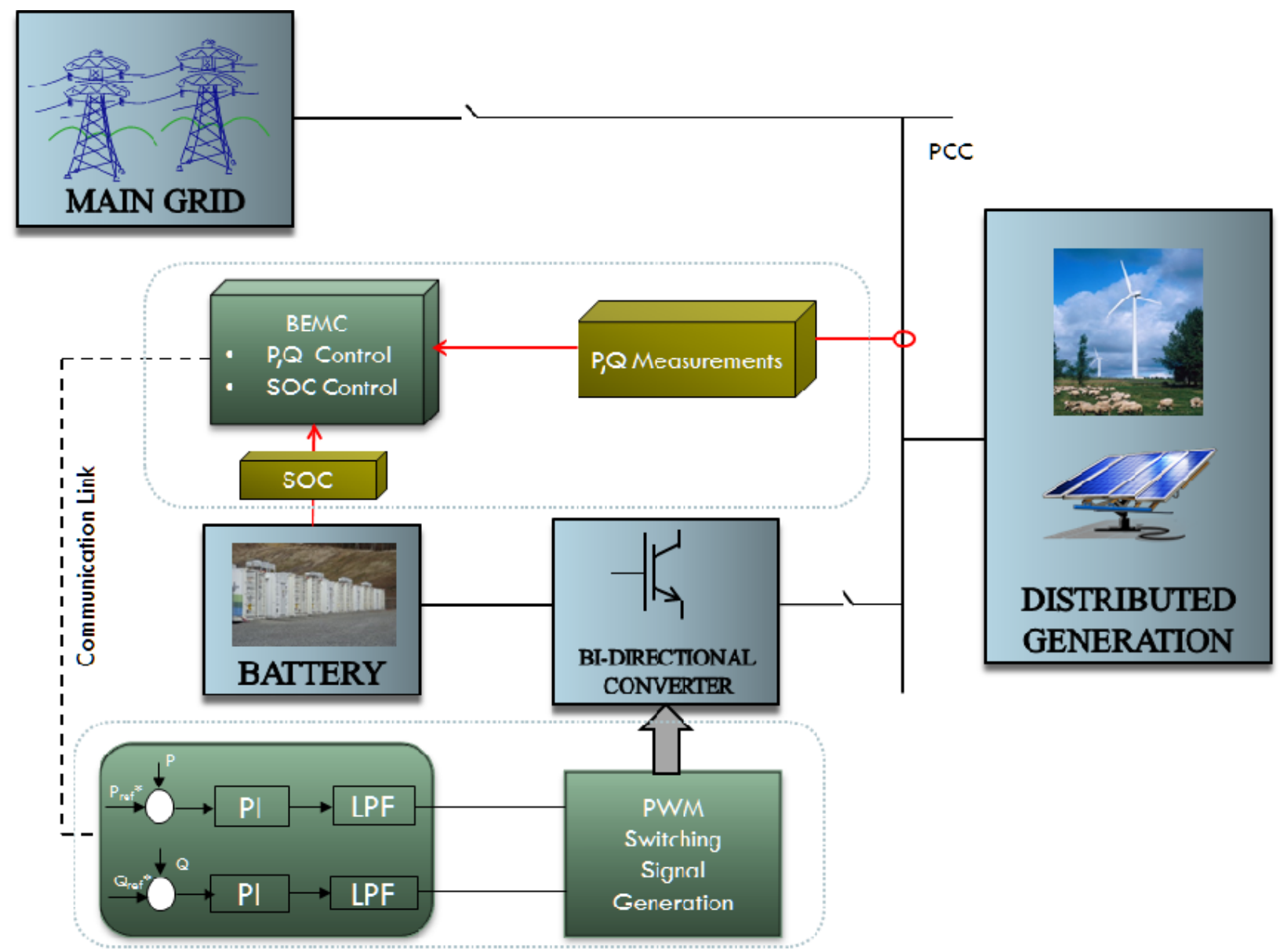

Figure 4-1 Microgrid

\subsubsection{Standalone network}

In the standalone network or the microgrid as mentioned earlier only two main components are used, the wind-turbine generator module and the battery-storage module. The wind generator module functions both as a source and a load. If the wind generator module operates as source then the energy storage will be in the charge mode and if the wind generator module runs as a load, the battery will either be in the discharge mode or the inactive mode based on state of charge of battery. This concept is explained in detail in the battery energy management section. The PSCAD standalone simulation network is shown in the figure below. 


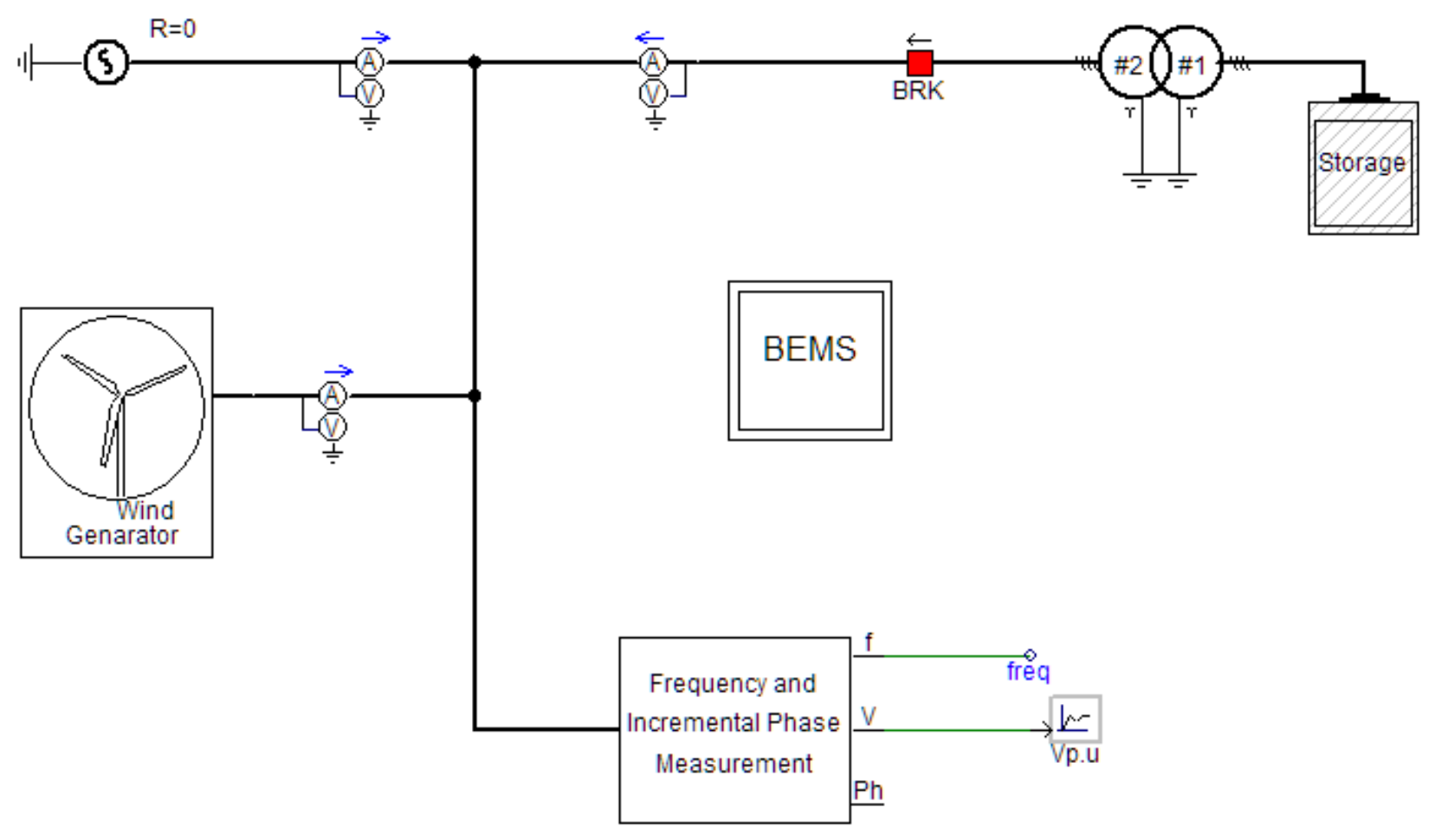

Figure 4-2 Standalone Network

\subsubsection{IEEE 13 Node Test Feeder Network}

The IEEE 13 node test feeder was also modeled in PSCAD using the components that are explained in chapter 3 of this thesis. To study the effects of distributed generation and storage on distribution network, a wind turbine generator module and an energy storage module is connected at the farthest point in the IEEE distribution system since the wind generators are normally in the remote areas in real scenarios. The battery has been modeled as a separate entity so that it can be connected anywhere in the system. But in this thesis work, it is connected at the same feeder node as the turbine to reduce the transmission losses. The model network is given in figures below. 


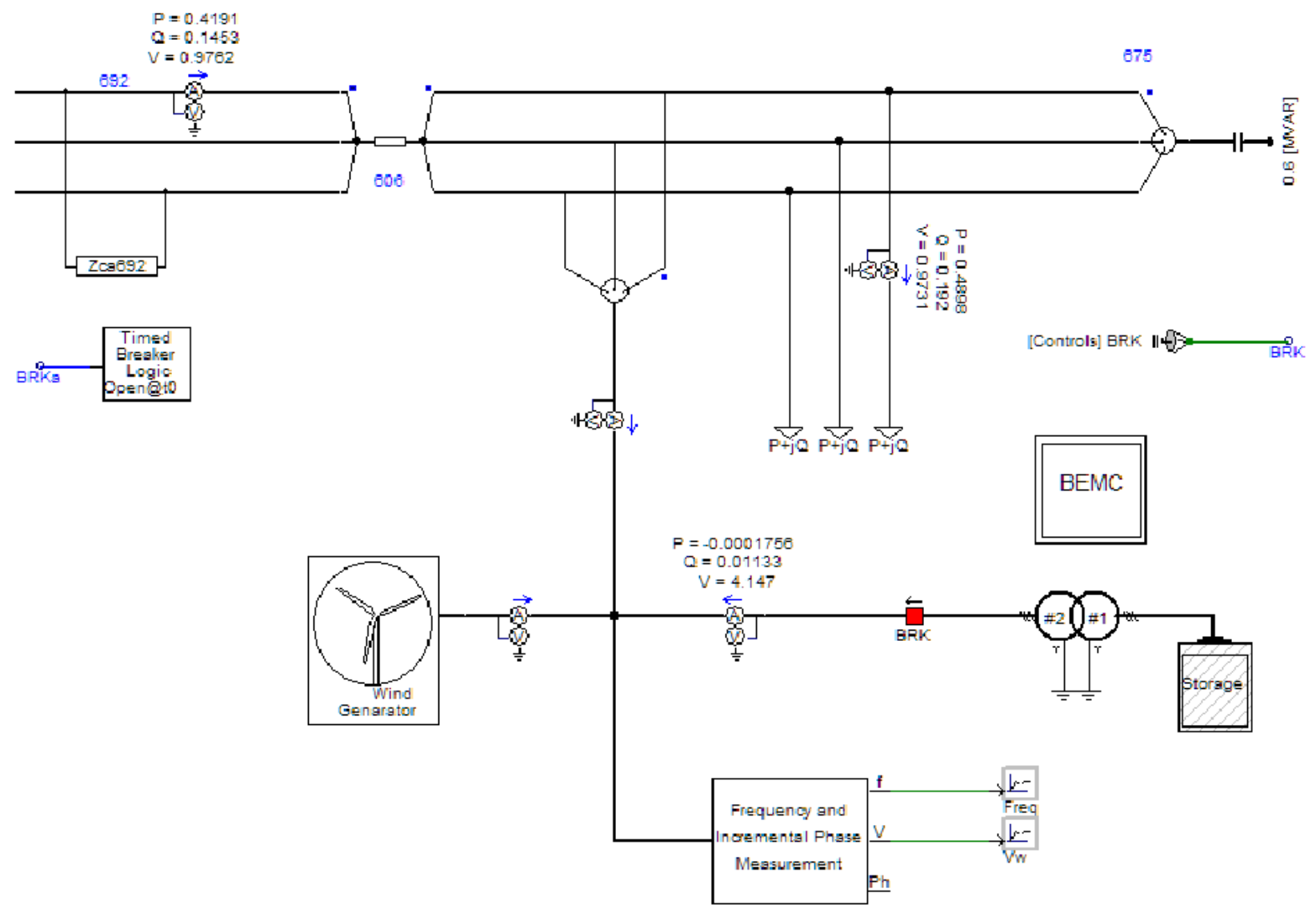

Figure 4-3 IEEE Distribution Network

\subsubsection{Building the model in PSCAD}

PSCAD is a powerful time-domain transient simulation software tool specifically designed for power systems. It uses graphical user interface for electrical components to build models which automatically creates subroutine assembly that are inserted into the EMTDC simulation engine. The users need not program their own subroutine. PSCAD employs the nodal analysis technique together with trapezoidal integration rule to obtain the output. The integration timestep is fixed. In this project the solution time step and the channel plot time is taken as 100 micro seconds. Another advantage of PSCAD is that it allows user to create his/her own component 
using FORTRAN coding language or using the master library. To build a new model the following steps are useful:

I. Create a new case by using the Menu at the top of the toolbar. Save the case with a name.

II. Go to the master library and copy the components that are required to build the model and paste the components in the newly created case project canvas.

III. New components or modules can be created by right clicking the mouse button or by clicking on the component wizard tab. Right clicking the mouse button and selecting the edit definition tab will allow users to edit the graphics, to add or remove parameters and to modify or enter FORTRAN codes for each component.

IV. The data for each component parameters can be entered by double clicking on the component which pops a window for the component.

V. In the main window connect the components together using a wire which is activated or deactivated by clicking on the wire tab.

VI. After building the model, the whole system is compiled using the compile button on the toolbar. Once the compilation is done, we can see the warning and errors in the messages window.

VII. If there are no errors we can run the simulation by clicking on the run button.

VIII. The output is obtained by connecting an output channel to the required signal label before running the simulation. The output can be viewed by the user by using either a graph or a meter component from the master library. The output channel component is linked to the graph by right clicking the mouse button and selecting "add as a curve" tab and pasting the curve on the graph plane by right clicking on it.

IX. Save the project case. 


\subsection{BATTERY ENERGY MANAGEMENT CONTROL (BEMC)}

Battery energy management control (BEMC) was programmed as a supervisory control for controlling the battery output power based on wind power generated and SOC of battery. The storage module is designed to store excess energy generated by the wind source. But due to the intermittent nature of wind speed, the wind turbine becomes a load when wind speed is low and starts generating when wind speed is high. When the wind generator operates as a load, the necessary power is drawn from the grid which leads to transmission losses and also affects the reliability of the system. Hence in order to reduce the transmission loss, an energy storage module is connected to the system which can store excess energy generated by the wind generator and also provides necessary power when the wind generator becomes a load. This reduces the burden on the transmission line as well as the need to absorb or supply power from the mains. Also the battery converter module is designed as a separate element in the system for better control and ease of connecting it to the system even though its output power and operation is heavily depended on wind generator.

For discharging or charging of battery, the state of charge (SOC) of battery plays an important role. The battery will discharge only if the SOC of the battery is greater than the SOC discharge limit irrespective of the wind conditions. So even if the wind speed is low, the battery will not discharge unless its SOC is greater than the SOC discharge limit. Also to prevent from overcharging, the extreme upper limit SOCmax is also defined. Once the battery reaches this limit, it automatically disconnects from the system. The same happens when it reaches the lower limit SOCmin too. This is done in order to increase the battery lifetime by preventing excess discharging. Hence three main modes of the battery operation is defined- the charging mode, the discharging mode and the inactive mode where the battery module is disconnected from the 
system. The different modes of battery operation are decided by the BEMC based on the wind power output. Initially the output powers and the SOC of battery are measured and communicated to the BEMC module. Inside the module it checks whether the wind power is greater or less than the threshold value. Then the BEMC sends the required signals to activate the charge mode, the discharge mode or the inactive mode. These rules are explained in the flow chart shown below.

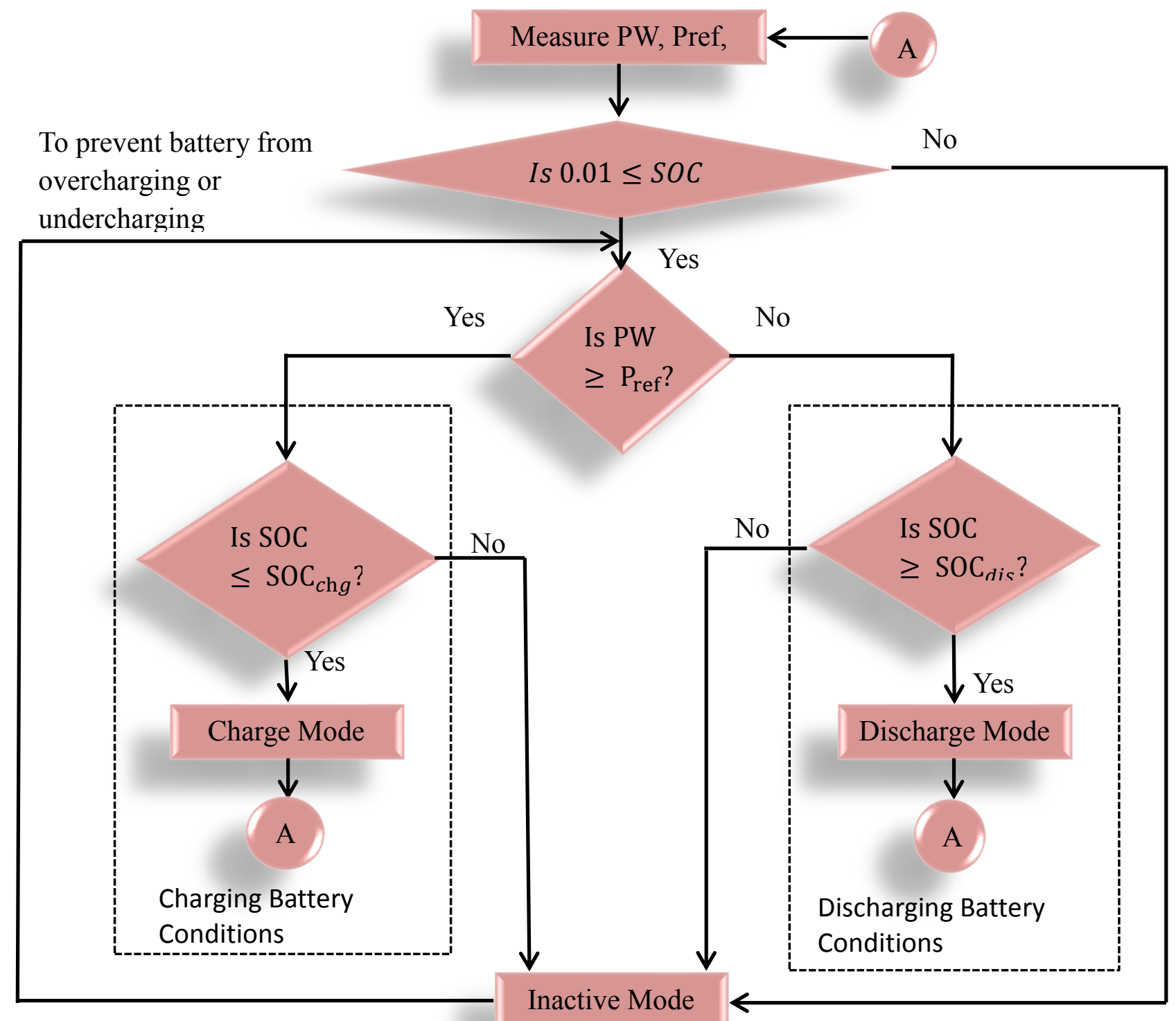

Figure 4-4 Flowchart for Battery Control 
The application of the above algorithm is shown in Figure 4-5. The control component compares the wind power and the reference power. In this thesis the battery power is taken as the reference value or the threshold value. The control component sends signals either to the battery charging control component or the discharging control component which in turn activates the breaker control. The BEMC ensures that the battery module completely supplements the wind turbine module by sending appropriate signals to the converter firing controls in the storage module. In this thesis ideal communication is assumed and it is realized using a radio link.

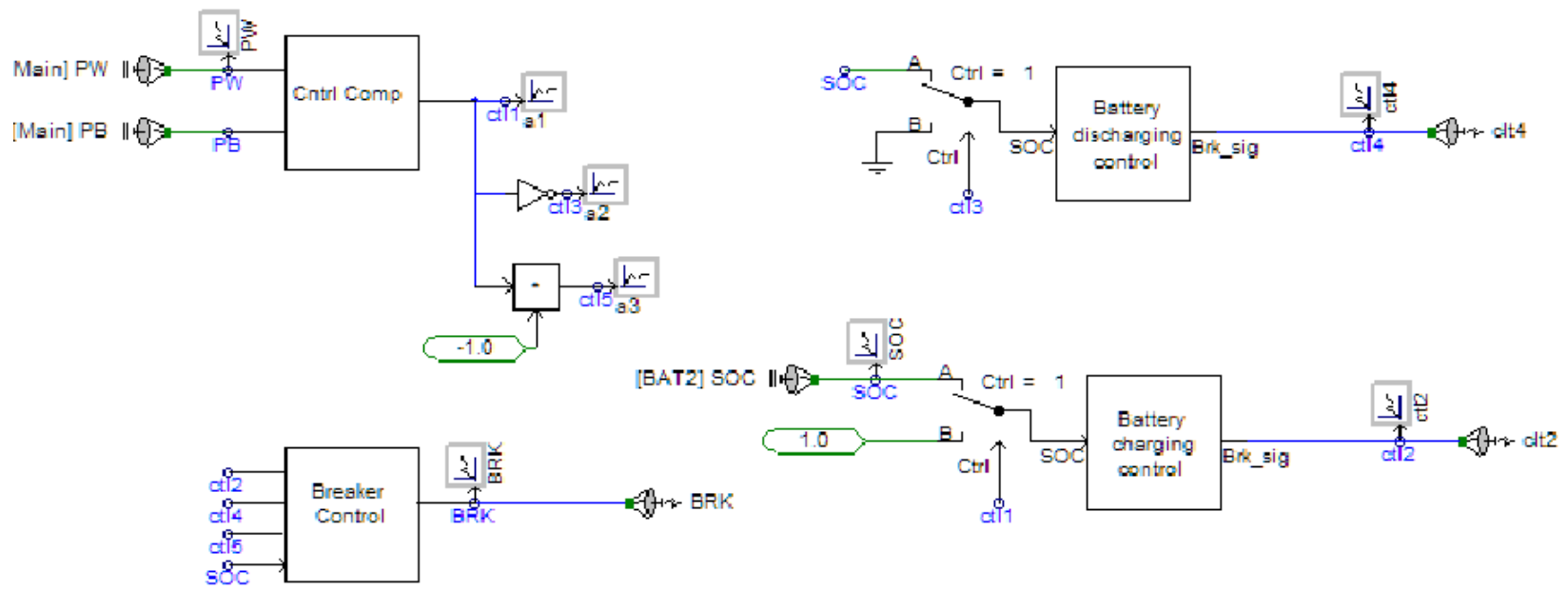

Figure 4-5 PSCAD control components for BEMC

\subsection{OPTIMIZATION POWER LOSS USING GENETIC ALGORITHM}

Genetic algorithm (GA) is a global search heuristic technique used to find exact or approximate solutions to optimization and search problems. Genetic algorithms (GA) mimic the natural evolution process to solve complex optimization and search problems. GA's use selection, recombination and mutation to iteratively improve a solution until it attains the final value. Essentially GA solves optimization problems by repeatedly modifying a population using 
rules modeled on gene combinations in biological reproduction. Due to its random nature, the genetic algorithm improves the chances of finding a global solution.

Genetic algorithms are implemented as a computer simulation. The set of feasible candidate solutions are represented as chromosomes or genotype or genomes. Traditionally, solutions are represented in binary as strings of 0's and 1's, but other encodings are also possible. The evolution usually starts from a population of randomly generated individuals. In each iteration, commonly referred to as generation in GA literature, GA attempts to improve the set of candidate solutions by generating better solution. In each generation, the fitness of every individual in the population is evaluated, multiple individuals are stochastically selected from the current population (based on their fitness), and modified (recombined and possibly randomly mutated) to form a new population. The new population is then used in the next iteration of the algorithm. Commonly the algorithm terminates when either a maximum number of generations has been produced, or a satisfactory fitness level has been reached for the population. If the algorithm has terminated due to a maximum number of generations, a satisfactory solution may or may not have reached. Genetic algorithms have the following advantages:

- Domain Independence: Genetic Algorithms can be applied to solve problems in a number of domains as long as the feasible region for the search process and the fitness function can be evaluated. Genetic algorithms have been proven to work to solve complex problems in a wide variety of engineering and science disciplines.

- Global Optimal: Traditional Newton style of descent based non- linear optimization solution methods can get trapped in local optima and may not be able to find the global optimal for complex objective functions and feasible regions. Genetic algorithms avoid falling into the trap of local optima due to the way the search process is defined. Mutation 
ensures that genetic algorithm solutions are not trapped in local optimality. However, care should be taken to ensure that mutation probability is low as otherwise the GA search becomes a random search.

- Complex Models: The GA search process is independent of the model structure. The GA can model complex non-convex feasible regions and objective functions. GA can also be used as a search process for problems with objective functions which are not analytically defined and can be evaluated only using simulation.

Genetic algorithms are particularly suitable for simulation based optimization as it is not possible to define gradients of objective function for such problems. The mathematical programming formulation for the nonlinear simulation based optimization is first provided.

The main objective is to minimize the integral of the power difference between wind and battery power. Let $P_{W}(t)$ and $P_{B}(t)$ represent the wind and battery power at time instant $t$ respectively and $[0, T]$ denote the simulation interval. The decision variables are $K_{p}$ and $T_{i}$ which represent the proportional gain constant and integral time constant for the PI controller.

$$
\operatorname{Min} Z=\int_{0}^{T} G\left[P_{D I F F}\left(t, K_{p}, T_{i}\right)\right] d t
$$

Subject to:

$$
\begin{gathered}
P_{D I F F}\left(t, K_{p}, T_{i}\right)=\left|P_{W}(t)-P_{B}(t)\right| \quad \forall t \in[0, T] \\
K_{p}^{M I N} \leq K_{p} \leq K_{P}^{M A X} \\
T_{i}^{M I N} \leq T_{i} \leq T_{i}^{M A X}
\end{gathered}
$$

For IEEE 13 node test feeder an additional objective was analyzed which was to minimize the transmission loss. The objective function is given as: 


$$
\operatorname{Min} Z=\int_{0}^{T} G\left[P_{l o s s}\left(t, K_{p}, T_{i}\right)\right] d t
$$

Subject to:

$$
\begin{gathered}
P_{\text {loss }}\left(t, K_{p}, T_{i}\right)=\left(P_{G}(t)-P_{L}(t)\right) \quad \forall t \in[0, T] \\
K_{p}^{M I N} \leq K_{p} \leq K_{P}^{M A X} \\
T_{i}^{M I N} \leq T_{i} \leq T_{i}^{M A X}
\end{gathered}
$$

Where

$$
P_{G}(t)=P_{S}(t)+P_{W}(t)+P_{B}(t)
$$

$P_{G}(t)$ and $P_{L}(t)$ represent the total generation and load power at time instant $t$ respectively. $P_{S}(t)$ is power drawn from the mains. $K_{P}^{M I N}, K_{P}^{M A X}, T_{i}^{M I N}, T_{i}^{M A X}$ are lower and upper bounds for the proportional gain and integral time constant. Note that these lower and upper bounds are chosen by sensitivity analysis. They serve two main purposes. When there are no constraints on the decision variables the GA can generate any value for these variables, especially in the population in the first generation. PSCAD simulation is highly sensitive and becomes unstable easily. Therefore there is a high likelihood of a large percentage of the initial population corresponding to unstable systems. Also intelligently restricting the feasible region helps the genetic algorithm in convergence as it will have to search in a small search space.

The procedure for applying genetic algorithm to optimize the system is shown below in flowchart. The genetic algorithm generates the initial population which consists of a number of possible values for the proportional gain constant and integral time constant. The PSCAD system performs the simulation and evaluates the objective function for each member of the population. The GA then checks for convergence based on the values of the objective function. If GA has 
converged the process stops. If the GA has not converged then GA generates a new set of population based on the old population and the process continues.

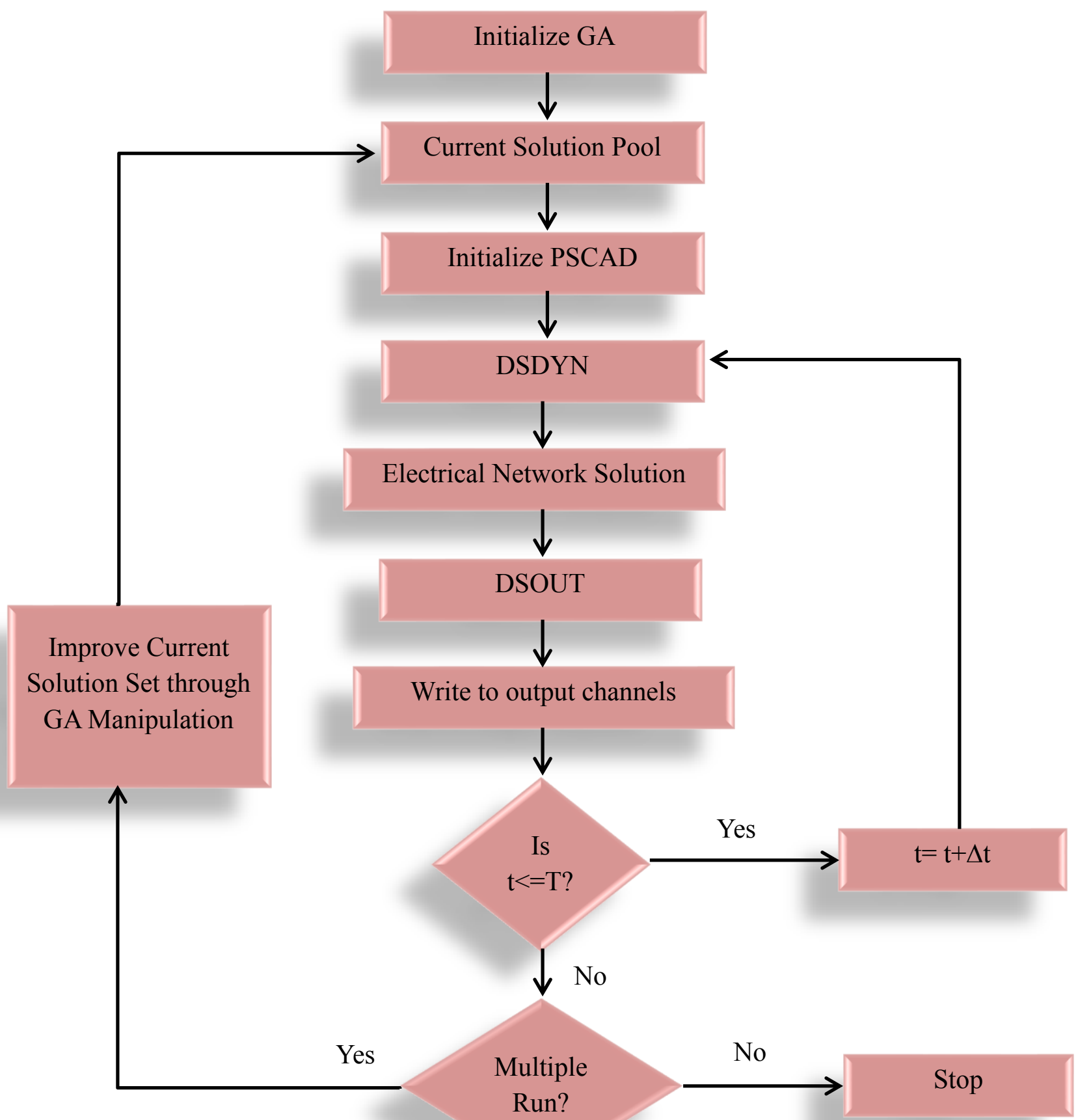

Figure 4-6 Flowchart 


\section{Chapter 5 SIMULATION RUNS AND ANALYSIS}

This chapter describes the computational runs conducted in this thesis and presents the important results and insights. First the power and voltages at each node for the IEEE 13 node feeder network is compared against standard published results. The output voltage, state of charge (SOC), battery charging current for the Li-Ion battery simulation model is validated. The performance of the Multi-mode Battery Energy Management (BEM) operation for different cases is presented for two networks. The results of optimization of the PI controller gains using Genetic Algorithm is shown.

\subsection{IEEE 13 NODE FEEDER RESULTS}

The IEEE 13 node test feeder was modeled in PSCAD and the simulated results were authenticated against the standard published results. The total power, real power, reactive power and the power factor are compared for both cases in Table 5-1 and Table 5-2 respectively. The maximum error in real power was approximately $2.1 \%$ in phase C. For reactive power the maximum error was less than $1.7 \%$ and the maximum total power error was approximately $2 \%$. The maximum error in power factor was $0.7 \%$. For the total system all the errors were found to be less than $1.5 \%$. 
Table 5-1 Power flow results comparison in each phase

\begin{tabular}{|c|c|c|c|c|c|c|c|c|c|}
\hline & \multicolumn{3}{|c|}{ Phase A } & \multicolumn{3}{|c|}{ Phase B } & \multicolumn{3}{|c|}{ Phase C } \\
\hline & IEEE & PSCAD & Error & IEEE & PSCAD & Error & IEEE & PSCAD & Error \\
\hline $\mathrm{kW}$ & 1251.389 & $1,228.85$ & 1.801119 & 977.332 & 972.806 & 0.463097 & 1348.461 & 1377.2 & 2.131244 \\
\hline kVAr & 681.57 & 690.06 & 1.246094 & 373.418 & 379.663 & 1.672389 & 669.784 & 680.11 & 1.541691 \\
\hline $\mathrm{kVA}$ & 1424.968 & $1,409.35$ & 1.096228 & 1046.241 & $1,044.27$ & 0.188587 & 1505.642 & $1,535.98$ & 2.014844 \\
\hline $\mathrm{PF}$ & 0.8782 & 0.87 & 0.714124 & 0.9341 & 0.93 & 0.271123 & 0.8956 & 0.90 & 0.114697 \\
\hline
\end{tabular}

Table 5-2 Comparison of total power flow

\begin{tabular}{|c|c|c|c|}
\hline \multirow{2}{*}{} & \multicolumn{3}{|c|}{ Total } \\
& IEEE & PSCAD & Error \\
\hline $\mathrm{kW}$ & 3577.191 & 3578.856 & 0.046545 \\
\cline { 1 - 1 } $\mathrm{kVAr}$ & 1724.772 & 1749.836 & 1.453178 \\
\cline { 1 - 1 } $\mathrm{kVA}$ & 3971.289 & 3983.734 & 0.313373 \\
\cline { 1 - 1 } $\mathrm{PF}$ & 0.9008 & 0.898367 & 0.270069 \\
\hline
\end{tabular}

The voltage at each node were compared and tabulated in Table 5-3. The maximum deviation in voltage from the standard results was found to be $2.6 \%$ for phase B at node 634 . The real and reactive power at each node is given in Table 5-5. Here we can see that nodes connected to capacitor banks have negative reactive power flow since capacitors supply reactive power to the system. Table 5-4 compares the regulator tap position of the simulated network with the standard IEEE results. The regulator tap positions are found to be similar. 
Table 5-3 Load flow results

\begin{tabular}{|c|c|c|c|c|c|c|c|c|c|}
\hline & \multicolumn{3}{|c|}{ A-N } & \multicolumn{3}{|c|}{ B-N } & \multicolumn{3}{|c|}{ C-N } \\
\hline NODE & IEEE & PSCAD & Error & IEEE & PSCAD & Error & IEEE & PSCAD & Error \\
\hline 650 & 1.0000 & 1.0000 & 0.0014 & 1.0000 & 1.0000 & 0.0013 & 1.0000 & 1.0000 & 0.0014 \\
\hline RG60 & 1.0625 & 1.0562 & 0.5948 & 1.0500 & 1.0437 & 0.5990 & 1.0687 & 1.0562 & 1.1715 \\
\hline 632 & 1.0210 & 1.0110 & 0.9755 & 1.0420 & 1.0325 & 0.9136 & 1.0174 & 1.0080 & 0.9200 \\
\hline 633 & 1.0180 & 1.0083 & 0.9509 & 1.0401 & 1.0299 & 0.9788 & 1.0148 & 1.0057 & 0.8987 \\
\hline 634 & 0.9940 & 0.9833 & 1.0738 & 1.0218 & 0.9948 & 2.6472 & 0.9960 & 1.0052 & 0.9187 \\
\hline 645 & & & & 1.0329 & 1.0231 & 0.9468 & 1.0155 & 1.0060 & 0.9365 \\
\hline 646 & & & & 1.0311 & 1.0214 & 0.9417 & 1.0134 & 1.0040 & 0.9325 \\
\hline 671 & 0.9900 & 0.9764 & 1.3782 & 1.0529 & 1.0417 & 1.0599 & 0.9778 & 0.9703 & 0.7703 \\
\hline 680 & 0.9900 & 0.9762 & 1.3905 & 1.0529 & 1.0416 & 1.0723 & 0.9778 & 0.9701 & 0.7827 \\
\hline 684 & 0.9881 & 0.9743 & 1.3935 & & & & 0.9758 & 0.9681 & 0.7876 \\
\hline 611 & & & & & & & 0.9738 & 0.9661 & 0.7907 \\
\hline 652 & 0.9825 & 0.9688 & 1.3911 & & & & & & \\
\hline 692 & 0.9900 & 0.9759 & 1.4258 & 1.0529 & 1.0417 & 1.0656 & 0.9777 & 0.9699 & 0.7985 \\
\hline 675 & 0.9835 & 0.9739 & 0.9746 & 1.0553 & 1.0472 & 0.7723 & 0.9758 & 0.9657 & 1.0334 \\
\hline
\end{tabular}

Table 5-4 Comparison of regulator tap position

\begin{tabular}{|c|c|c|}
\hline \multicolumn{3}{|c|}{ Voltage Regulator } \\
\hline & \multicolumn{2}{|c|}{ RG60 } \\
\hline Phase & IEEE & PSCAD \\
\hline A & 10 & 9 \\
B & 8 & 7 \\
C & 11 & 9 \\
\hline
\end{tabular}


Table 5-5 Power flow at each node

\begin{tabular}{|c|c|c|c|c|c|c|}
\hline \multicolumn{7}{|c|}{ Power Flow KW/kVR } \\
\hline & $\mathrm{P}$ & Q & $\mathrm{P}$ & Q & $\mathrm{P}$ & Q \\
\hline NODE & A & A & B & B & $\mathrm{C}$ & $\mathrm{C}$ \\
\hline 650 & $1,228.85$ & 690.06 & 972.806 & 379.663 & 1377.2 & 680.11 \\
\hline RG60 & 1265 & 607 & 911.9 & 367.3 & 1433 & 704.7 \\
\hline 632 & 143.9 & 105 & 112.3 & 94.75 & 153.6 & 93.13 \\
\hline 633 & 143.6 & 104.8 & 112.1 & 94.51 & 153.3 & 92.91 \\
\hline 634 & 173 & 111.6 & 116.3 & 91.77 & 114 & 87.83 \\
\hline 645 & & & 150.2 & 1.961 & 78.84 & 134.8 \\
\hline 646 & & & 150 & 0.5935 & 78.58 & 134.5 \\
\hline 671 & 941.2 & 296.7 & 432.7 & 79.18 & 829 & 270.5 \\
\hline 684 & 121.7 & 80.24 & & & 165.8 & -16.17 \\
\hline 611 & & & & & 165.4 & -16.13 \\
\hline 652 & 121 & 79.78 & & & & \\
\hline 692 & 492.8 & 3.03 & 69.04 & -159.1 & 307.1 & 25.33 \\
\hline 675 & -12.2 & -187.8 & 7.484 & -217.6 & 7.334 & -184.9 \\
\hline 680 & 0 & 0 & 0 & 0 & 0 & 0 \\
\hline
\end{tabular}

Table 5-6 tabulates the voltage at each node when the wind turbine component is connected to the system at node 675 . We can note that the steady state voltage error is drastically reduced when a distribution generator is connected to this node. So we can conclude that distributed generators can be used to improve the voltage profiles in remote areas of a weak grid. 
Table 5-7 shows the voltage regulator tap positions when wind generator module is connected. Here also we can observe that the values are closer to the IEEE standard values.

Table 5-6 Comparison of node voltages

\begin{tabular}{|c|c|c|c|c|c|c|c|c|c|}
\hline NODE & IEEE & w_Wind & Error & IEEE & w_Wind & Error & IEEE & w_Wind & Error \\
\hline 650 & 1.0000 & 0.999985 & 0.0015 & 1.0000 & 0.999985 & 0.0015 & 1.0000 & 0.999987 & 0.0013 \\
\hline RG60 & 1.0625 & 1.06243 & 0.0066 & 1.0500 & 1.0562 & 0.5905 & 1.0687 & 1.06868 & 0.0019 \\
\hline 632 & 1.0210 & 1.01952 & 0.1450 & 1.0420 & 1.0376 & 0.4223 & 1.0174 & 1.02383 & 0.6320 \\
\hline 633 & 1.0180 & 1.01682 & 0.1159 & 1.0401 & 1.03507 & 0.4836 & 1.0148 & 1.02149 & 0.6592 \\
\hline 634 & 0.9940 & 0.993545 & 0.0458 & 1.0218 & 1.0041 & 1.7322 & 0.9960 & 1.01567 & 1.9749 \\
\hline 645 & & & & 1.0329 & 1.02825 & 0.4502 & 1.0155 & 1.02173 & 0.6135 \\
\hline 646 & & & & 1.0311 & 1.02651 & 0.4452 & 1.0134 & 1.01966 & 0.6177 \\
\hline 671 & 0.9900 & 0.985957 & 0.4084 & 1.0529 & 1.03929 & 1.2926 & 0.9778 & 0.988999 & 1.1453 \\
\hline 680 & 0.9900 & 0.985834 & 0.4208 & 1.0529 & 1.03916 & 1.3050 & 0.9778 & 0.988876 & 1.1327 \\
\hline 684 & 0.9881 & 0.983906 & 0.4245 & & & & 0.9758 & 0.986855 & 1.1329 \\
\hline 611 & & & & & & & 0.9738 & 0.984863 & 1.1361 \\
\hline 652 & 0.9825 & 0.978353 & 0.4221 & & & & & & \\
\hline 692 & 0.9900 & 0.985638 & 0.4406 & 1.0529 & 1.03932 & 1.2898 & 0.9777 & 0.988752 & 1.1304 \\
\hline 675 & 0.9835 & 0.983772 & 0.0277 & 1.0553 & 1.04267 & 1.1968 & 0.9758 & 0.985324 & 0.9760 \\
\hline
\end{tabular}

Table 5-7 Comparison of regulator tap position with wind generator

\begin{tabular}{|c|c|c|}
\hline \multicolumn{3}{|c|}{ Voltage Regulator } \\
\hline & \multicolumn{2}{|c|}{ RG60 } \\
\hline Phase & IEEE & PSCAD \\
\hline A & 10 & 10 \\
B & 8 & 9 \\
C & 11 & 11 \\
\hline
\end{tabular}


The IEEE 13 bus network model PSCAD simulation results were found to be very similar to the standard IEEE results with minimal errors. The next section presents the analysis of the battery model used in this thesis. 


\subsection{LI-ION BATTERY MODEL RESULTS}

The output simulation parameters of the generic battery model provided by the PSCAD support team are shown in Figure 5-1 below. The simulation time is 50000 seconds. The SOC discharge and charge limits are 0.3 and 0.8 respectively. $E_{\text {bat }}$ gives the battery output voltage for a single cell, $V_{b a t}$ is the constant de voltage obtained across a resistor, $I_{b a t t}$ is the charging current which is kept constant at $0.5 \mathrm{~A}$ and $I_{\text {load }}$ is the constant dc output current flowing through the load. In the generic battery model, the charge and discharge cycle have approximately the same time period.

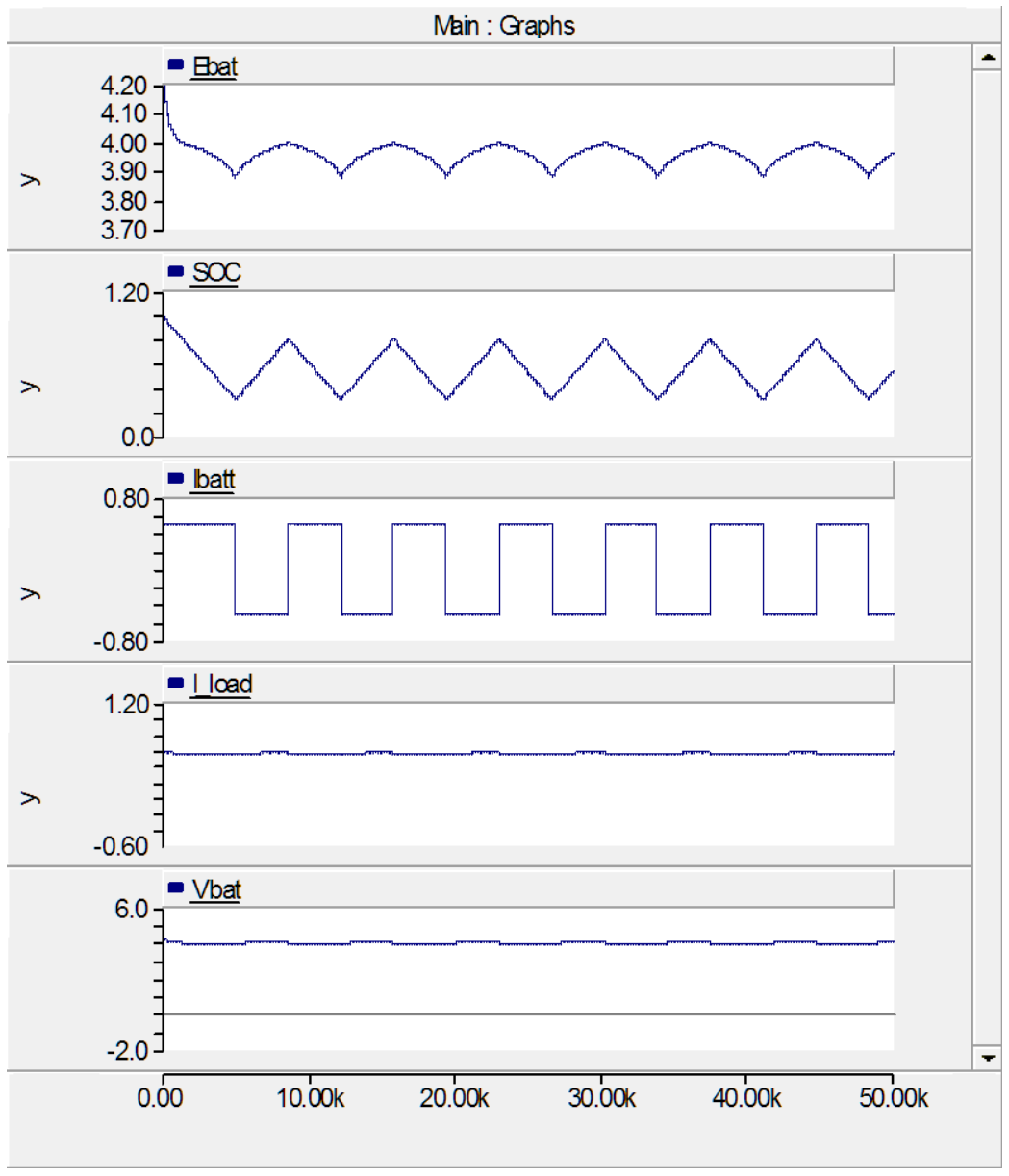

Figure 5-1 Generic battery output parameters 
Li-ion battery was programmed in PSCAD and simulated keeping the load conditions same as the generic battery circuit. The model output simulation parameters are shown in Figure 5-2 below. The simulation time and the SOC are the same as before. The initial SOC of battery is more than 0.95 ; the battery is free to discharge. The SOC of battery varies between 0.8 and 0.3 in consecutive cycles. Here we can see that the discharge time is longer than the charge time which is favorable since the number of charging and discharging cycles are reduced. This increases the battery life. Also faster charging yields better response. The discharge period is approximately 2 hours and the charge period is only 1 hour. Constant output dc voltage and current are obtained and the battery charging current is maintained constant at $0.5 \mathrm{~A}$.

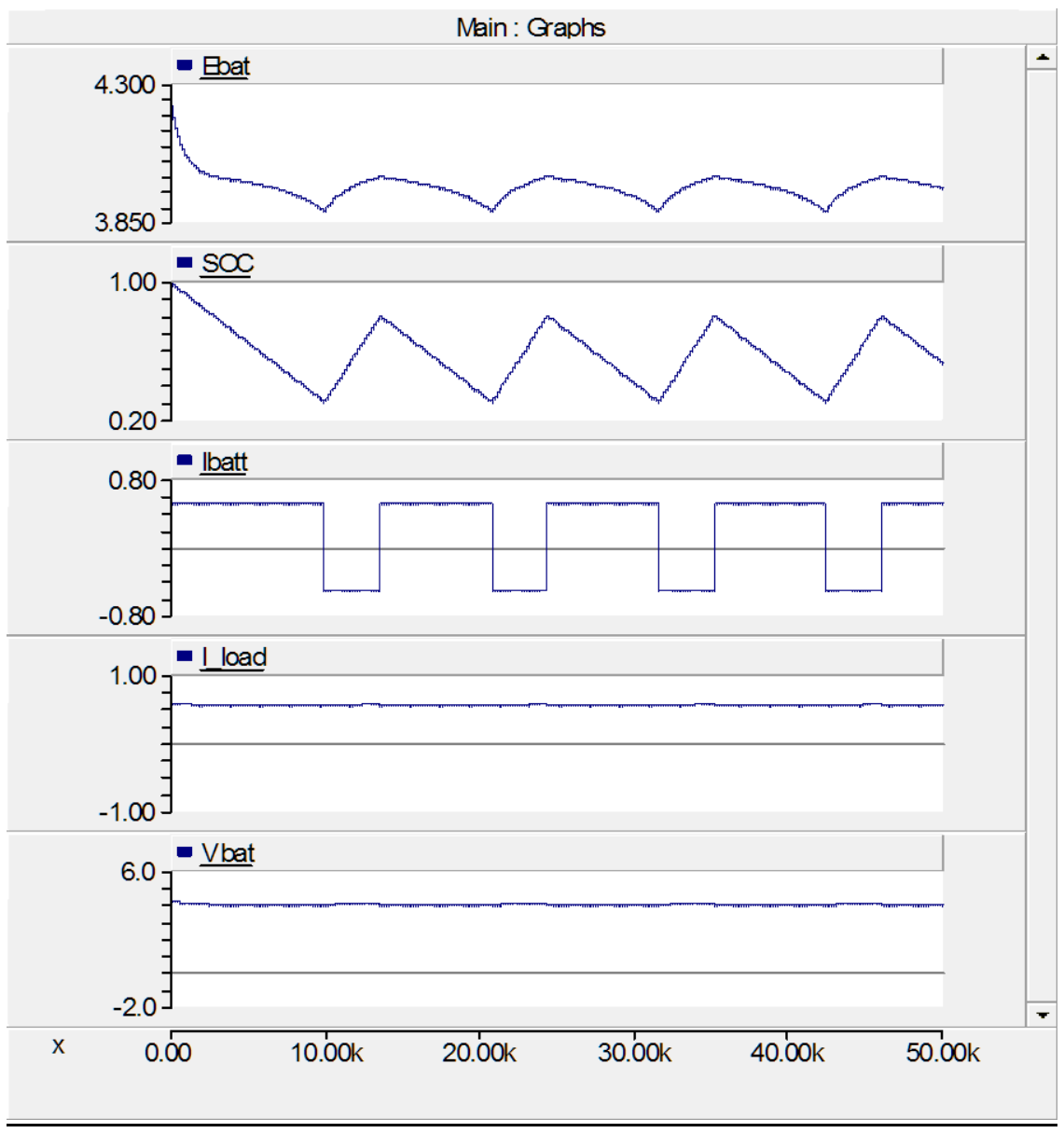

Figure 5-2 Li-ion battery output parameters 


\subsubsection{Battery Discharging Mode Simulation Output Parameters}

The Li-ion battery is connected to the power conditioning unit. The mode of battery operation is determined by the battery energy management control system depending on the wind conditions and SOC of battery. Two typical cases of battery discharging and charging are considered first. In this case the wind speed was assumed to be $6 \mathrm{~m} / \mathrm{sec}$ and the initial SOC of the battery is 0.9 . Hence the battery operates in discharging mode to supply the required power to the grid as the wind power output is low. The figures below show the variation of different parameters of storage module and wind turbine module in this mode.

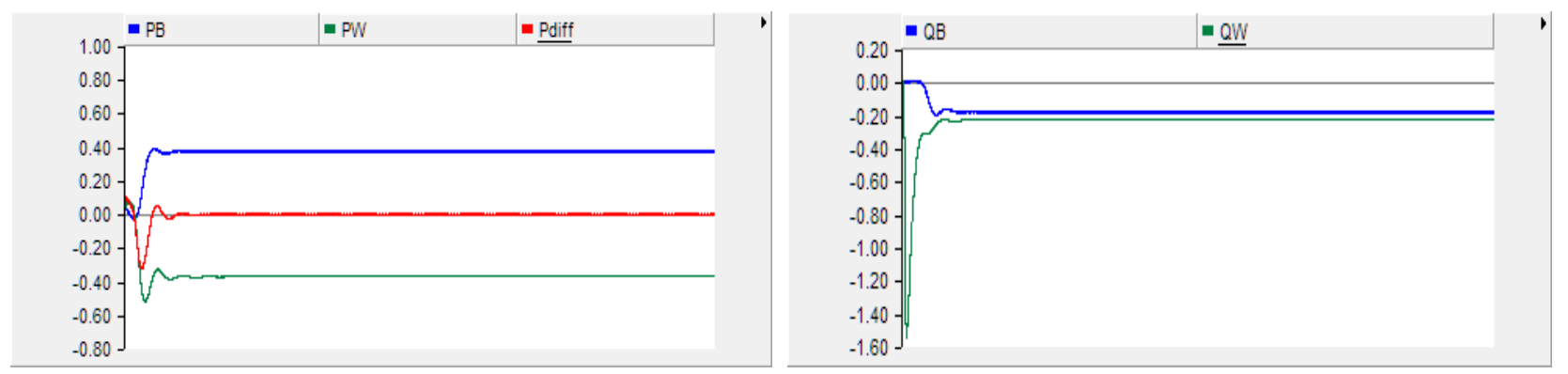

Figure 5-3 Real and reactive power variation of storage/wind turbine module

The Figure 5-3 above shows the real power and reactive power for storage module and wind turbine generator in discharging mode of battery. $P B$ and $Q B$ represent real and reactive power for storage module respectively. $P W$ and $Q W$ represent real and reactive power for wind turbine generator module. Pdiff is the absolute difference of real power between the wind turbine generator module and the storage module. The main objective of this thesis is to make Pdiff closer to zero so that real power magnitudes of wind and storage module are almost equal with opposite phases. If the value of Pdiff is not zero, the system absorbs or supplies power from the main grid which affects the reliability of the system and results in transmission losses. In other words we can say that the storage module should act as a backup generation scheme 
where the wind power and battery power complement each other. In Figure 5-3 we can see that since the wind speed is low, the wind module act as a load which is compensated by battery by going into the discharge mode and supplying the required power to balance the system.
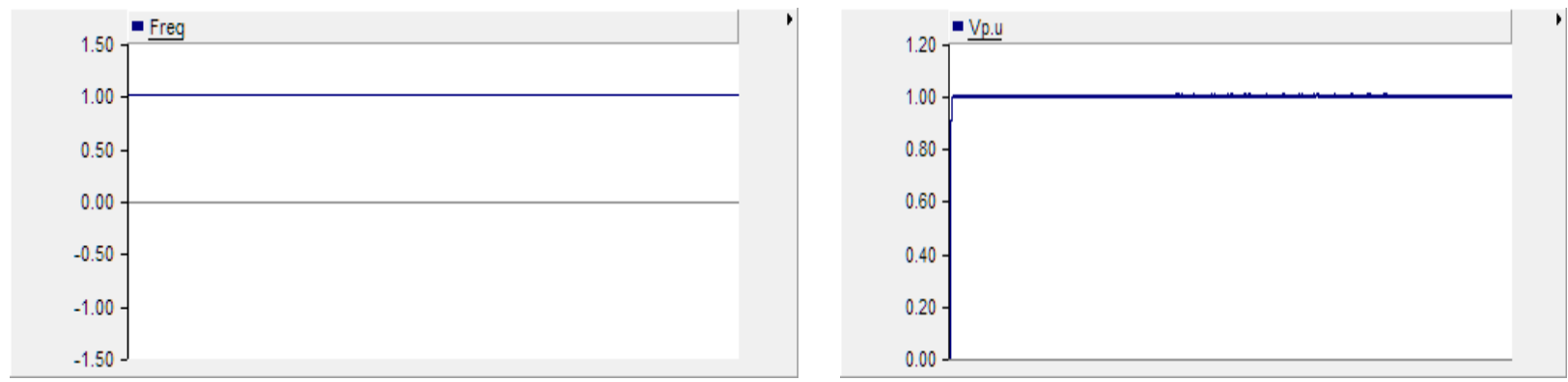

Figure 5-4 Frequency and voltage variation of storage/wind turbine module in p.u

In Figure 5-4, the frequency and voltage at the point of common coupling is shown in per units. The frequency and voltage were found to be 1 p.u in the steady state. Figure 5-5 shows the inverted output voltage for each phase and its RMS value in p.u for the storage module. The RMS voltage is maintained at 1 p.u in steady state.
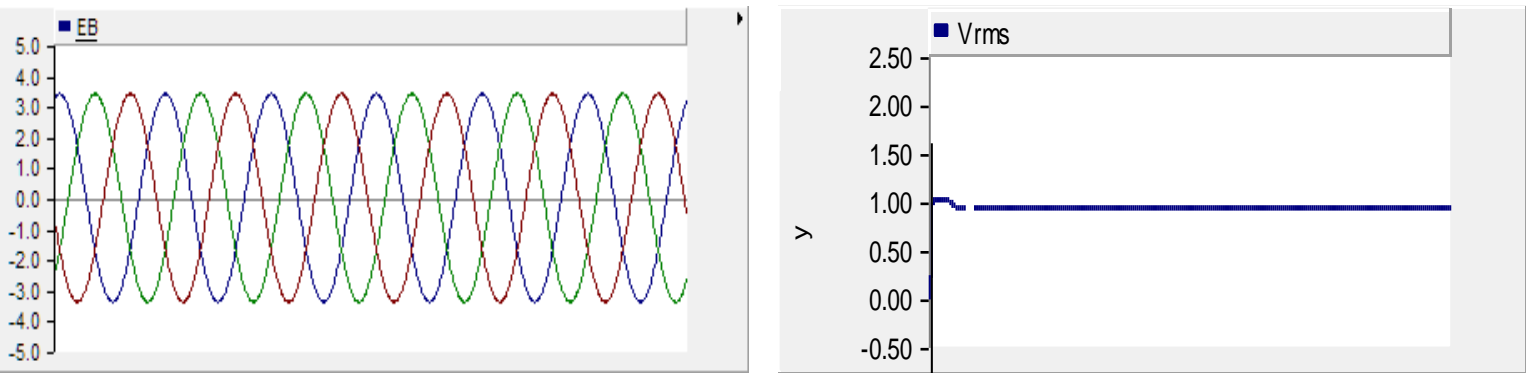

Figure 5-5 Converter output voltage three phase waveform and rms value

Figure 5-6 shows the constant de voltage across the dc link capacitor and the dc current flowing into the power conditioning unit. In the discharging mode the dc current output varies between 0 and $0.1 \mathrm{kA}$ in the steady state region. Figure 5-7 gives the magnitude and angle of the reference signal. In discharging mode the angle is varied from 0 to 90 degrees to control the output power while keeping the magnitude constant at 1 p.u. 

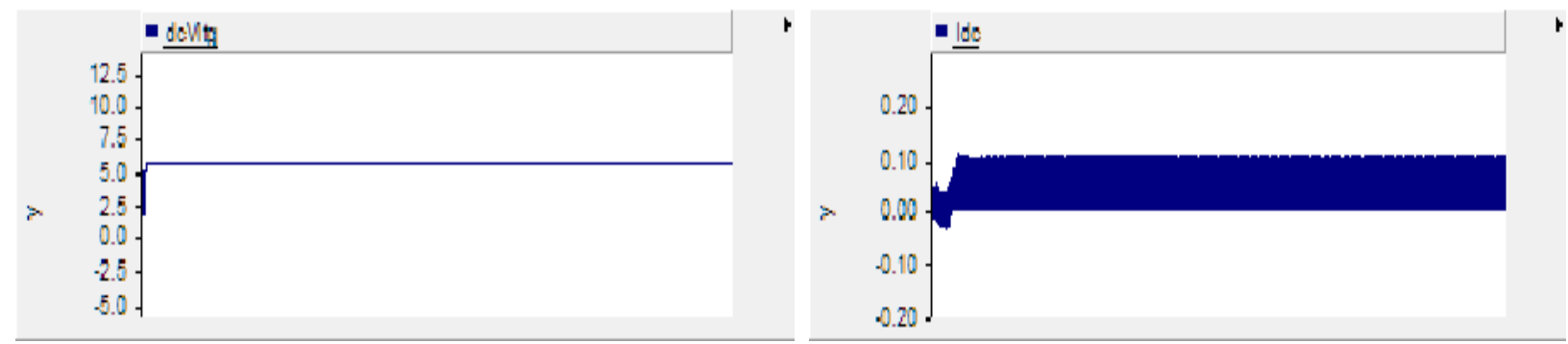

Figure 5-6 Voltage and current across the dc link capacitor
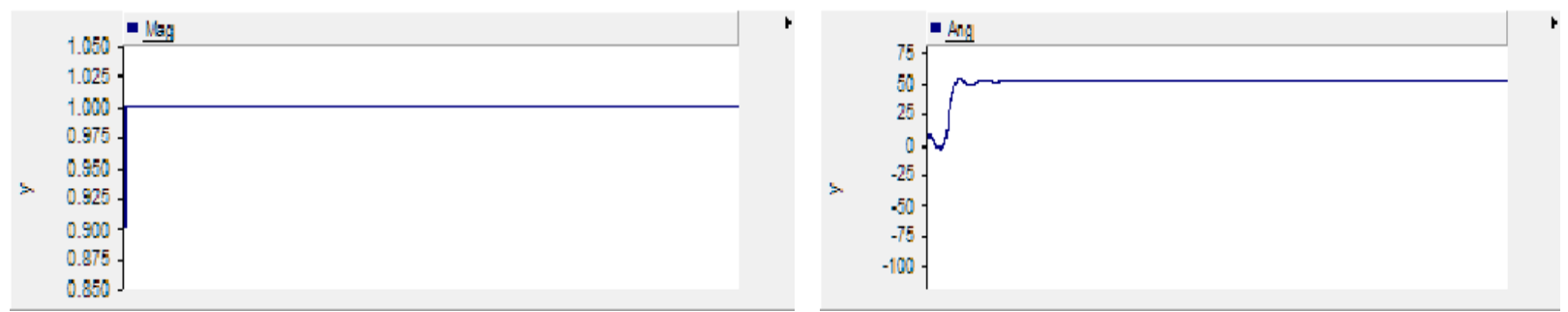

Figure 5-7 Magnitude and angle variation of the reference signal

Figure 5-8 shows the modulating reference signals for all phases and the battery charging current whose maximum value is kept constant at $0.5 \mathrm{kA}$ in steady state. Figure 5-9 gives the battery output voltage and the SOC. In discharging mode both battery voltage and SOC are decreasing steadily.
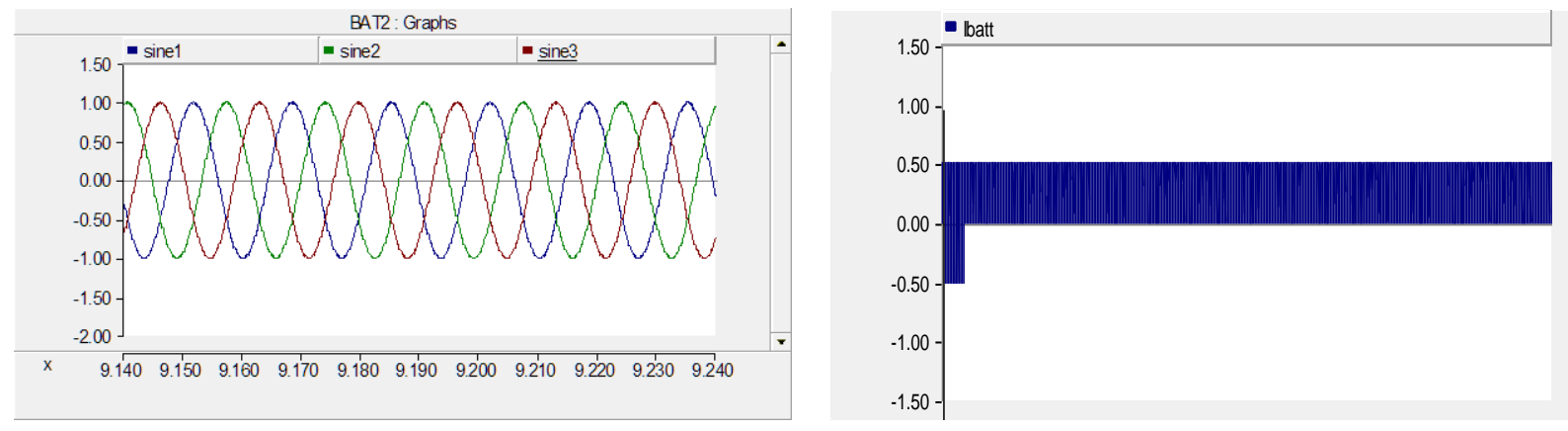

Figure 5-8 Modulation signals and battery discharging current 

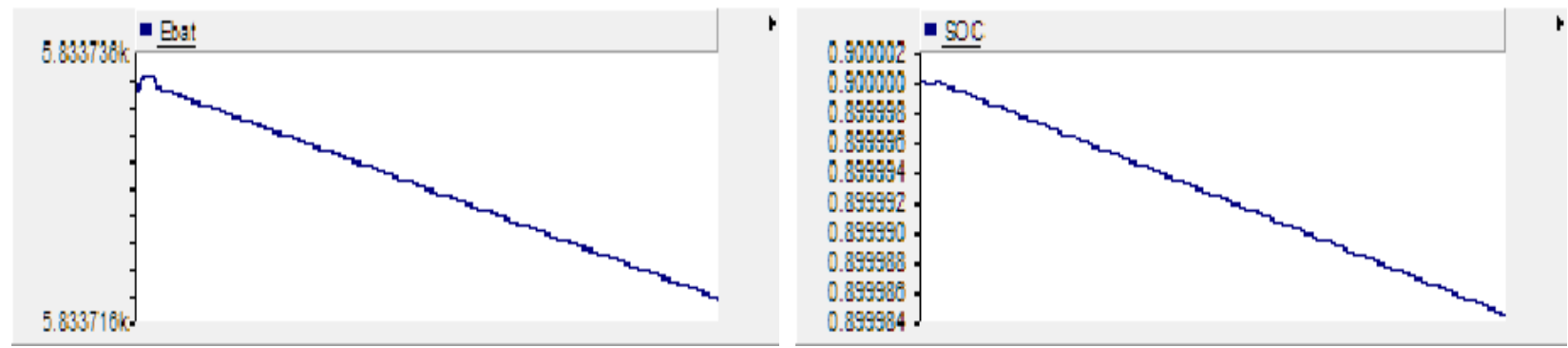

Figure 5-9 Output voltage and SOC of battery

Figure 5-10 gives the speed in p.u and output current of the induction generator for the wind turbine generator module. Since the wind turbine acts as a load due to low wind speed, in the discharging mode the speed of the generator goes less than 1 p.u.
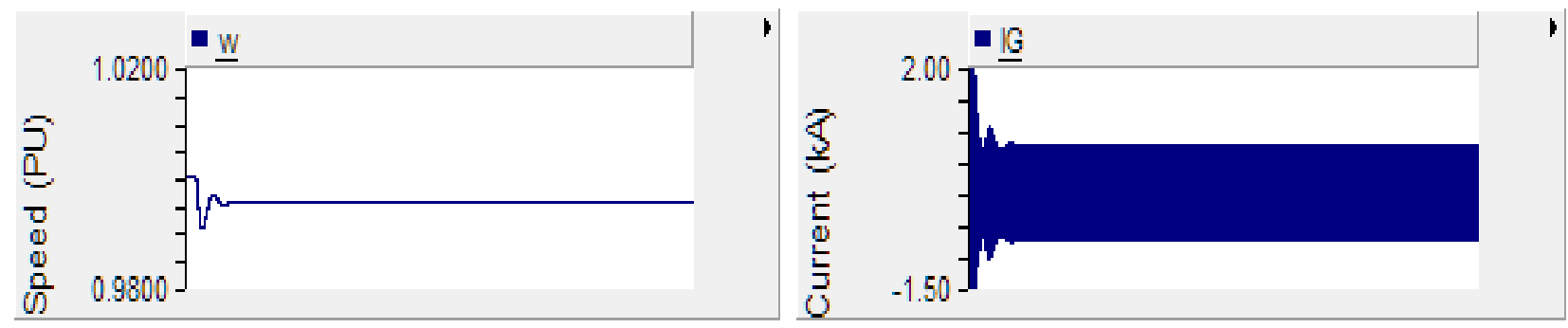

Figure 5-10 Output speed and current of the induction generator

\subsubsection{Battery Charging Mode Simulation Output Parameters}

In this case the battery operates in charging mode. The wind speed was assumed to be 18 $\mathrm{m} / \mathrm{sec}$ and the initial SOC of the battery is 0.1 . The storage module absorbs the required power from the grid as the wind power output is high. The figures below show the variation of different parameters of storage module and wind turbine module in this mode. 

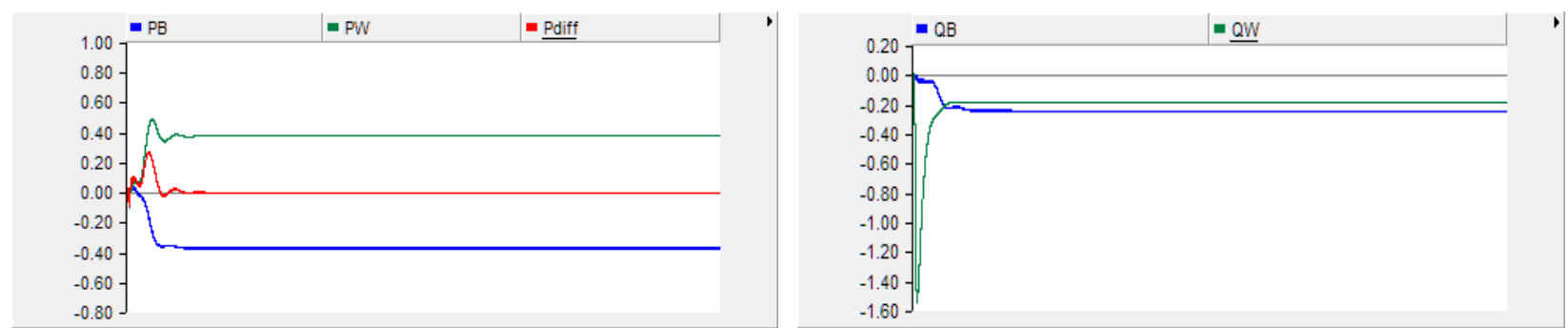

Figure 5-11 Real and reactive power variation of storage/wind turbine module

Figure 5-11 above shows the real and reactive power for storage module and wind turbine generator in charging mode of battery. Here we can see that since the wind speed is high, the wind module act as a source which supplies power to the battery which is in the discharge mode.
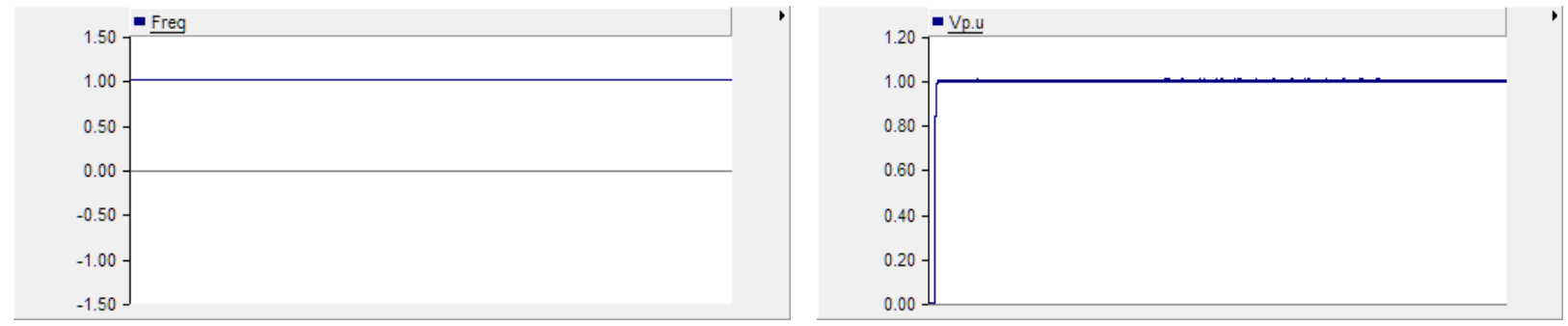

Figure 5-12 Frequency and voltage variation of storage/wind turbine module in p.u
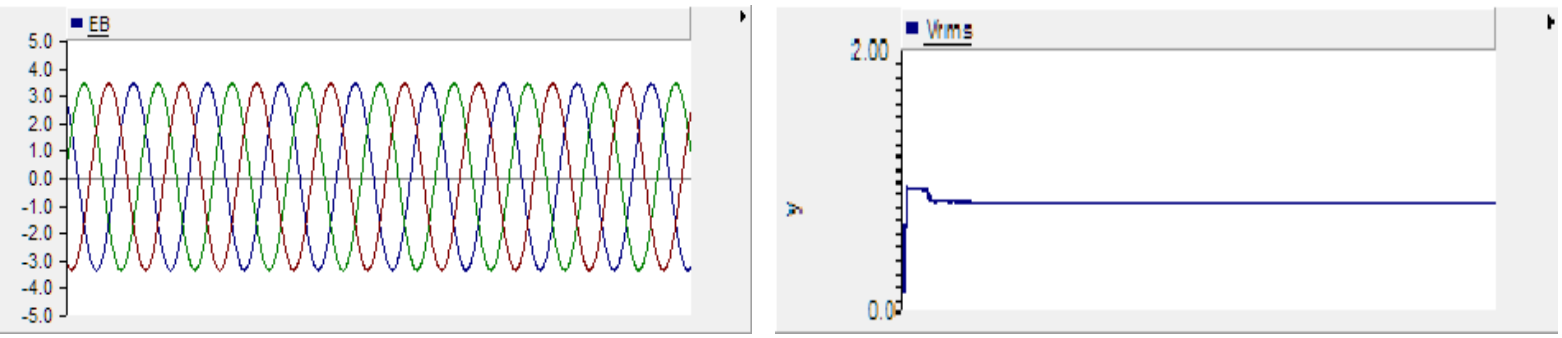

Figure 5-13 Converter output voltage three phase waveform and rms value

In Figure 5-12, the frequency and voltage at the point of common coupling is shown in per units. The frequency and voltage were found to be 1 p.u in the steady state. Figure 5-13 shows the output voltage for each phase and its RMS value in p.u for the storage module. 

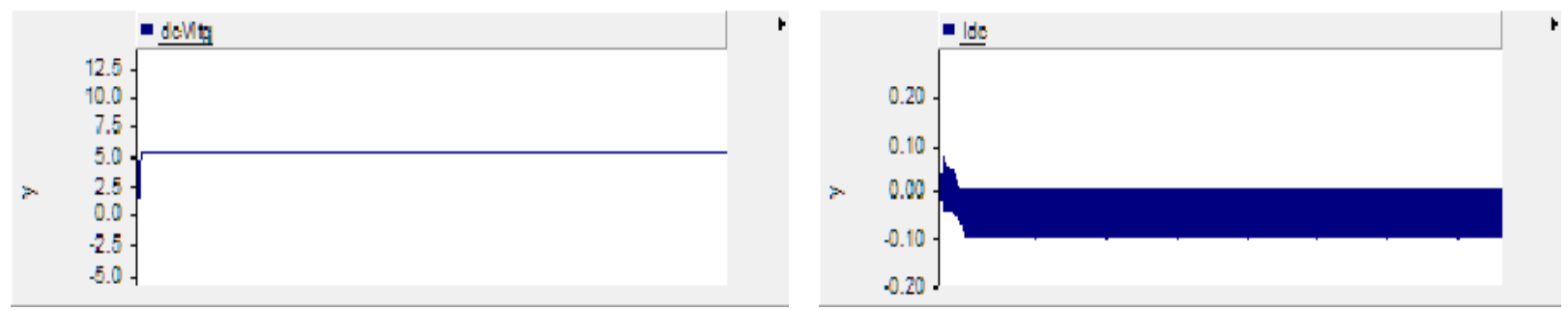

Figure 5-14 Voltage and current across the de link capacitor
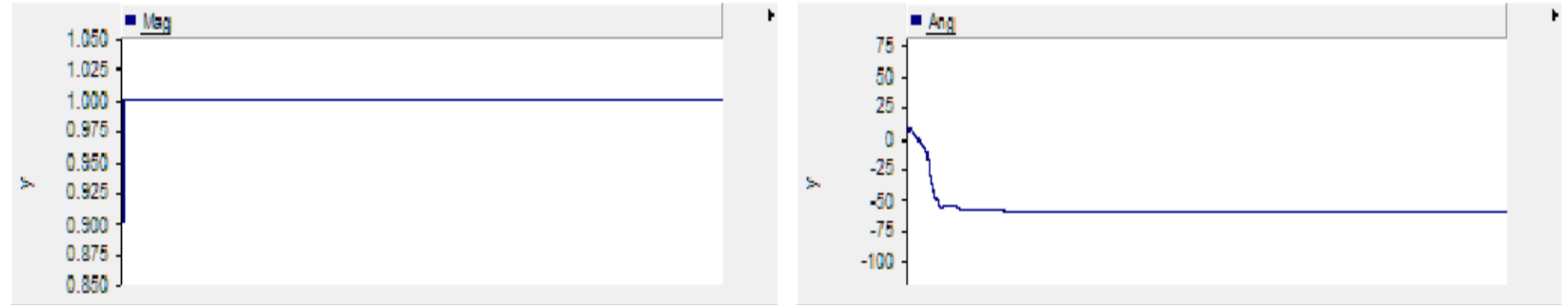

Figure 5-15 Magnitude and angle variation of the reference signal

Figure 5-14 shows the constant dc voltage across the dc link capacitor and the dc current flowing into the power conditioning unit. In the charging mode the dc current output varies between 0 and $-0.1 \mathrm{kA}$ in the steady state region. Figure 5-15 gives the magnitude and angle of the reference signal. In charging mode the angle is varied from 0 to -90 degrees to absorb power while keeping the magnitude constant at 1 p.u.
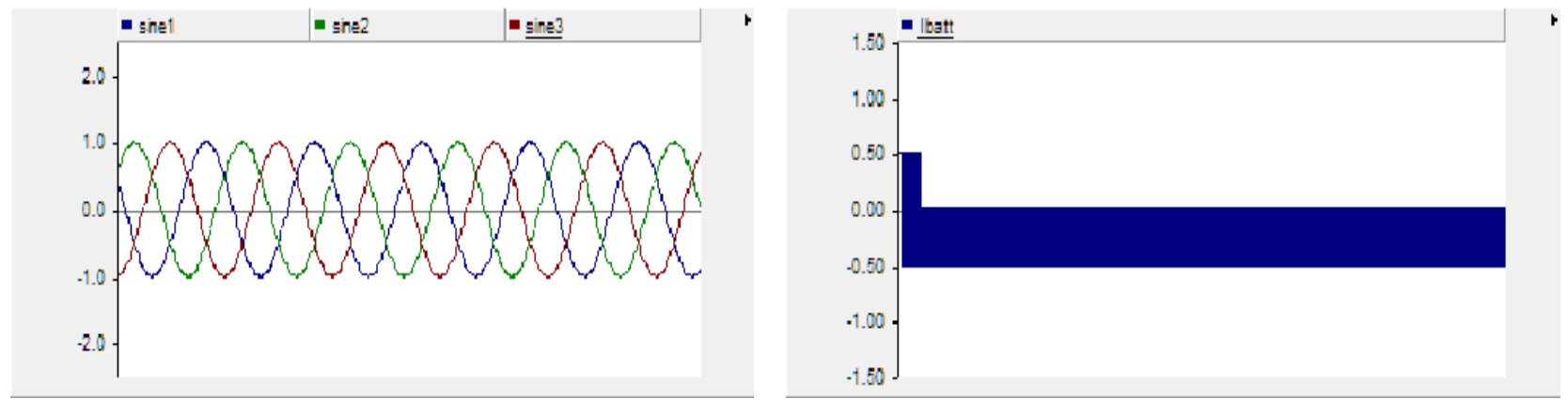

Figure 5-16 Modulation signals and battery charging current 
Figure 5-16 shows the modulating reference signals for all phases and the battery charging current whose minimum value is kept constant at $-0.5 \mathrm{kA}$ in steady state. Figure $5-17$ gives the battery output voltage and the SOC. In charging mode both battery voltage and SOC are increasing steadily.
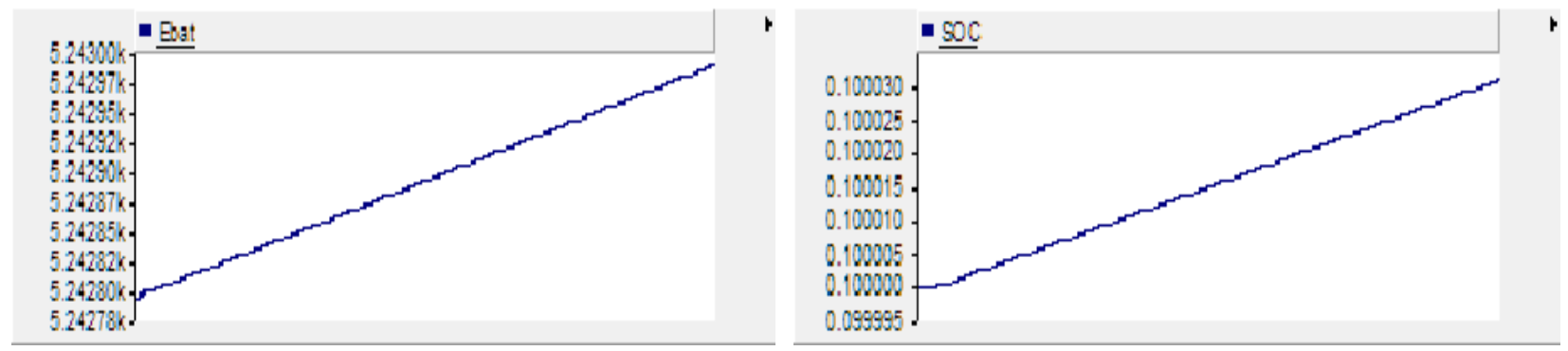

Figure 5-17 Output voltage and SOC of battery

Figure 5-18 gives the speed in p.u and output current of the induction generator for the wind turbine generator module. Since the wind turbine acts as a source at high wind speeds, the speed of the generator goes more than 1 p.u.
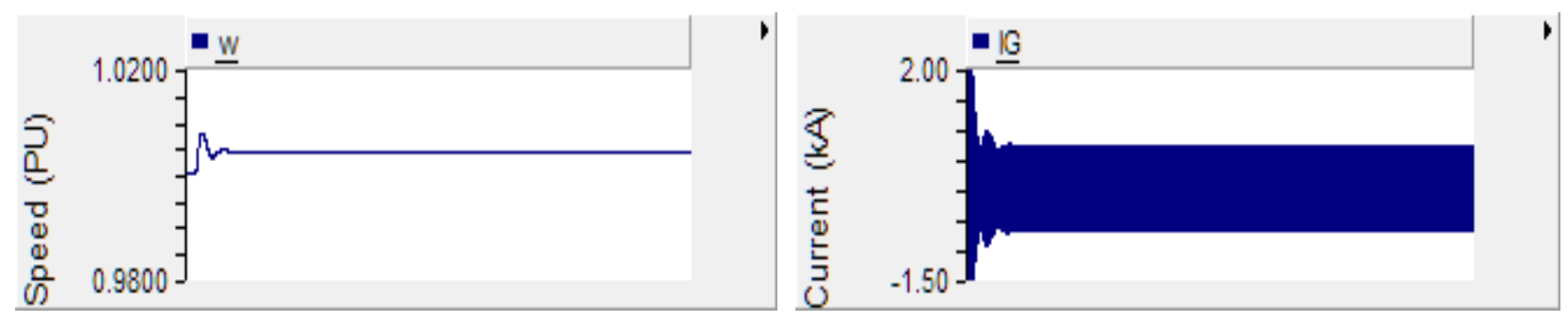

Figure 5-18 Output speed and current of the induction generator 


\subsection{MULTI-MODE BATTERY ENERGY MANAGEMENT CONTROL (BEMC) OPERATION}

The focus of the following simulations is to demonstrate the performance of the battery energy management control systems under a variety of battery operation modes. The simulations are conducted on a standalone network and a network with IEEE 13 node, battery, and wind generator.

\subsubsection{Standalone Network}

Four cases of wind speed are considered: (i) Case 1: constant low wind speed, (ii) Case 2: constant high wind speed, (iii) Case 3: step change in wind speed, and (iv) Case 4: variable wind speed. The SOC limits for discharging and charging of the battery are normally 0.3 and 0.95 for Li-ion batteries. For each of the wind speed cases, battery conditions corresponding to an initial state of charge of 0.9 and 0.1 are considered. The mode of operation of battery depends on the wind conditions and the SOC of the battery. To prevent overcharging SOC maximum is taken as 0.99. To improve the lifetime of the battery the minimum value of the SOC is taken as 0.01 . If the battery reaches these limits then it is automatically disconnected. The variation in SOC and the power variation in battery and wind generator are shown for the above mentioned cases. The simulation is conducted for a period of 10 minutes. However for clarity of presentation of the trends, the parameters are shown for a period of 10 seconds.

\section{Case 1: Constant Low Wind Speed}

In this case the wind speed was assumed to be a low constant value of $6 \mathrm{~m} / \mathrm{sec}$. The figures below show the variation in SOC and battery and wind generation power variation for three SOC initial conditions. 

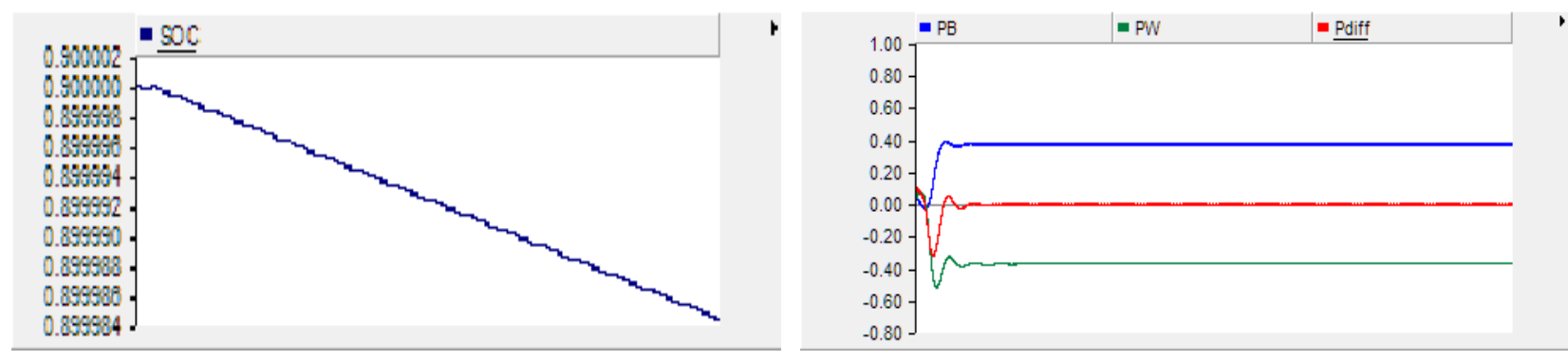

Figure 5-19 SOC Variation and Wind/Battery Power for Initial SOC 0.9

In the above case since the wind speed is low and the battery SOC is more than the SOC discharging limit, the battery goes into discharging mode and supplies the required power to compensate for the wind load. The difference of real power between the wind and the storage module is zero in the steady state region.
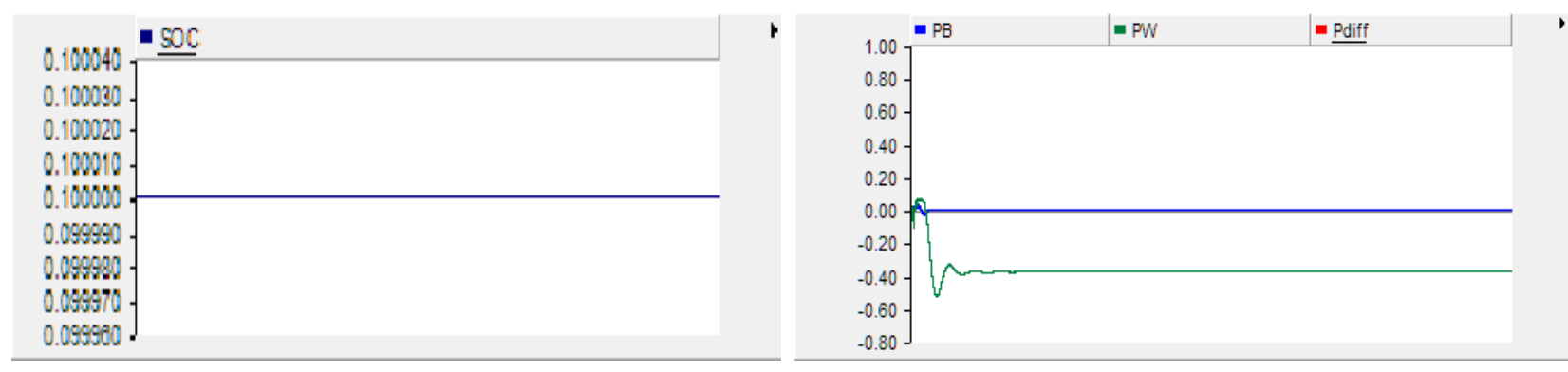

Figure 5-20 SOC Variation and Wind/Battery Power for Initial SOC 0.1

In Figure 5-20, the battery SOC is in the charging limit but since the wind speed is low the battery cannot charge. Hence in this case also the battery goes into inactive mode where it is disconnected from the system and the required power to compensate for the wind load is supplied by the mains. The difference of real power between the wind and the storage module Pdiff is equal to the wind power since the battery power is also zero in this case. 


\section{Case 2: Constant High Wind Speed}

In this case the wind speed was assumed to be $18 \mathrm{~m} / \mathrm{sec}$. The figures below show the variation in SOC and battery and wind generation power variation for three SOC initial conditions. Based on the SOC conditions the battery discharges, charges or goes into inactive mode.
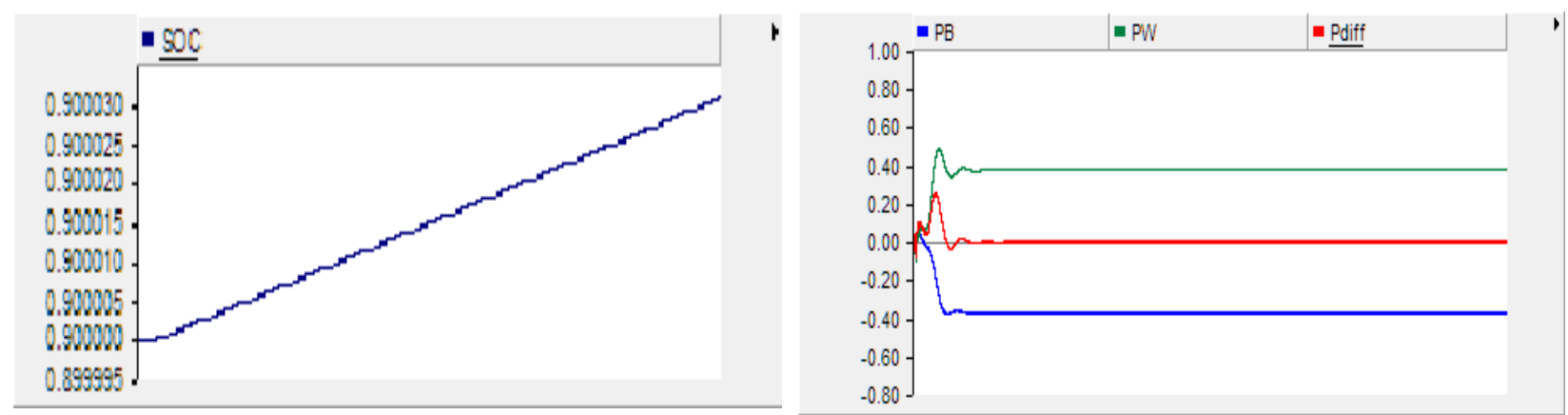

Figure 5-21 SOC Variation and Wind/Battery Power for Initial SOC 0.9

In the above case since the wind speed is high. Even though the battery SOC is more than the SOC discharging limit, it is not fully charged and hence the battery goes into charging mode until the SOC of battery reaches the maximum SOC limit of 0.99 . The wind turbine module generates power which is stored in the battery module. The difference of real power between the wind and the storage module is zero in the steady state region.
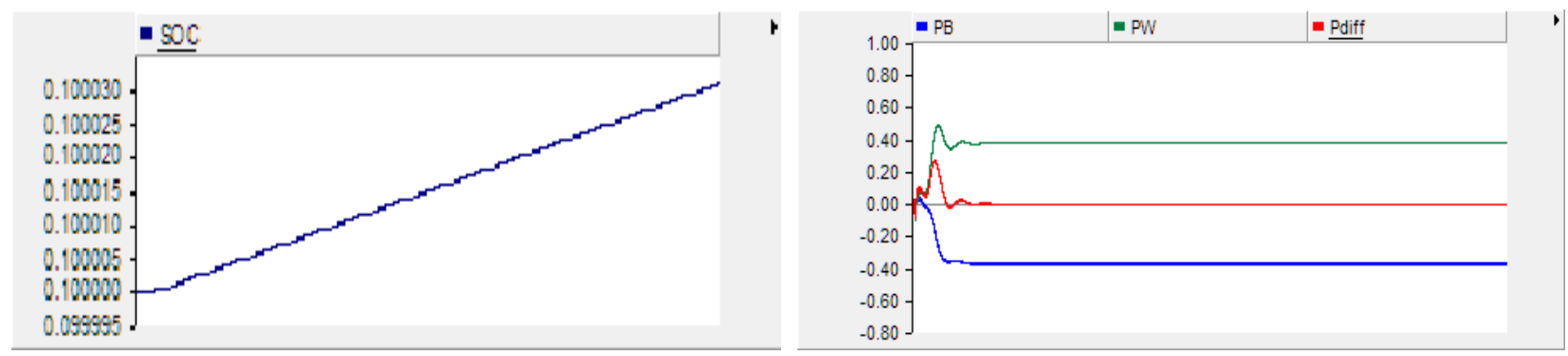

Figure 5-22 SOC Variation and Wind/Battery Power for Initial SOC 0.1 
In Figure 5-22, the wind speed is high and the initial battery SOC is 0.1 which is in the charging range. So the battery goes into charging mode until the SOC of battery reaches the maximum SOC limit of 0.99 . The power generated by wind turbine module is stored in the battery module. The difference of real power between the wind and the storage module is zero in the steady state region and hence no power is absorbed from the mains.

\section{Case 3: Step Change Wind Speed (Low $6 \mathrm{~m} / \mathrm{s}$ to High $18 \mathrm{~m} / \mathrm{s}$ Wind Speed)}

In this case the wind speed is stepped up from $6 \mathrm{~m} / \mathrm{s}$ to $18 \mathrm{~m} / \mathrm{sec}$ at threshold value of 5seconds. The figures below show the variation in SOC and battery and wind generation power variation for three SOC initial conditions.
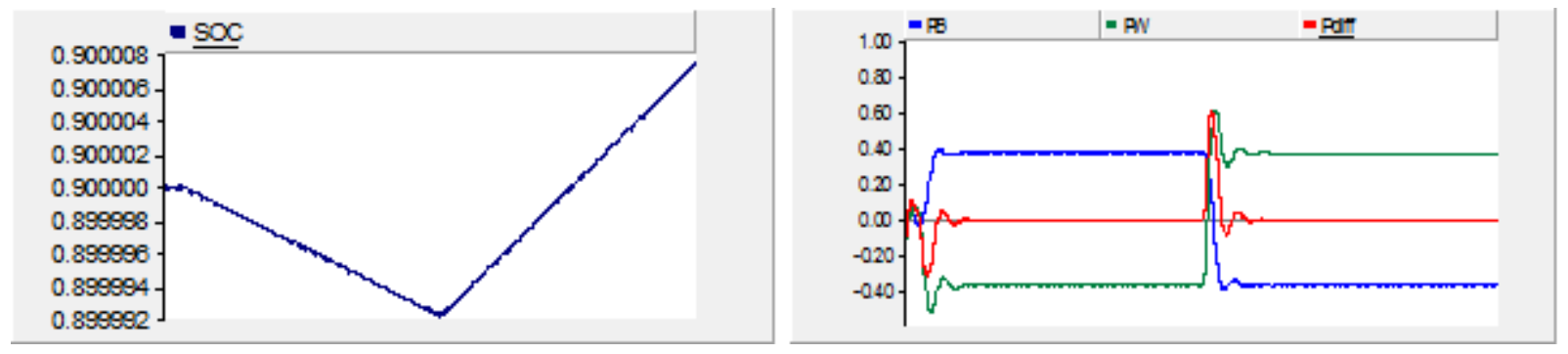

Figure 5-23 SOC Variation and Wind/Battery Power for Initial SOC 0.9

In the above case, initially the wind speed is low and the battery SOC is at 0.9. During this time period the battery discharges to meet the wind power demand since its initial SOC is greater than the SOC discharge limit. But as the wind speed goes up, the wind turbine generator produces power and this power is again used to charge the energy storage module. The maximum SOC limit for battery charging is given as 0.99 . The power difference is maintained at zero except at the transition point in both time periods. Hence we can see that battery power characteristics and wind turbine module characteristics supplement each other 

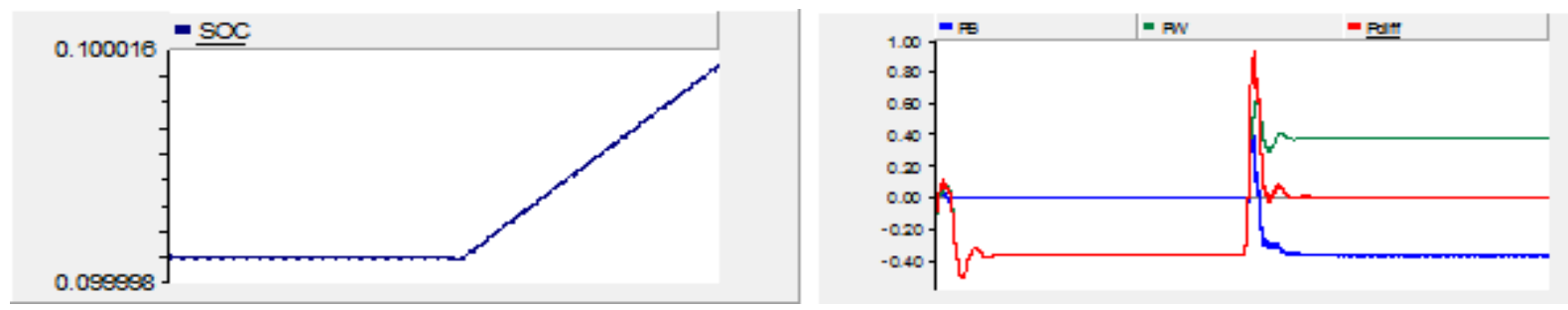

Figure 5-24 SOC Variation and Wind/Battery Power for Initial SOC 0.1

In Figure 5-24 also we can observe the same conditions as the previous case. Initially the wind speed is low and the battery SOC is at 0.1 . During this time the battery goes into the inactive mode even though its initial SOC is in the SOC charging limit as the wind speed is low. But as the wind speed goes up, the wind turbine generator produces power and this power is again used to charge the energy storage module. Power difference curve behaves in the same way as the previous scenario.

\section{Case 4: Variable Wind Speed}

In this case the wind speed is varied stochastically. The wind is generated using the PSCAD wind source component. The base wind speed is taken as $14 \mathrm{~m} / \mathrm{s}$ in addition to the gust, ramp and noise parameters. The figures below show the variation in SOC and battery and wind generation power variation for three initial conditions of state of charge of battery.

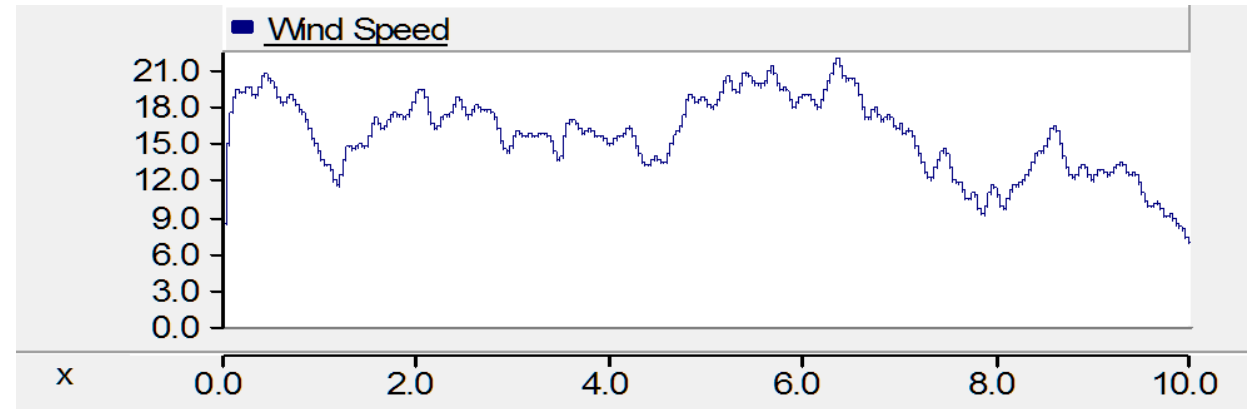

Figure 5-25 Variable wind speed 

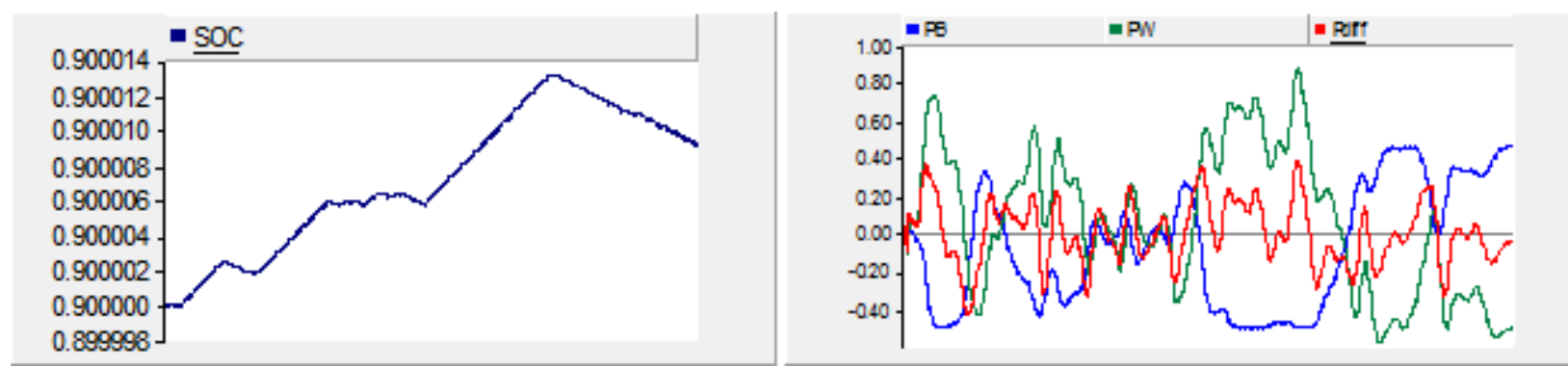

Figure 5-26 SOC Variation and Wind/Battery Power for Initial SOC 0.9

In the above case, the initial SOC of battery is taken as 0.9 and hence it is free to discharge. But as mentioned earlier discharging or charging of battery depends on the wind conditions. When the wind speed is high the battery goes into charging mode as its SOC has not reached its upper extreme limit. But when the wind speed decreases, the wind power output reduces and now the battery goes into the discharging mode to supply the required power until it reaches its discharging limit of 0.3. As the intermittency of wind increases as shown in Figure 5-25, the battery goes into different cycles of charging and discharging. The power difference curve and the SOC of the battery also vary accordingly.
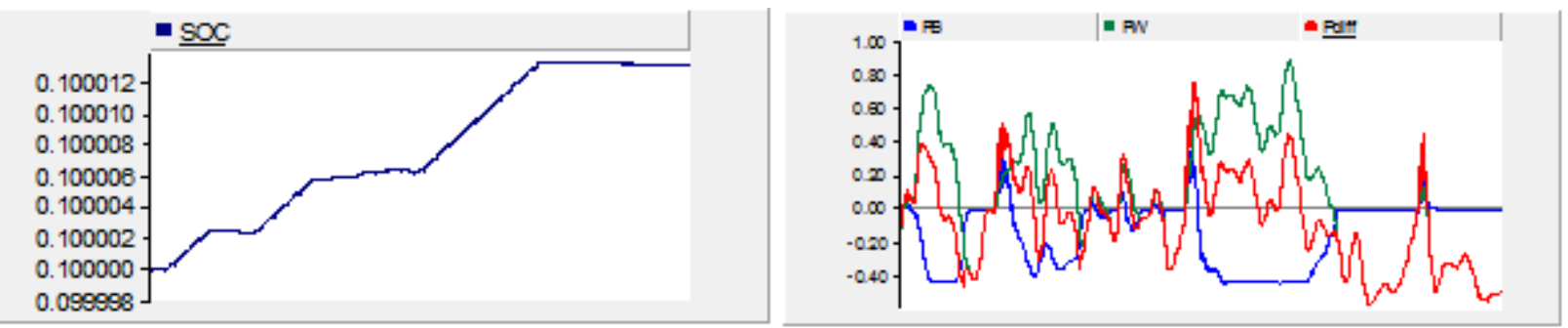

Figure 5-27 SOC Variation and Wind/Battery Power for Initial SOC 0.1

In the above case, the initial SOC of battery is taken as 0.1 which is in the battery charging limit. So when the wind turbine generator produces positive power, the battery goes into charging mode and when the wind power becomes negative the battery goes into inactive mode. The SOC curve and the power difference curve vary according to the battery modes. 


\section{SOC Limits Simulations}

The next set of runs study the behavior of the standalone system when the SOC of battery reaches the upper extreme limit of 0.99 and lower extreme limit of 0.01

\section{Case 1: SOC extreme limit 0.99}

The initial SOC of battery is assumed to be 0.98999 with high wind speed of $18 \mathrm{~m} / \mathrm{s}$. The variation of SOC and wind generator and battery power along with their difference is shown below. When SOC reaches a value of 0.99 , the storage module disconnects and the battery becomes inactive as shown by the SOC and power graphs in Figure 5-28.
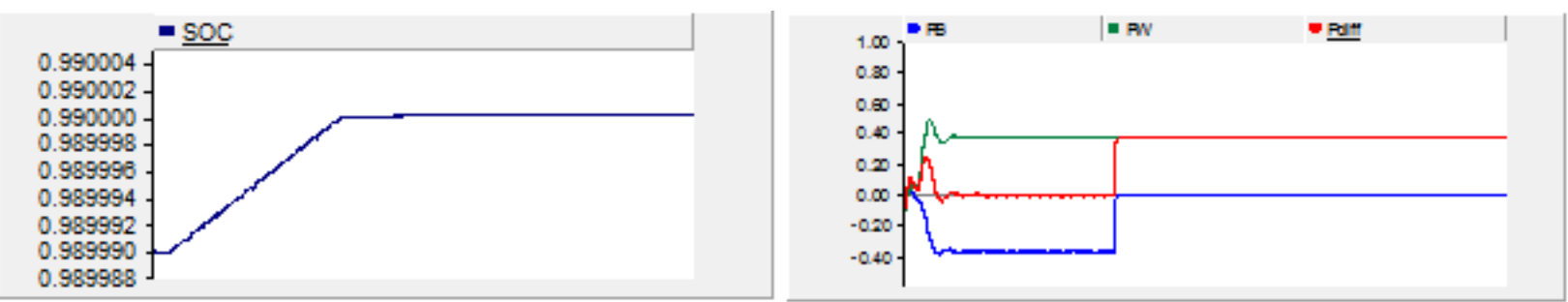

\section{Figure 5-28 SOC upper charging limit variation and Wind/Battery power variation}

\section{Case 2: SOC extreme limit 0.01}

The initial SOC of battery is assumed to be 0.001 which is lower than SOC minimum limit. Hence the battery operates in inactive mode as shown in Figure 5-29 below.
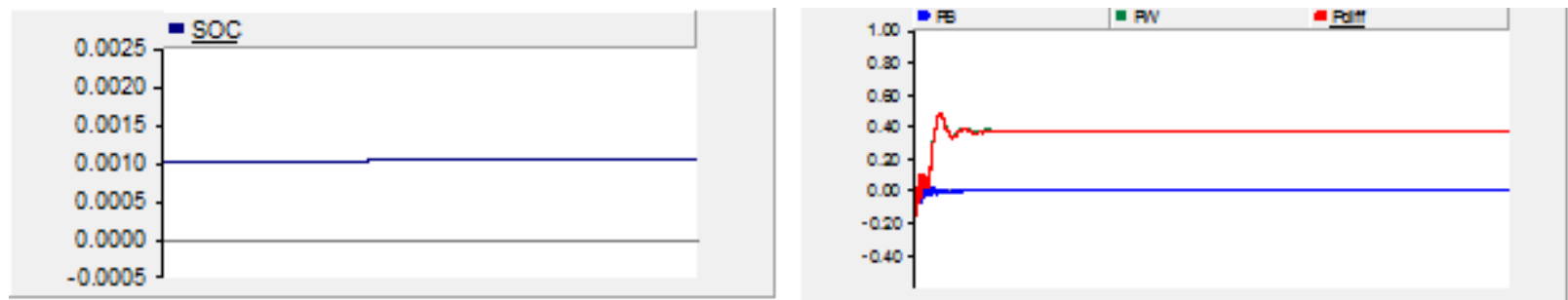

Figure 5-29 SOC lower discharging limit variation and Wind/Battery power variation 
In this section we demonstrated the performance of the BEMC for various operating conditions and show that it responds appropriately to changes in wind conditions. The next section focuses on the larger network with the IEEE 13 node feeder distribution analysis.

\subsubsection{IEEE 13 Node Feeder Distribution System Analysis with Wind Turbine Generator}

The IEEE 13 node distribution system feeder is connected to a wind turbine generator component, an energy storage unit with a power conditioning system and a supervisory battery energy management control system to control the modes of operation of battery depending on the wind conditions. In this case the wind speed is variable which is closer to the real scenario as the intermittent nature of wind speed is taken into account. The wind source component is connected to a wind turbine generator. The base wind speed is maintained $14 \mathrm{~m} / \mathrm{s}$ in addition to the gust, ramp and noise parameters. The figures below show the variation in SOC and battery and wind generation power variation for three SOC initial conditions.
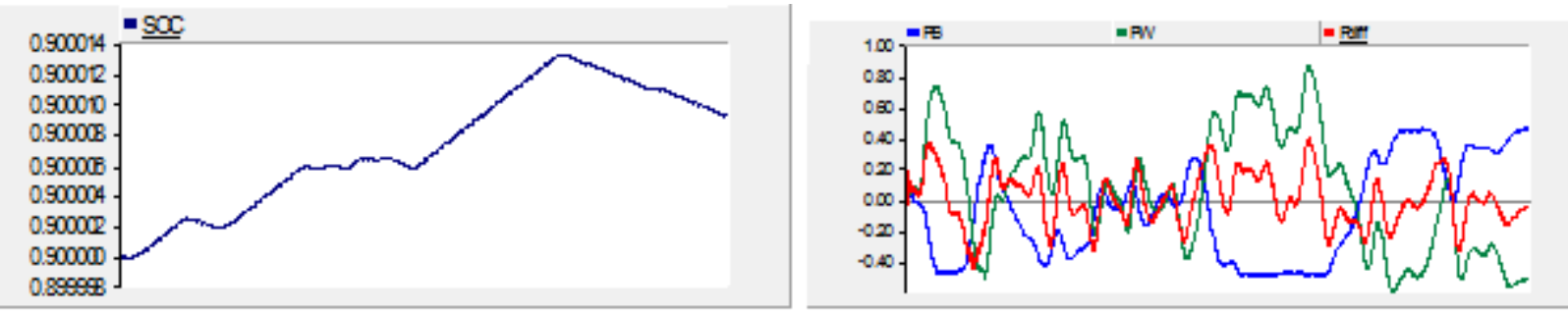

\section{Figure 5-30 SOC Variation and Wind/Battery Power for Initial SOC 0.9}

When the initial SOC of battery is 0.9 , it is free to discharge. Depending on the wind conditions, when the wind speed is high the battery goes into charging mode until its SOC reaches the upper extreme limit. But when the wind power output decreases, the battery goes into the discharging mode to supply the required power until it reaches its discharging limit of 0.3. 
The storage module output power varies according to the wind power. The power difference curve and the SOC of the battery also vary accordingly as shown in Figure 5-30.
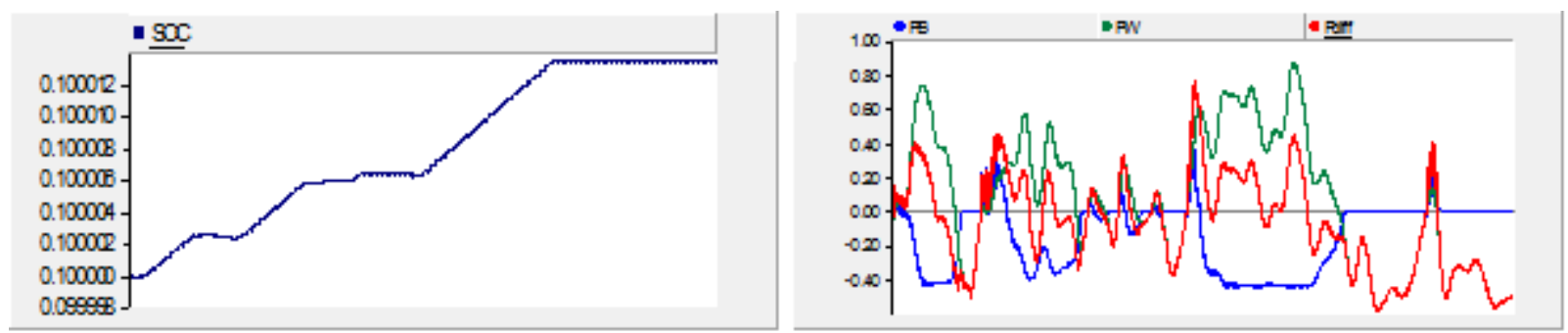

Figure 5-31 SOC Variation and Wind/Battery Power for Initial SOC 0.1

The initial SOC of battery is taken as 0.1 which is lower than the battery charging limit. So when the wind turbine generator produces positive power, the battery goes into charging mode and when the wind power becomes negative the battery goes into inactive mode as the SOC is less than the discharge limit of 0.3. The SOC curve and the power difference curve vary according to the battery modes which are shown in Figure 5-31.

\subsubsection{IEEE 13 Node Feeder Distribution System Analysis with Photovoltaic Panel}

To study the effects of different types of distributed generation and storage on distribution network, a photovoltaic panel module from the master library and an energy storage module is connected at node 675 of the IEEE 13 node feeder system. The battery has been modeled as a separate entity so that it can be connected anywhere in the system. But in this thesis work, it is connected at the same feeder node as the PV panel to reduce the transmission losses since the output of a PV panel is very low compared to other sources. Two different cases of battery discharging with initial SOC 0.9 and battery charging with initial SOC 0.1 were studied. Initially the solar radiation is set at 607.407 and the temperature is set at $50^{\circ} \mathrm{C}$ to simulate the day time conditions. At 5 seconds the solar radiation is reduced to zero and the temperature to 
$25^{\circ} \mathrm{C}$ to simulate the night time. The steady state results for the battery and PV panel power output and SOC of battery are shown below.
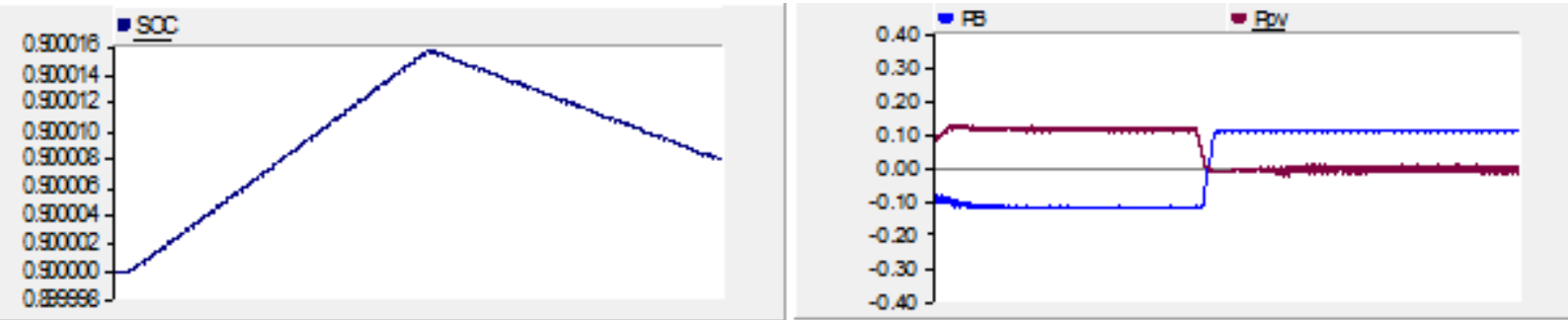

Figure 5-32 SOC Variation and PV/Battery Power for Initial SOC 0.9

In the above Figure 5-32, we can see that initially the solar power is high, so the battery goes into charging mode until it reaches its full charge capacity. When the solar power reduces to zero, since the battery SOC is greater than the discharge limits it provides the required power to the system by going into the discharge mode. This can be also seen in the SOC curve which is initially charging and the discharging.
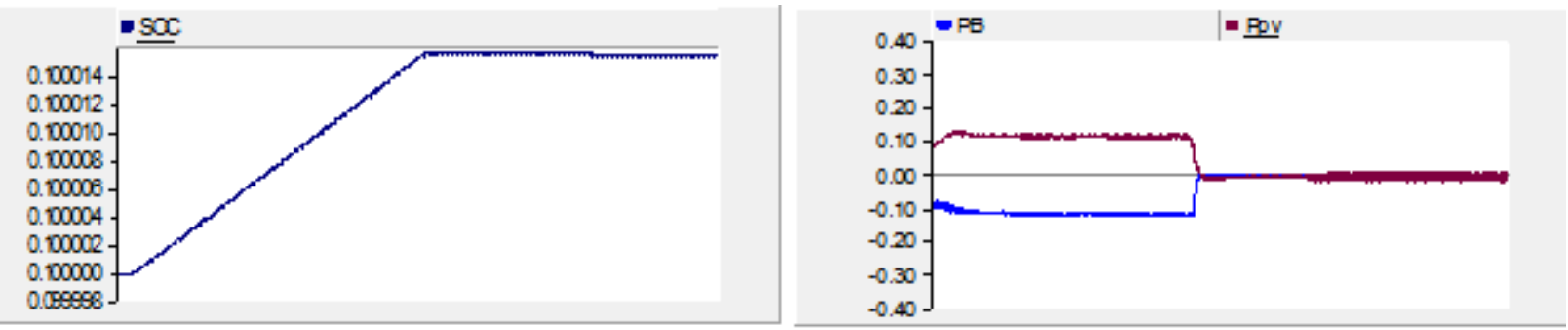

Figure 5-33 SOC Variation and PV/Battery Power for Initial SOC 0.1

For an initial SOC of 0.1 , we can see that when the solar power is high, the battery goes into charging mode. When the solar power reduces to zero, since the battery SOC is less than the discharge limits of 0.3 , it is unable to provide the required power to the system and hence goes into the inactive mode. This is shown in Figure 5-33. The SOC curve which is initially charging 
and then constant. From the above results we can conclude that the real/reactive battery power controller as well as the BEMC is effective in controlling the power output of the battery.

\subsubsection{Microgrid Hybrid System Analysis}

A hybrid system is also simulated to study the effect of both wind and solar power generation. This system is shown in Figure 5-34. It consists mainly of a wind turbine generator module, a PV panel module and an energy storage device. The wind turbine module generates a variable output based on the wind conditions and the photovoltaic panel produces a constant output. The battery power output varies by according to wind, solar and SOC of battery. The mode of battery operation is determined using BEMC.

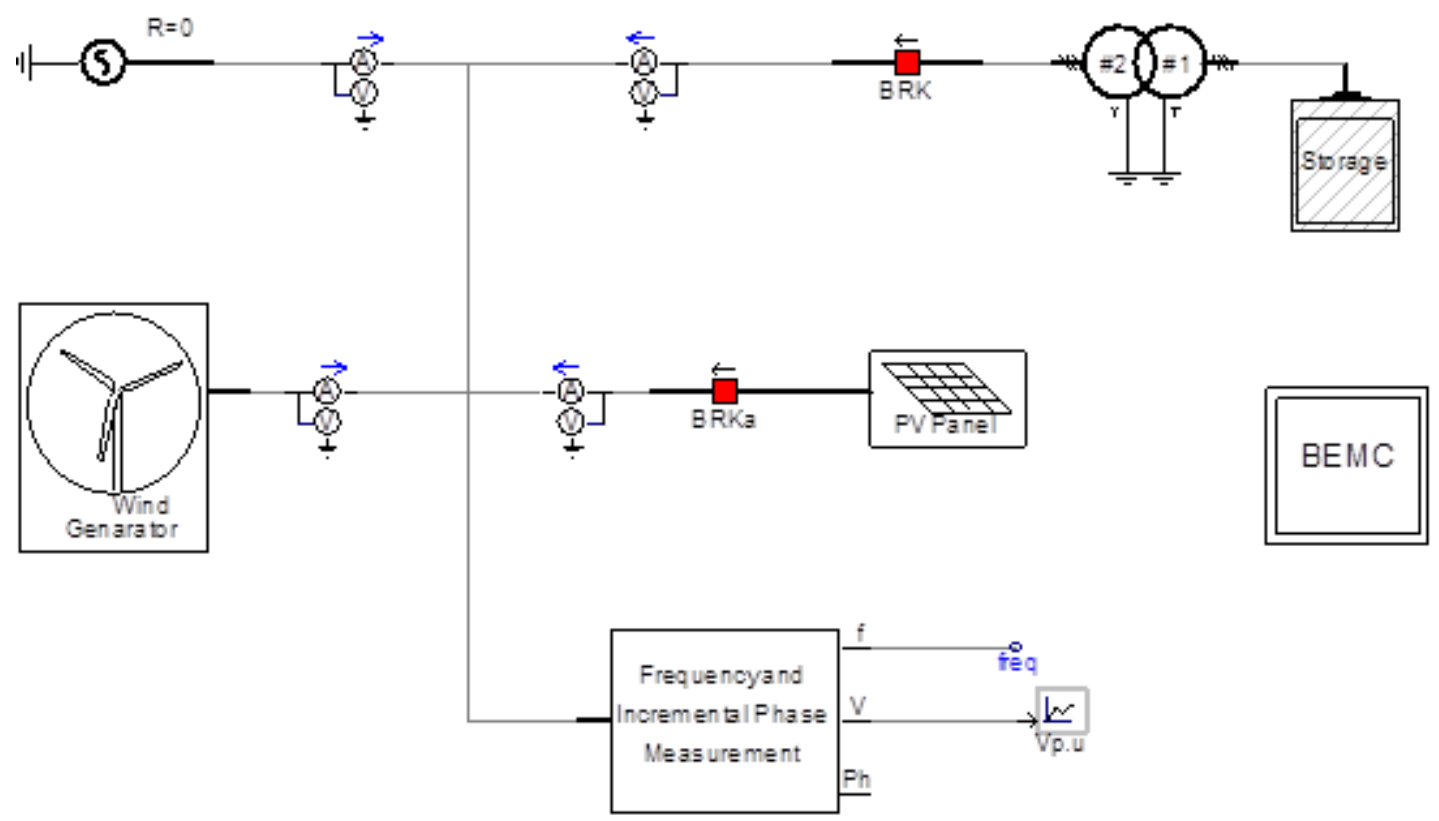

Figure 5-34 Hybrid system with wind turbine generator and solar panel 
The wind speed is variable and the battery SOC is given as 0.9. Hence the battery is free to charge and discharge based on the wind and solar conditions. The graphs for battery power output and SOC with and without PV panel is shown in figures below.

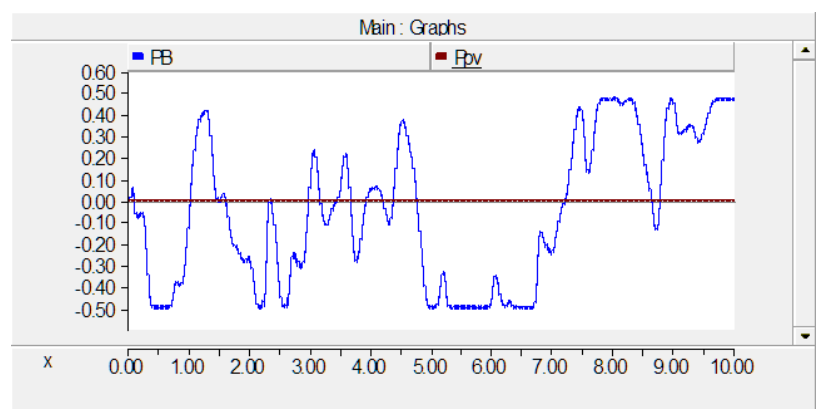

Figure 5-35 Real power output of battery without PV module

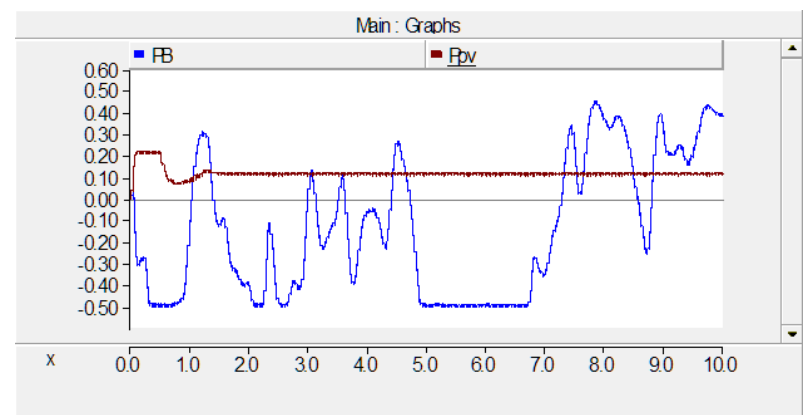

Figure 5-36 Real power output of battery with PV module

From the above Figure 5-35 and Figure 5-36 for solar and battery power, it can be seen that when we connect PV panel to the system, the amount of power injected into the grid by the energy storage module reduces and hence the battery can be used for a longer time period. Also there is reduction in the number of charge and discharge cycles of battery operation which increases the battery lifetime.

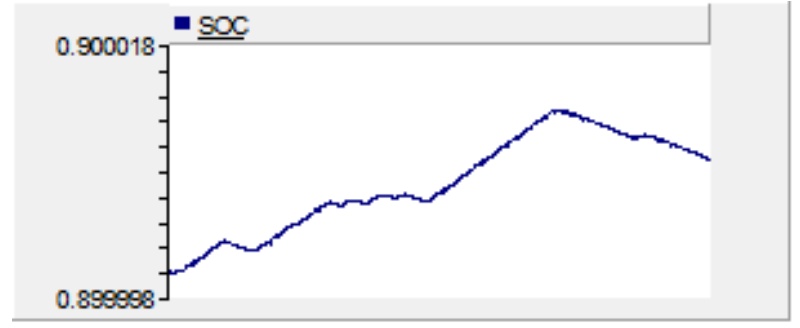

Figure 5-37 SOC of battery without PV module

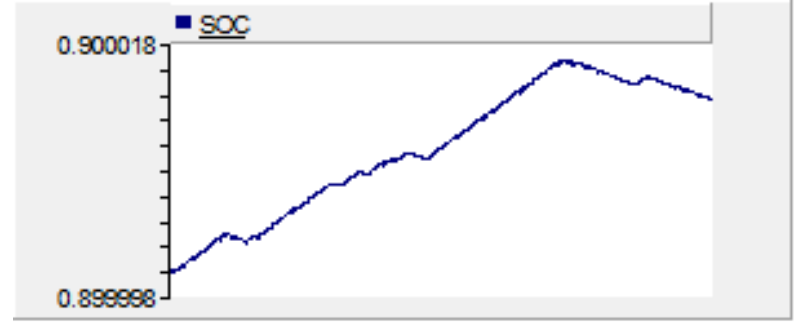

Figure 5-38 SOC of battery with PV module

The effect of solar power on SOC of the battery can be seen in Figure 5-37 and Figure 5-38. It can be noted that when we include PV panel module to the system, the battery SOC has a higher ramp rate and is more charged compared to the SOC of the battery without photovoltaic panel. 


\subsection{POWER LOSS OPTIMIZATION}

\subsubsection{Standalone network}

The objective function of the optimization is to minimize the integral of the power difference between wind and battery power. Both standalone as well as distribution grid connected cases were optimized under variable wind speed and battery discharge mode condition to obtain better performance for the controllers. The standalone system was optimized using genetic algorithm and simplex method. In the case of genetic algorithm, for a proportional gain $\left(K_{p}\right)$ value of 0.1 and integral time constant $\left(T_{i}\right)$ of $0.001 \mathrm{~s}$, the objective function was found to be 13304.6 for an initial SOC of battery equal to 0.9 . The simulation run time was 10 seconds as shown. Optimization of $K_{p}$ and $T_{i}$ parameters were conducted with the same simulation time using the PSCAD optimum run component with number of runs 50 and the population sizes of 10, 20 and 50. The minimum value of objective function is found to be 6041.386 for a proportional gain $\left(K_{p}\right)$ value of 0.0830 and integral time constant $\left(T_{i}\right)$ of $0.00015 \mathrm{~s}$ for all cases of initial population. In the case of simplex method, the minimum value of objective function is found to be 5991.471 for a proportional gain $\left(K_{p}\right)$ value of 0.0830 and integral time constant $\left(T_{i}\right)$ of $0.00015 \mathrm{~s}$ for multiple run 50 and initial step size as 0.2 . After applying these values to the system, the objective function was 6002.71 which are closer to both the genetic algorithm and simplex method optimization results as shown in Figure 5-40. 


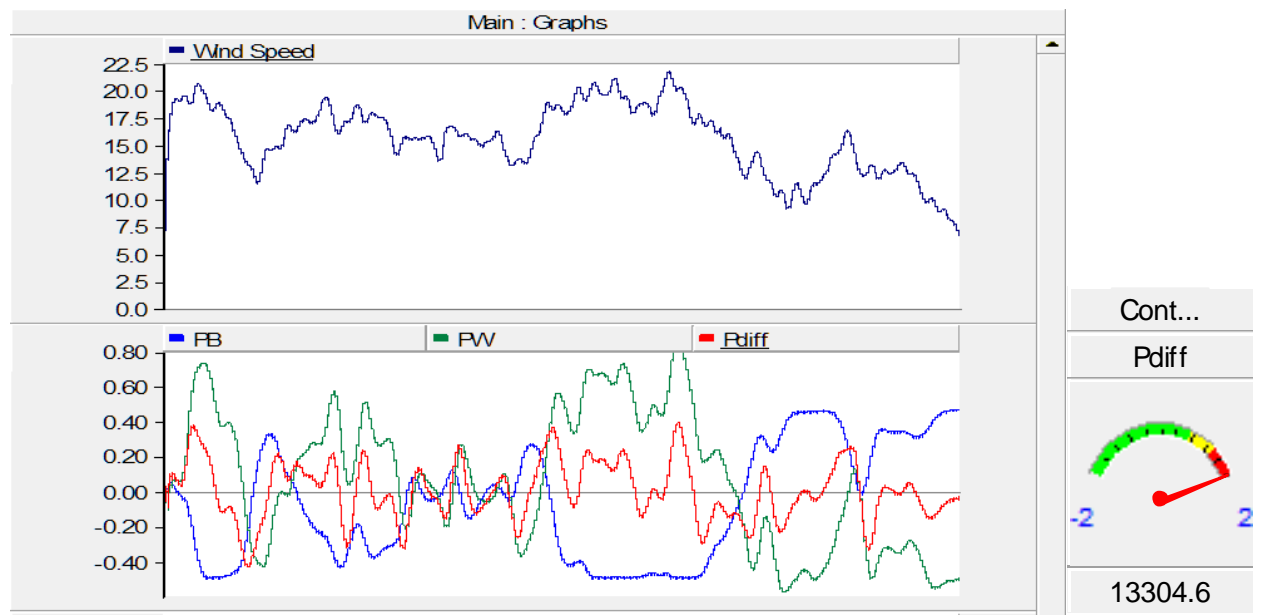

Figure 5-39 Power waveforms and total Pdiff for 10s run time

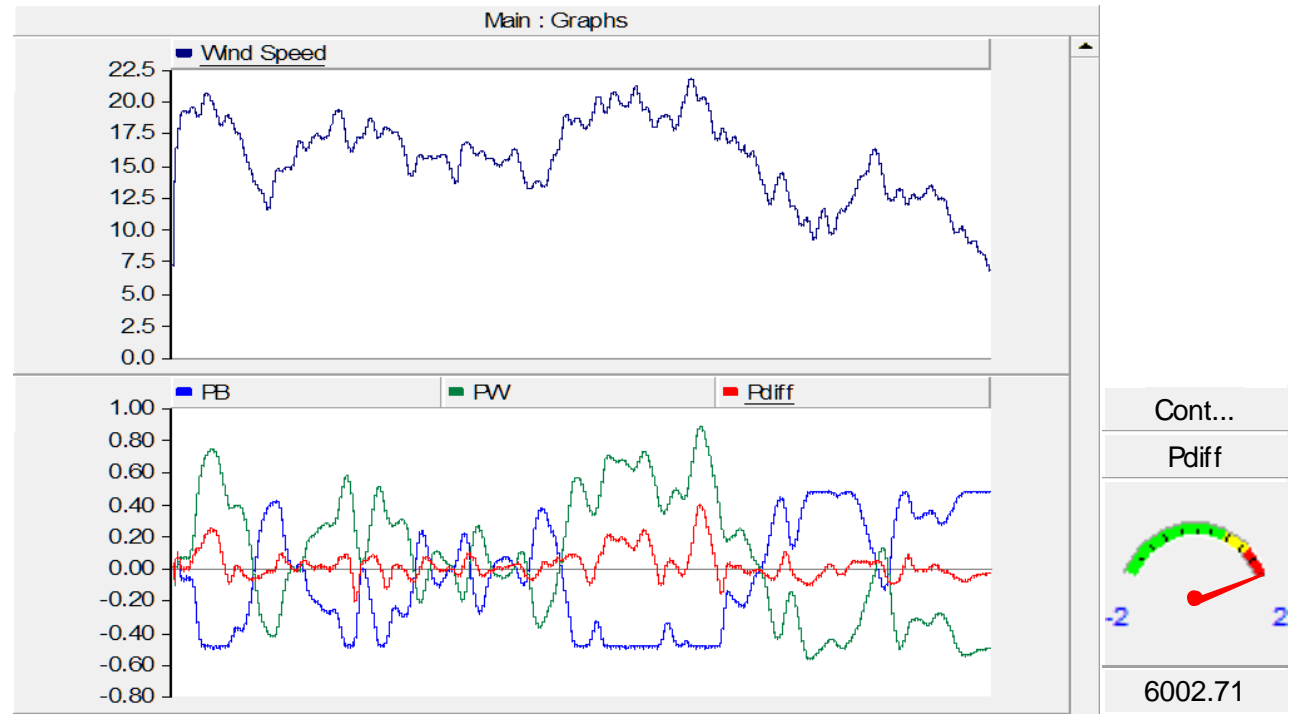

Figure 5-40 Optimized power waveforms and total Pdiff for 10s run time

The system was also run for 60 seconds to observe the effect of controllers for longer run.

It was found that with optimized parameters proportional gain ( $\left.K_{p}\right)$ equal to 0.0830 and integral time constant $\left(T_{i}\right)$ equal to 0.00015 the system was more stable compared to the system without optimized parameters for the PI controller which can be noticed from Figure 5-41 and Figure 5-42. The limits for controllers after sensitivity analysis were found to be 0.01 to 1 for $K_{p}$ and 0.0001 to 0.01 for $T_{i}$. 


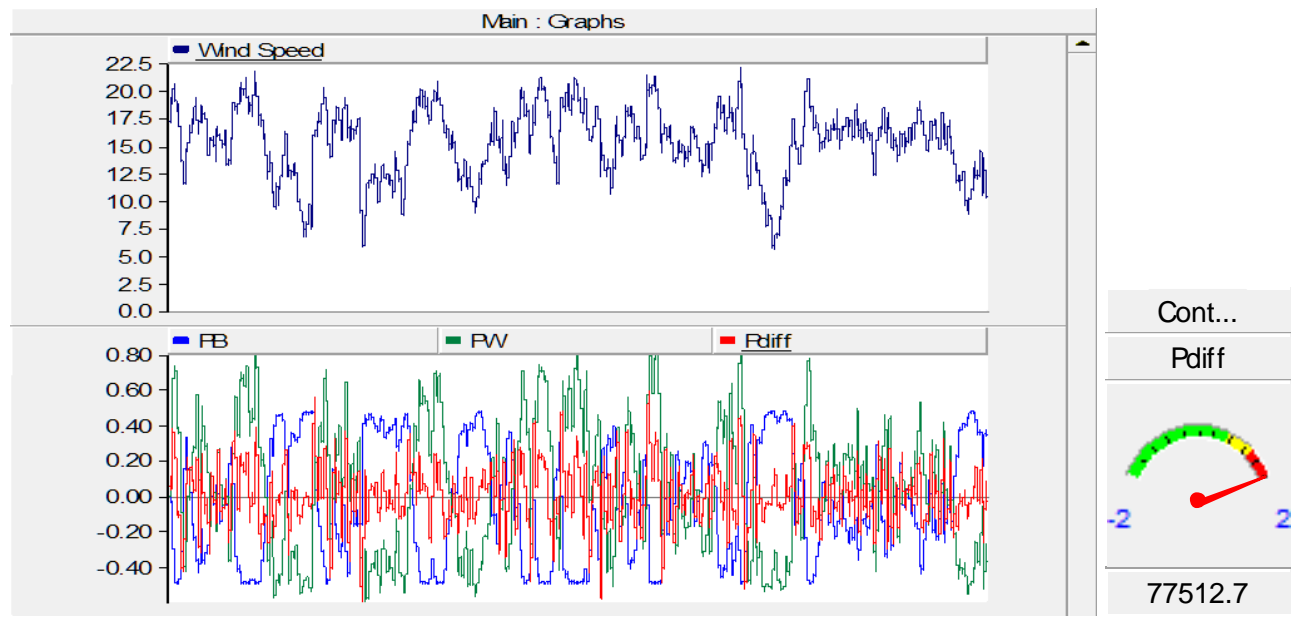

Figure 5-41 Power waveforms and total Pdiff for 60s run time

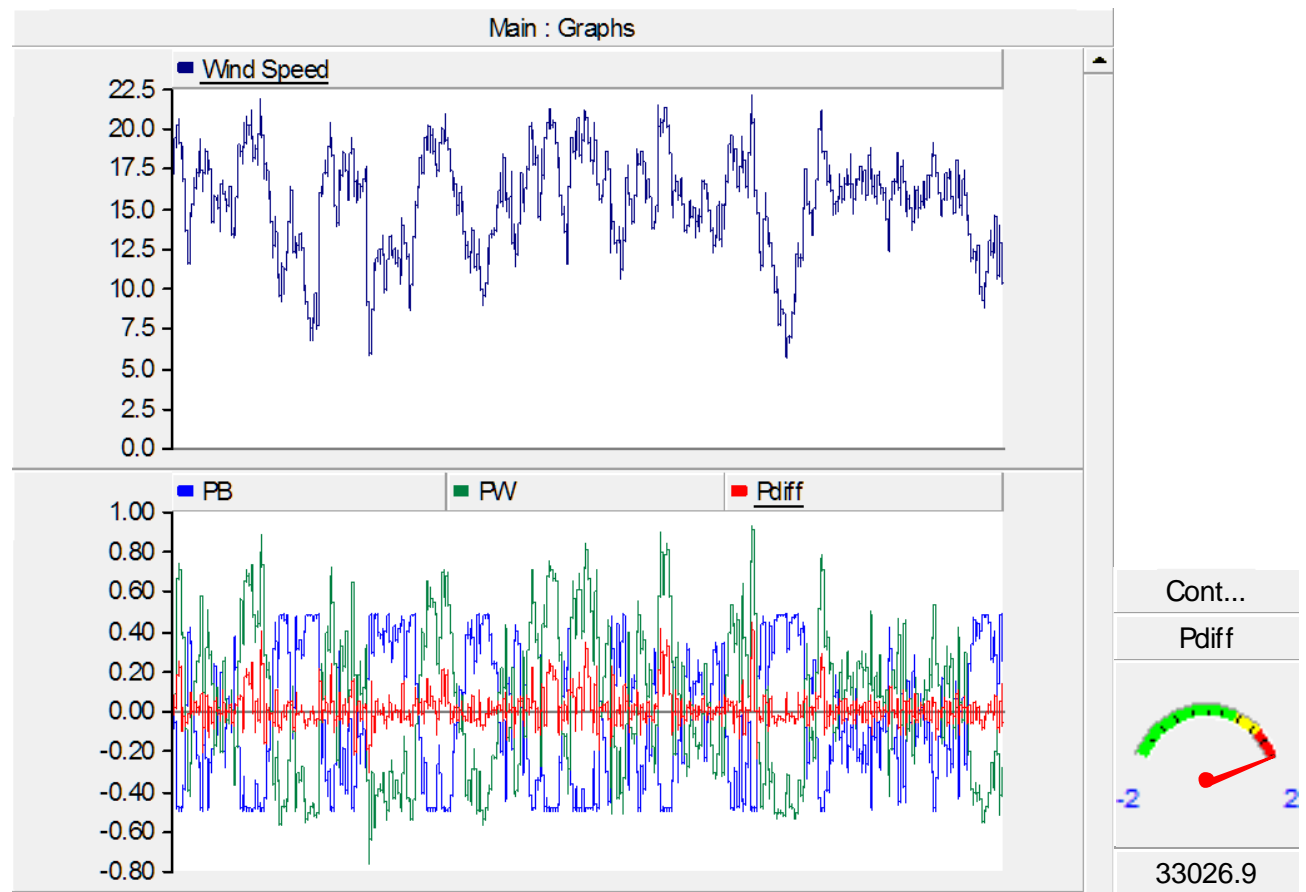

Figure 5-42 Optimized power waveforms and total Pdiff for 60s run time

Figure 5-43 and Figure 5-44 shows the effect of the power absorbed and injected by the wind generator into the grid with and without the energy storage module. It describes how the battery is successful in storing the wind power and releasing it when need, thus reducing the amount of power obtained from the main supply. 


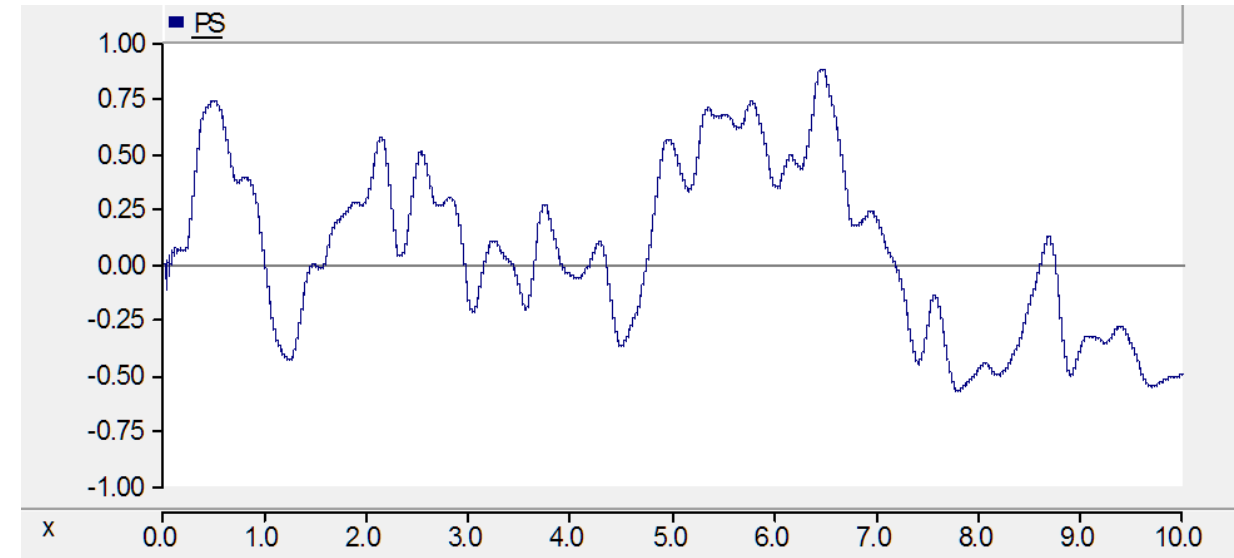

Figure 5-43 Power output to grid without battery

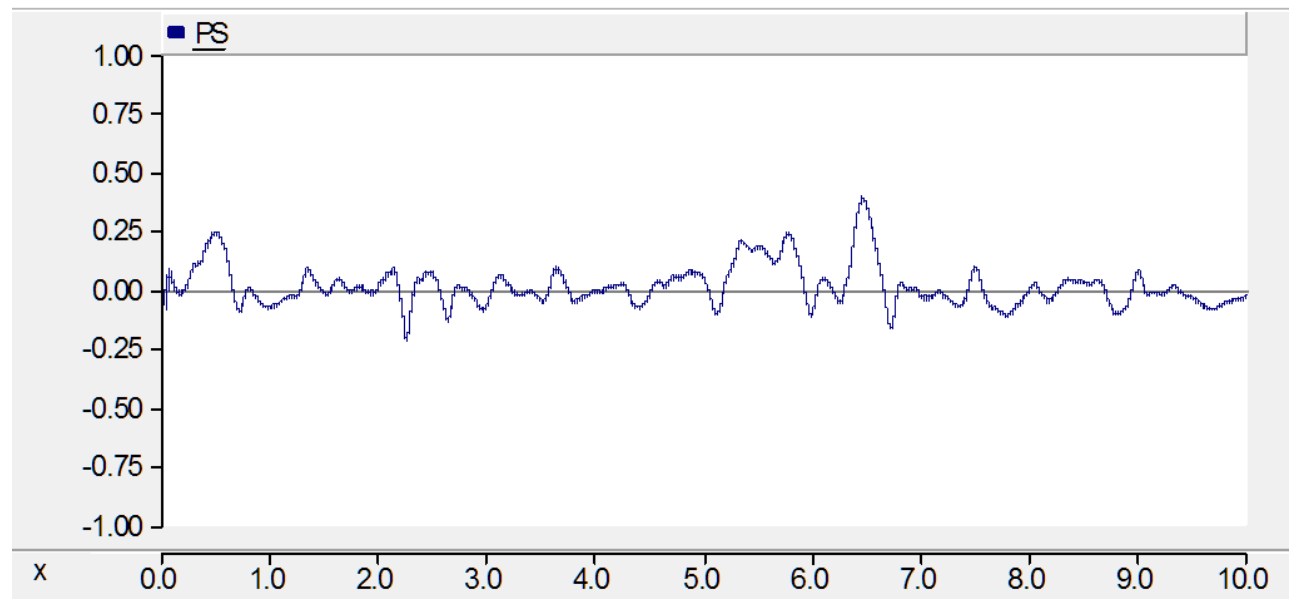

Figure 5-44 Power output with battery

\subsubsection{IEEE 13 Node Distribution Feeder Network}

The same procedure for optimization to minimize the integral of the power difference between wind and battery power was conducted for the IEEE distribution network with wind and storage modules. For a $K_{p}$ value of 0.1 and $T_{i}$ of $0.001 \mathrm{~s}$, the objective function was found to be 7357.52 for an initial SOC of battery equal to 0.9 . The simulation run time for optimization was taken only as 5 seconds because the system was not able to write into the output file for higher values of simulation time. The minimum value of objective function was found to be 7072.026 
for a proportional gain $\left(K_{p}\right)$ value of 0.098 and integral time constant $\left(T_{i}\right)$ of $0.0009 \mathrm{~s}$ for initial population of 10, 20 and 50. After applying these values to the system, the objective function was 7053.3 which is closer to the optimization results. The limits for the PI controller gains after sensitivity analysis were found to be 0.09 to 0.2 for $K_{p}$ and 0.0009 to 0.002 for $T_{i}$.

From the waveforms for the power difference and the value for total power output we can see that a larger value of Pdiff is attained when the proportional gain $\left(K_{p}\right)$ value is 0.1 and integral time constant $\left(T_{i}\right)$ value is $0.001 \mathrm{~s}$. This power difference value is either absorbed from the grid or supplied to it which increases the transmission loss and reduces the efficiency of the system. This can be seen from Figure 5-45 and Figure 5-46 and for simulation time 60 seconds and 10 seconds.

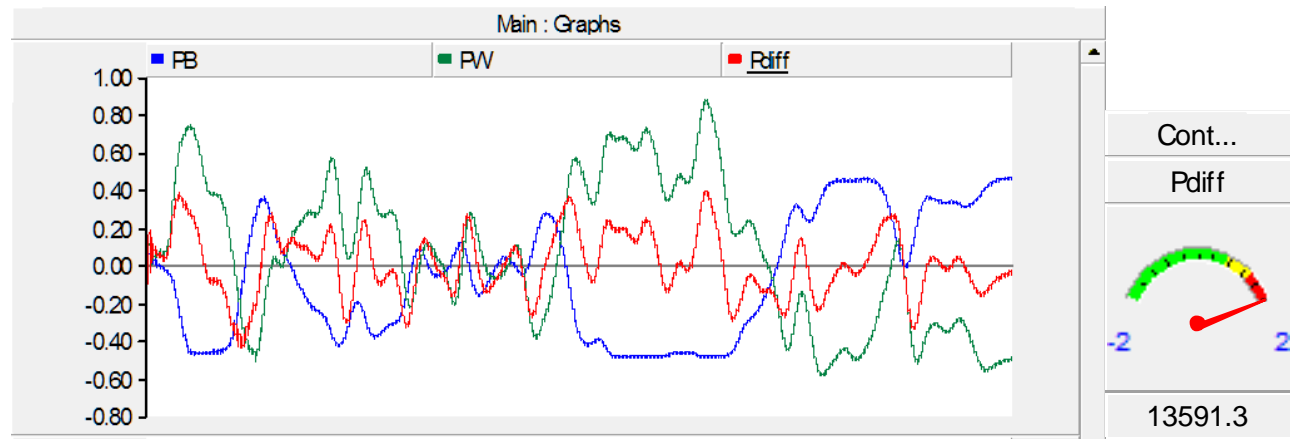

Figure 5-45 Power waveforms and total Pdiff for 10s run time

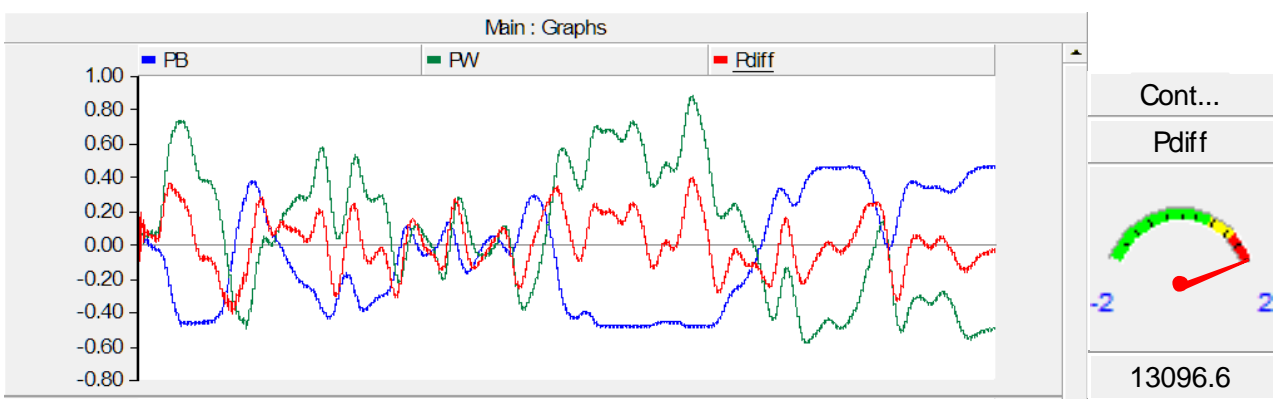

Figure 5-46 Optimized power waveforms and total Pdiff for 10s run time 
When the same system is controlled using optimized parameters for PI controller gains, the power difference curve is closer to zero which can be seen from the Figure 5-47 and Figure 5-48.The total sum of the Pdiff curve is reduced for both run time.

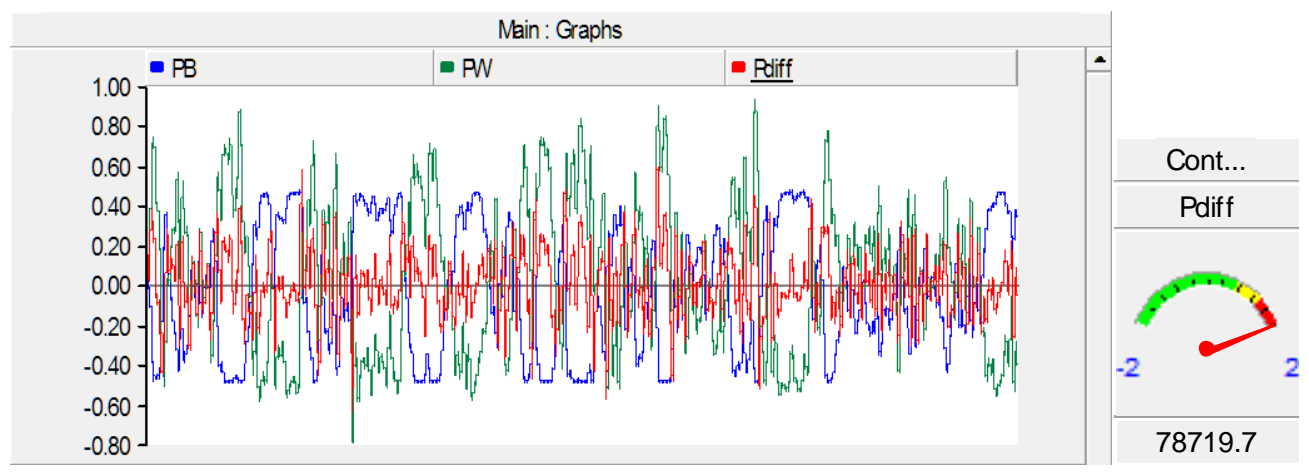

Figure 5-47 Power waveforms and total Pdiff for 60s run time

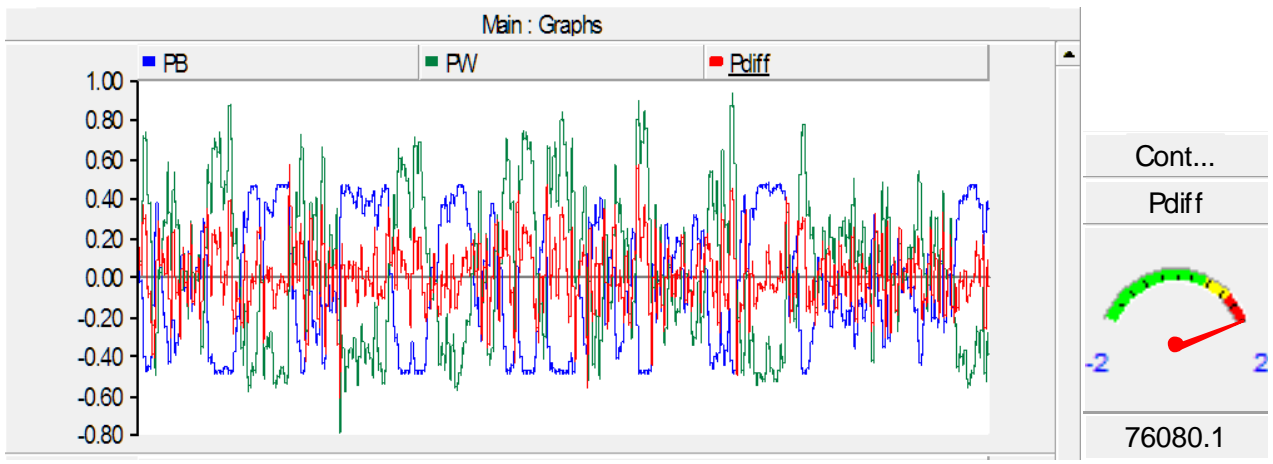

Figure 5-48 Optimized power waveforms and total Pdiff for 60s run time

It can be observed that more accuracy is obtained for smaller systems than larger networks. Almost $120 \%$ reduction is obtained for standalone system with optimized parameters, but for the distribution network only $4 \%$ reduction is noticed. As the complexity of the system increases it becomes difficult to optimize the system. The optimized parameters were also checked for different values of SOC and the results were found favorable. Hence it can be 
concluded that the optimized controllers reduces the burden on the main grid and increases the efficiency of the system.

Figure 5-49 and Figure 5-50 shows the effect of the power absorbed and injected by the wind generator into the distribution grid with and without the energy storage module. It describes how the battery is able to store the wind power and provide the required power when wind power output decreases, thus reducing the amount of power absorbed or injected into the main supply.

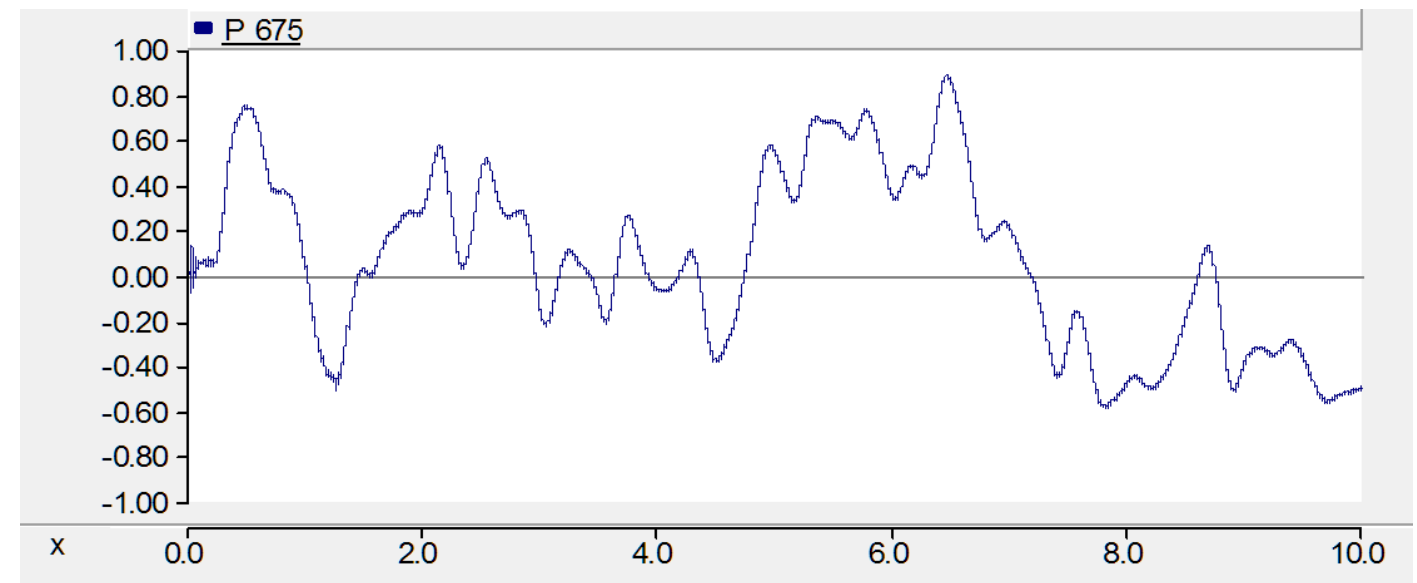

Figure 5-49 Power output to grid without battery

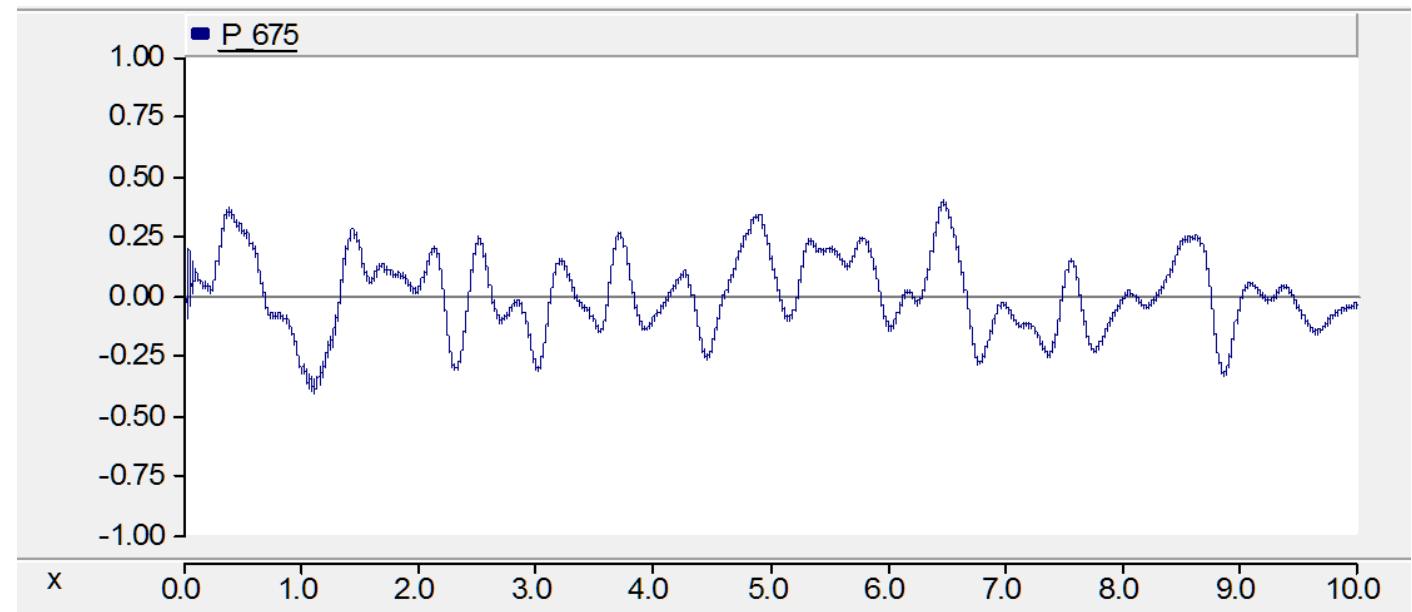

Figure 5-50 Power output with battery 
Optimization to minimize the total transmission loss with wind and battery power was conducted for the IEEE distribution network with wind and storage modules. For a $K_{p}$ value of 0.1 and $\mathrm{T}_{\mathrm{i}}$ of $0.001 \mathrm{~s}$, the objective function was found to be 11952.7 for an initial SOC of battery equal to 0.9 as shown in Figure 5-51. The minimum value of objective function was found to be 11311.3 shown in Figure 5-52 for a proportional gain $\left(\mathrm{K}_{\mathrm{p}}\right)$ value of 0.3737 and integral time constant $\left(T_{i}\right)$ of $0.0966 \mathrm{~s}$ for initial population of 6 and multiple run of 20 . The limits for the PI controller gains after sensitivity analysis were found to be 0.01 to 1 for $K_{p}$ and 0.0001 to 0.1 for $T_{i}$. The transmission loss reduced more than $5 \%$ after optimization. The node voltages with optimized parameters for the PI controller are given in Table 5-8. The node voltage variation is maintained between \pm 5 percent. The maximum voltage deviation is in phase B for node 634 which is about $3.1 \%$. Thus we can note that after optimization transmission loss is reduced as well as voltages at all nodes are maintained within limits

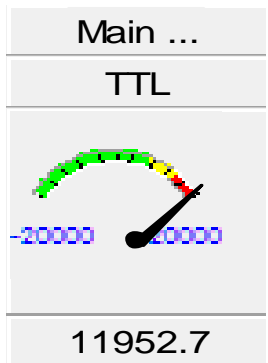

Figure 5-51 Total transmission loss before optimization

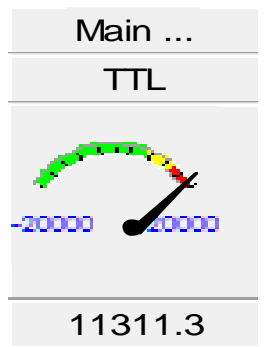

Figure 5-52 Total transmission loss after optimization 
Table 5-8 Comparison of node voltages with optimized parameters

\begin{tabular}{|c|c|c|c|c|c|c|c|c|c|}
\hline & \multicolumn{3}{|c|}{ A-N } & \multicolumn{3}{c|}{ B-N } & \multicolumn{3}{c|}{ C-N } \\
\hline NODE & IEEE & PSCAD & Error & IEEE & PSCAD & Error & IEEE & PSCAD & Error \\
\hline 650 & 1.0000 & 0.9994 & 0.0600 & 1.0000 & 1.0010 & 0.1000 & 1.0000 & 0.9991 & 0.0900 \\
RG60 & 1.0625 & 1.0610 & 0.1412 & 1.0500 & 1.0560 & 0.5714 & 1.0687 & 1.0690 & 0.0281 \\
632 & 1.0210 & 1.0099 & 1.0911 & 1.0420 & 1.0308 & 1.0710 & 1.0174 & 1.0171 & 0.0305 \\
633 & 1.0180 & 1.0073 & 1.0501 & 1.0401 & 1.0279 & 1.1758 & 1.0148 & 1.0150 & 0.0197 \\
634 & 0.9940 & 0.9908 & 0.3214 & 1.0218 & 0.9896 & 3.1548 & 0.9960 & 1.0088 & 1.2871 \\
645 & & & & 1.0329 & 1.0210 & 1.1521 & 1.0155 & 1.0150 & 0.0492 \\
646 & & & & 1.0311 & 1.0200 & 1.0765 & 1.0134 & 1.0130 & 0.0395 \\
671 & 0.9900 & 0.9681 & 2.2171 & 1.0529 & 1.0273 & 2.4276 & 0.9778 & 0.9758 & 0.2067 \\
680 & 0.9900 & 0.9681 & 2.2171 & 1.0529 & 1.0273 & 2.4276 & 0.9778 & 0.9758 & 0.2067 \\
684 & 0.9881 & 0.9660 & 2.2366 & & & & 0.9758 & 0.9736 & 0.2255 \\
611 & & & & & & & 0.9738 & 0.9716 & 0.2259 \\
652 & 0.9825 & 0.9606 & 2.2290 & & & & & & \\
692 & 0.9900 & 0.9681 & 2.2171 & 1.0529 & 1.0273 & 2.4276 & 0.9777 & 0.9758 & 0.1965 \\
675 & 0.9835 & 0.9645 & 1.9305 & 1.0553 & 1.0297 & 2.4306 & 0.9758 & 0.9707 & 0.5264 \\
\hline
\end{tabular}




\section{Chapter 6 CONCLUSION AND FUTURE RESEARCH}

\subsection{CONCLUSIONS}

Electrical energy storage is becoming an integral part of power systems. This work primarily focusses on designing a storage unit whose capacity matches with the distributed generation and has its power characteristics in inverse variation with the distributed generation power characteristic. The latest developments and the applications of energy storage in power sector are reviewed initially followed by the detailed description of building the test system in PSCAD. The battery model used in this thesis is the Li-ion battery which has high energy density and efficiency. Standalone system and IEEE 13 node feeder distribution system with wind turbine generator and photovoltaic panel were the two test systems considered to show the effect of energy storage unit on distribution system. The integration and control of energy storage system is achieved using a battery energy management control system at the upper level and a real/reactive power controlled VSC at the lower level. To enhance the control optimization based on genetic algorithm is also performed where the proportional gain and the integral time constant of the PI controller are optimized which reduces the losses and decreases the burden on the main grid. From the results it can be conclude that the battery energy management control is effective in controlling the modes of operation of energy storage module based on the wind and solar conditions and is able to completely balance the power produced by the wind generator module and PV panel module. In this thesis all the test systems and the control were implemented in PSCAD as it is emerging as the new industry standard for power applications research. 


\subsection{DIRECTIONS FOR FUTURE RESEARCH}

The technologies for storing electrical energy are emerging fast. The control phase needs regular updating. Security and protection attributes from over voltage and overcurrent can also be included with the system. This system can also be tested with other battery models as well as with other distributed generators with intermittent nature. Control and optimization based on wind speed and solar radiation forecasted data can be also included in the model. Different power system scenarios like demand management, peak shaving, stability analysis, fault analysis etc. can also be performed to test the reliability and efficiency of the system. Our research team is also developing a communication module which will be included in future studies to analyze the effects of communication on control. 


\section{REFERENCES}

[1] A. Abedini and H. Nikkhajoei, "Dynamic model and control of a wind turbine generator with energy storage,” IET Trans. Renewable Power Generation, vol. 5, pp. 67-78, Jan. 2011.

[2] A. Esmaieli, S. A. N. Niaki, A. Tajfar and H. Nademi, "Unified Modeling of UPFC-SMES in Power System Application,” in Proc. 2008 IEEE Conference on Industrial Electronics and Applications, pp. 2051-2056, June 2008.

[3] A. Gabash and P. Li, "Active-Reactive Optimal Power Flow in Distribution Networks with Embedded Generation and Energy storage,” IEEE Trans. Power Systems, Volume 27, pp. $2026-2035,2012$.

[4] A. Gabash and P. Li, "Flexible Optimal operation of Energy storage System for Energy Supply Networks,” IEEE Trans. Power Systems, Volume 99, pp. 1 - 10, 2012.

[5] A. H. Shahirina, S. M. M. Tafreshi and A. H. Gastaj, "Optimal Sizing of Hybrid Power System using Genetic Algorithms," International Conference on Future Power Systems, pp. 6 $-12,2005$

[6] A. K. Srivastava, A. A. Kumar and N. N. Schulz, "Impact of Distribution Generators with Energy Storage Devices on the Electric Grid,” IEEE Systems Journal, Volume 6, pp. 110 $117,2012$.

[7] A. M. Gee, F. V. P. Robinson and R. W Dunn, "Analysis of Battery Lifetime Extension in a Small-Scale Wind-Energy System Using Supercapacitors,” IEEE Trans. Energy Conversion, vol. 28, pp. 24-33, March. 2013. 
[8] A. Mohamed, M. Elshaer and O. Mohammed, "Bi-Directional AC-DC/ DC- AC Converter for Power Sharing of Hybrid AC/DC Systems," in Proc. 2011 IEEE Power and Energy Society General Meeting, pp. 1-8.

[9] A. Oudalov, D. Chartouni, and C. Ohler, "Optimizing a Battery Energy Storage System for Primary Frequency Control," IEEE Trans. Power Systems, vol. 22, pp. 1259-1266, Aug. 2007.

[10] A. Rabiee, H. Khorramdel, J. Aghaei, "A review of energy storage systems in microgrids with wind turbines," Renewable and Sustainable Energy Reviews, Volume 18, 316 - 326, 2013.

[11] A. Vijay, P. Dutta and S. Kalyanaramn, "On mitigating Wind Energy Variability with Storage," Fifth International Conference on Communication Systems and Networks, pp. 1-9, 2013.

[12] A. Yazdani, and R. Iravani, "Voltage-Sourced Converters in Power System: Modeling, Control and Applications,” IEEE Press, John Wiley and Sons, 2010.

[13] Advanced Systems for Power Engineering, ASPEN, http://www.aspeninc.com/aspen/index.php

[14] B. Parkhideh, J. Zeng, S. Baek, S. Bhattacharya, M. Baran, A. Q. Huang, " Improved Wind Farm's Power Availability by Battery Energy storage Systems Modeling and Control," in Proc. 2008 IECON 34 ${ }^{\text {th }}$ Annual Industrial Electronics, pp. 784-789.

[15] BCP Inc., Neplan, http://www.neplan.ch/html/e/e home.htm

[16] C. Abbey and G. Joos, "Energy Management Strategies for Optimization of Energy Storage in Wind Power Hybrid System," in Proc. 2005 IEEE Power Electronics Specialists Conference, pp. 2066-2072. 
[17] C. Chompoo-inwai, W-J. Lee, P. Fuangfoo, M. Williams and J. R. Liao, "System Impact Study for the Interconnection of Wind Generation and Utility System," IEEE Trans. on Industry Applications, Volume 41, Jan.-Feb. 2005.

[18] C. M. Shepherd, "Design of Primary and Secondary Cells: II. An Equation Describing Battery Discharge,” Journal of The Electrochemical Society, Volume 112, Issue 7, pp. 657664,1965

[19] Carribean Renewable Energy Development Programme (CREDP), Wind-Grid Integration Brief, Available at: http://www.caricom.org/jsp/projects/wind-grid_integration.pdf, Last accessed, 2012.

[20] Chang, J., Madjarov, K., Baldick, R., Alvarez, A., Renewable Integration Model and Analysis, IEEE PES Transmission and Distribution Conference and Exposition, 2010

[21] Chant, T.I., Shafiullah, G.M., Oo, A .M. T., Harvey, B., Impacts of increased photovoltaic Panel Utilization on Utility Grid Operations - A Case Study, IEEE PES Innovative Smart Grid Technologies, 2011.

[22] D. Manz, R. Piwko, and N. Miller, "Look before you leap, the Role of Energy Storage in Grid,” IEEE Power and Energy Magazine, Volume 10, pp. 75 - 84, 2012.

[23] D. Xu, L-Y. Y. Kang, L. Chang and B-G. Cao, "Optimal Sizing method of standalone Hybrid Solar Wind System with LPSP technology using Genetic Algorithms," Canadian Conference on Electrical and Computer Engineering, pp. 1722 - 1725, 2005.

[24] DIgSILENT GmbH, PowerFactor Monitor, http://www.digsilent.de/

[25] ESA International LLC., EasyPower, http://www.easypower.com/

[26] G. Brinkman, P. Denholm, E. Drury, R. Margolis and M. Mowers, "Toward a SolarPowered Grid,’ IEEE Trans. Power and Energy Magazine, vol. 9, May-June 2011. 
[27] General Electric Energy, PSLF, http://www.ge-

nergy.com/products_and_services/products/utility_operations_software/index.jsp

[28] H. Oh, "Optimal Planning to include Storage Devices in Power System," IEEE Trans.

Power Systems, Volume 26, pp. 1118 - 1128, 2011.

[29] Homer Energy LLC., Homer, http://homerenergy.com/

[30] IEEE 13-Node Test Feeder, Available at:

http://ewh.ieee.org/soc/pes/dsacom/testfeeders/index.html

[31] IPSA Power Ltd., IPSA, http://www.ipsa-power.com/

[32] L. Bam and W. T. Jewell, "Review: Power System Analysis Software Tools", IEEE

Power Engineering Society General Meeting, Volume 1, pg 139 - 144, 2005.

[33] Laurel Mountain Wind Storage, 2011 [online] Available:

http://www.aesenergystorage.com/projects.html

[34] Linh, N.T., Power Quality Investigation of Grid Connected Wind Turbines, Proceedings of the 4th IEEE Conference on Industrial Electronics and Applications, 2009.

[35] Lisserre, M., Sauter, T., Hung, J.Y., Future Energy Systems: Integrating Renewable Energy Sources into the Smart Power Grid through Industrial Electronics, IEEE Industrial Electronics Magazine, Volume 4 (1), 2010.

[36] Lu, M.S., Chang, C-L., Lee W-J, Impact of Wind Generation on Transmission Systems, 39th North American Power Symposium, 2007.

[37] M. E. Glavin, P. K. W. Chan and W. G. Hurley, "Optimization of Autonomous Hybrid Energy Storage System for Photovoltaic Applications," in Proc. 2009 IEEE Energy Conversion Congress and Exposition, pp. 1417-1424. 
[38] M. Ghofrani, A. Arabali and M. Etezadi- Amoli, "Electric Drive Vehicle to Grid Synergies with Large scale Wind Resources," IEEE Power and Energy Society General Meeting, pp. 1-6, 2012.

[39] M. S. Whittingham, "History, Evolution and Future status of Energy Storage," Issue: Special Centennial Issue Proceedings of the IEEE, Volume 100, pp. 1518 - 1534, 2012.

[40] Manitoba Hydro International Ltd., PSCAD, https://hvdc.ca/pscad/

[41] Mathworks, SIMULINK generic battery model, http://www.mathworks.com/help/physmod/powersys/ref/battery.html

[42] Milsoft Utility Solutions, Windmil, http://milsoft.com/products/windmil

[43] N. H. Ishak, I. S. Isa, S. B. Abdullah, S. Masri and F. M. T. Tawi, "Performance Comparison of Electric Power Flow Solutions Using PSCAD," International Conference on Science and Social Research (CSSR), pg 542-547, 2010.

[44] O. Tremblay, L. A. Dessaint and A. I. Dekkiche, "A Generic Battery Model for the Dynamic Simulation of Hybrid Electric Vehicles,” in Proc. 2007 IEEE Vehicle Power and Propulsion, pp. 284-289.

[45] Operational Technology, Inc., http://etap.com/Index.htm

[46] PowerWorld Corporation, PowerWorld, http://www.powerworld.com/

[47] Q. Jiang and H. Wang, "Two time-scale coordination control for a Battery Energy Storage System to mitigate wind power fluctuations," IEEE Trans. Energy Conversion, vol. 28, pp. $52-61,2013$.

[48] R. D. Lopez and J. L. B. Augustin, HOGA: Hybrid Renewable Optimization by Genetic Algorithms, Available at: http://www.hoga-renewable.es.tl/ 
[49] R. Wu, S. B. Dewan, and G. R. Slemon, "Analysis of an ac-to-dc Voltage Source Converter Using PWM with Phase and Amplitude Control," IEEE Trans. On Industrial Applications, vol. 27, pp. 355-364, Mar/Apr. 1991.

[50] Renewable Energy Research Laboratory, Hybrid2, http://www.umass.edu/windenergy/research.topics.tools.software.hybrid2.php

[51] S. Kim, J. Jeon, C. Cho, J. Ahn and S. Kwon, "Dynamic Modeling and Control of a GridConnected Hybrid Generation System With Versatile Power Transfer," IEEE Trans. Industrial Electronics, vol. 55, pp. 1677-1688, April 2008.

[52] S. Mishra, G. Mallesham and A. N. Jha, "Design of Controller and Communication for Frequency Regulation of a Smart Microgrid," IET Renewable Power Generation, Volume 6, pp. $248-258,2012$.

[53] S. Mohan, E. P. Cheriyan, "Bilateral Converter to Interface Small Battery Energy Storage System with Micro-grid," in Proc. 2012 IEEE Students' Conference on Electrical, Electronics and Computer Science, pp. 1-4

[54] S. Shajari and R. K. Pour, "Reduction of Battery Size and Charge-Discharge for Active Power Smoothing of DFIG," $11^{\text {th }}$ International Conference on Environment and Electrical Engineering, pp. $112-114,2012$.

[55] S. Teleke, M. E. Baran, S. Bhattacharya and A. Q. Huang, "Optimal Control of Battery Energy Storage for Wind Farm Dispatching," IEEE Trans. Energy Conversion, vol. 25, pp. 787-794, Sept. 2010.

[56] S. Tewari and N. Mohan "Value of NAS Energy Storage Toward Integrating Wind: Results From the Wind to Battery Project," IEEE Trans. Power Systems, vol. 28, pp. 532541, Feb. 2013. 
[57] Shafiullah, G.M., Oo, A .M. T., Jarvis, D., Shawkat Ali, A.B.M., Wolfs, P., Potential Challenges: Integrating Renewable Energy with the Smart Grid, 20th Australasian Universities Power Engineering Conference, 2010

[58] T. K. A. Brekken, A. Yokochi, A. von Jouanne, Z. Z. Yen, H. M. Hapke and D. A. Halamay, "Optimal Energy Storage Sizing and Control for Wind Power Applications," IEEE Trans. Sustainable Energy, vol. 2, pp. 69-77, Jan. 2011.

[59] The GL Group, SynerGEE Electric, http://www.gl-group.com/en/powergeneration/SynerGEE_Electric.php

[60] The Mathworks Inc., SimPowerSystems, http://www.mathworks.com/products/simpower/

[61] W. H. Kersting, "Distribution Feeder Voltage Regulation Control," IEEE Trans. Industry Applications, vol. 46, pp. 620-626, March-April 2010.

[62] W. Hu, C. Su, Z. Chen and B. B. Jensen, "Optimal operation of Plug-In Electric Vehicles in Power Systems with High Wind Power Penetrations," IEEE Trans. Sustainable Energy, vol. PP, pp. 1-9, 2013.

[63] W. Zhou, C. Lou, Z. Li, L. Lu and H. Yang, "Current status of research on Optimum Sizing of Standalone Hybrid Solar Wind Power Generation Systems," Applied Energy, vol. 87, pp. $380-389,2010$.

[64] X. Tan, Q. Li, H. Wang, "Advances and Trends of energy storage technology in microgrid," Electrical Power and Energy Systems, Volume 44, 179 - 191, 2013.

[65] X. Y. Wang, D. Mahinda, and S. S. Choi, "Determination of a Energy storage Capacity in Energy Buffer for Wind Farm," IEEE Trans. Energy Conversion, vol. 23, pp. 868-878, Sept. 2008. 
[66] Y. M. Atwa and E. F. El-Saadany, "Optimal allocation of ESS in Distribution Systems with a high penetration of Wind Energy,” IEEE Trans. Power Systems, Volume 25, pp. 1815 $-1822,2010$.

[67] Yao, M., Yao, L., Integration of Large Scale Wind Farm into the Electrical Grid, China International Conference on Electricity Distribution, 2010. 